Key Words:

Subsurface Bacteria Chemotactic Behavior Amino Acids Carbohydrates Trichloroethylene (TCE) Bimodal Response

\title{
CHEMOTACTIC BEF:AVIOR OF DEEP SUBSURFACE BACTERIA TOWARD CARBOHYDRATES, AMINO ACIDS AND A CHLORINATED ALKENE
}

Geralyne López de Victoria

Approved by:

D. B. Moore, Superintendent, Ecology

Environmental Sciences Division

Publication Date: February 1989

E. I. du Pont de Nemours and Company Savannah River Laboratory Alken, SC 29808

PR MARED FOR THE U.S. DEPARTMENT OF ENEAGY UNDER CONTR ,T NO. DE-AC09-76SR00001 


\title{
Chemotactic Behavior of Deep Subsurface Bacteria toward Carbohydrates, Amino Acids and a Chlorinated Alkene
}

\author{
b y \\ Geralyne López de Victoria
}

A Thesis submitted in Partial Fulfillment of the Requirements for the Degree of Master in Science

$$
\begin{gathered}
\text { University of Puerto Rico } \\
\text { Rio Piedras Campus } \\
\text { Department of Biology }
\end{gathered}
$$

Faculty of Natural Sciences

$$
\text { February, } 1989
$$

(C) Geralyne López de Victoria 
This thesis has been accepted by faculty of the

Department of Biology

Faculty of Natural Sciences

University of Puerto Rico

Río Piedras Campus

in partial fulfillment of the requirements for the degree of

\section{MASTER OF SCIENCE IN BIOLOGY}

Thesis Committee:

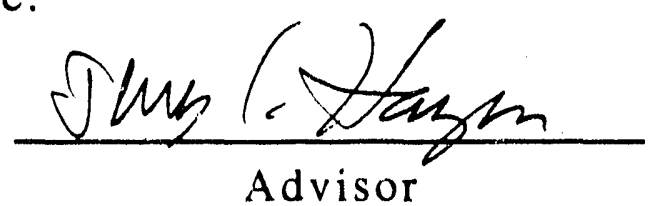

Terry C. Hazen, Ph. D.

Sharon File Emperador, Ph. D.

Carl B. Fliermans, Ph. D.

Jose E. García Arrarás, Ph. D.

Ivette García Castro, Ph. D.

Gary A. Toranzos, Ph. D. 
To Mom and Dad, with all my love... 


\section{AKNOWLEDGEMENTS}

I want to give special thanks to my "academic father", Dr. Terry C. Hazen for his advice and guidance through this study, and for offering me the opportunity to be involved in the Deep Probe Program of the Department of Energy. I also want to give thanks to Dr. Carl B. Fliermans from the Savannah River Laboratory for making helpful suggestions to this work and for teaching me new techniques in the field of Microbial Ecology. I am also grateful to Dr. Jack Corey, Research Manager of the Savannah River Laboratory, E. I. du Pont de Nemours and Co., Inc. and the rest of the people of the plant for supporting and giving me the opportunity of doing my research at their facility. I feel indebted for the work experience I acquired while doing my investigation at the Savannah River Plant. I aiso want to acknowledge Dr. Osvaldo Rosario, Olga and Ruty from the SUBE program for their support and assistance during the study. To the members of my committee Dr. Ivette García Castro, Dr. Sharon File, and Dr. José E. García Arrarás, and Dr. Gary Toranzos from the University of Puerto Rico, I am also grateful for their suggestions. My gratitude to Luis Jiménez for sharing ideas, for offering me his knowledge and help, and most of all, for being close when we were far away from home. I want to give special thanks to my other "academic brother" and true friend, José Marcos Soto Muñoz, for helping me with all my academic responsibilities and moreover for his patience and unconditional friendship. I am deeply indebted to my parents, Héctor and Patria López de Victoria for their love, support, and faith. There is also someone who needs special recognition, my husband James M. Guirau. His love, support, 
patience, help and most of all, his encouragement and understanding has made this possible. Thanks for always being there for me.

This work was supported by Minority Biomedical Research Support Grant RR-8102 of the National Institutes of Health and under contract no. DE-AC09-76SR00001 with the U. S. Department of Energy. 


\section{TABLE OF CONTENTS}

\section{Page}

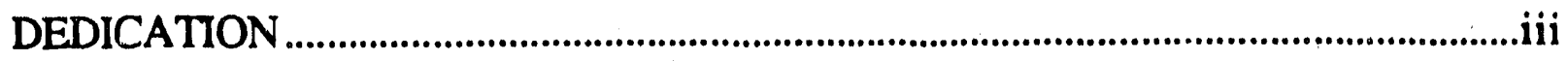

AKNOWLEDGEMENTS....................................................................................................

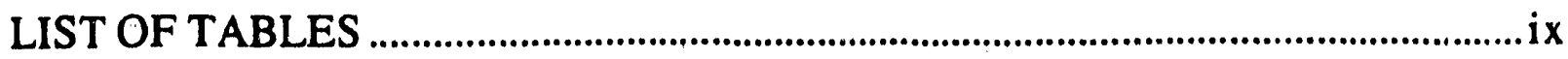

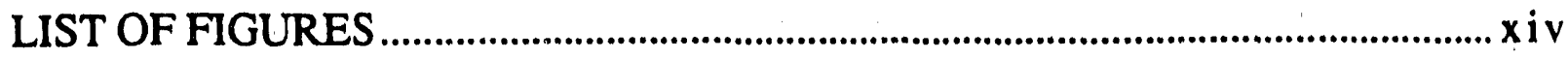

ABSTRACT

\section{INTRODUCTION}

Subsurface and Groundwater Contamination Problem.......................1

Biodegradation as a Solution to the Contamination Problem..........2

Common Environmental Pollutants .........................................................3

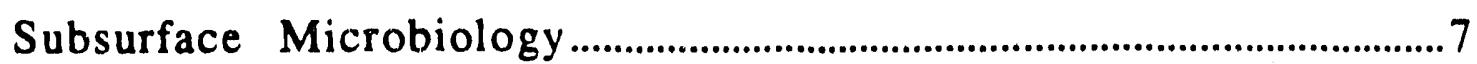

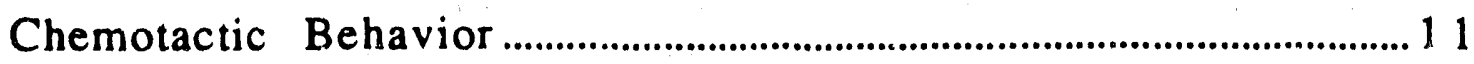

Importance of Chemotaxis in Subsurface Environments ................ 17

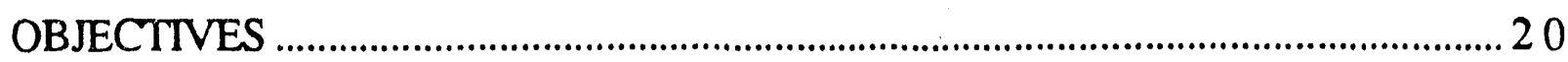

MATERIALS AND METHODS

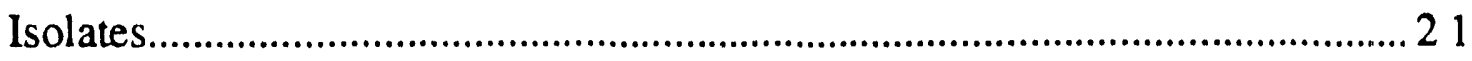

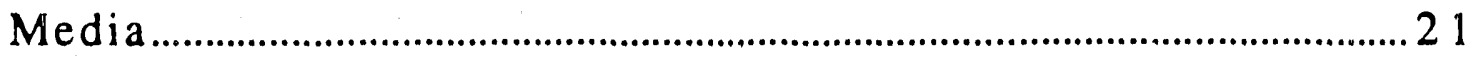

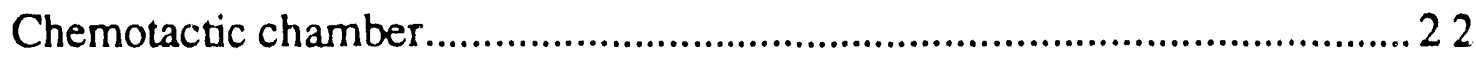

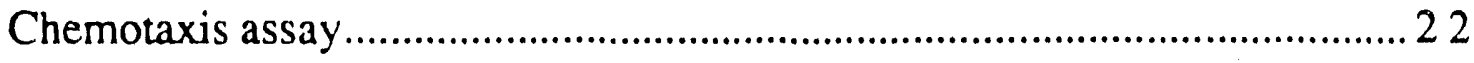

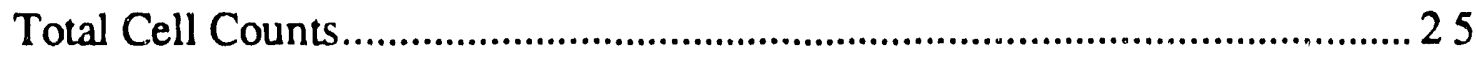

Rates of bacterial movement in sediments. 25

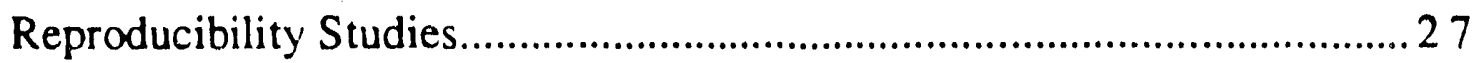

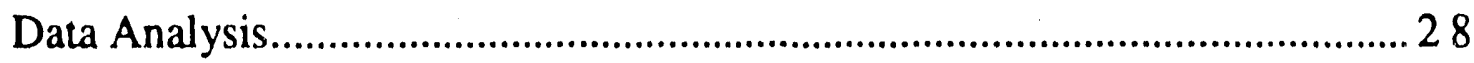

RESULTS

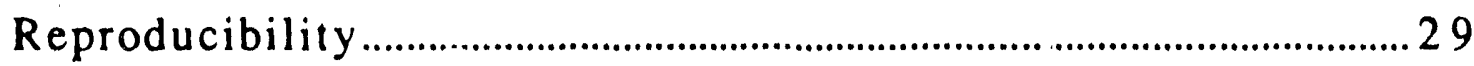




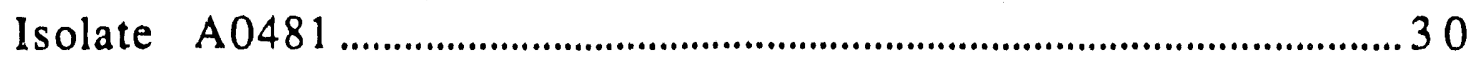

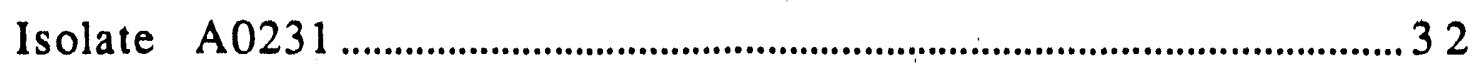

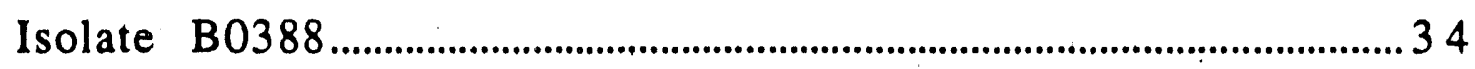

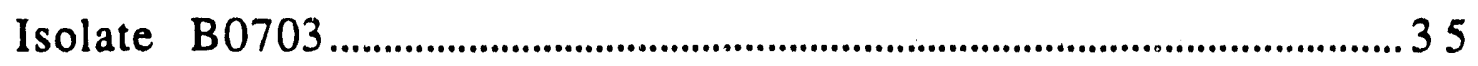

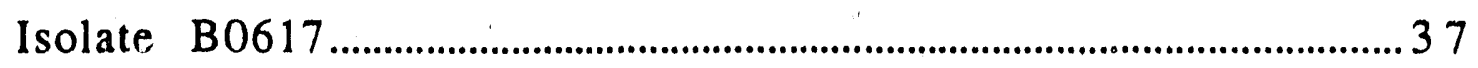

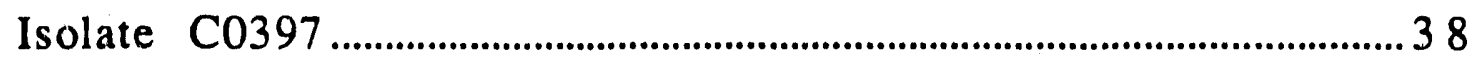

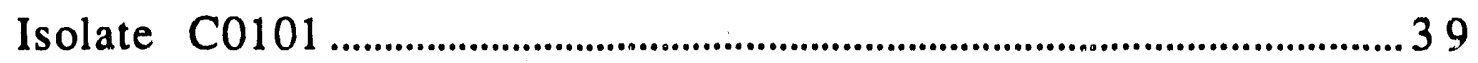

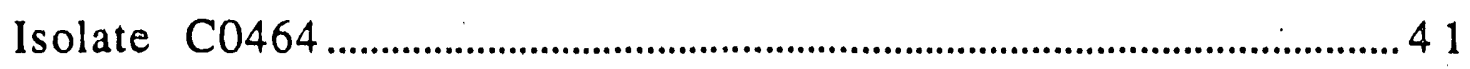

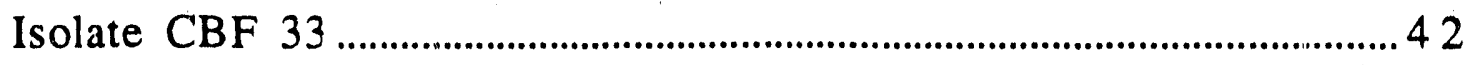

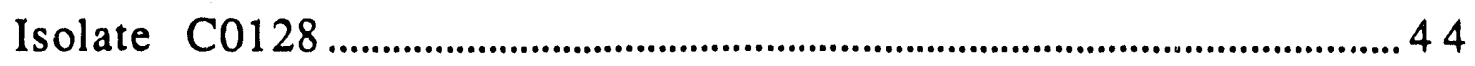

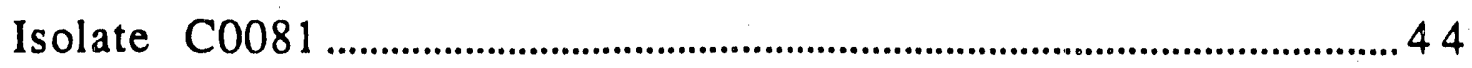

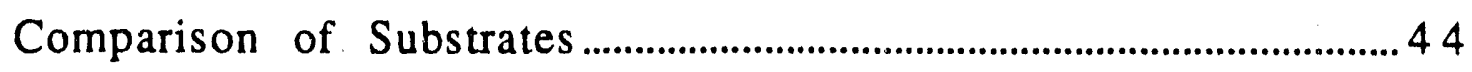

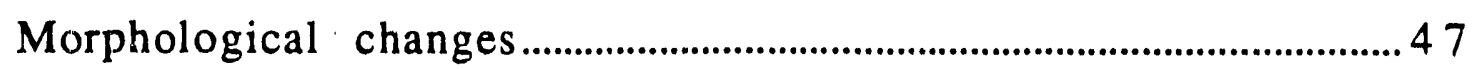

Rates of bacterial movement in sediments.......................................47

Comparison of isolates from the Middendorf geological formation 49

Comparison of isolates from the Black Creek geological formation

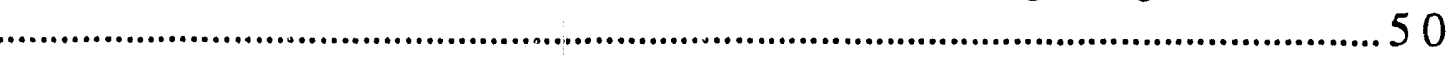

Comparison of isolates from the McBean geological formation..5 1

Comparison of isolates from Borehole P28.......................................5 1

Comparison of isolates from Borehole P24 ...................................52

Comparison of isolates from Borehole P29.....................................5 3

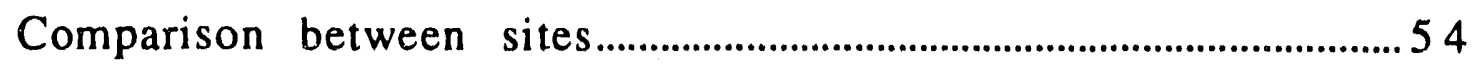




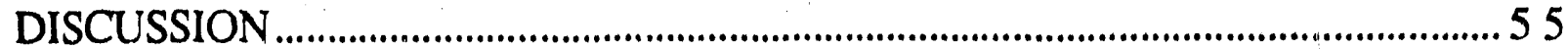

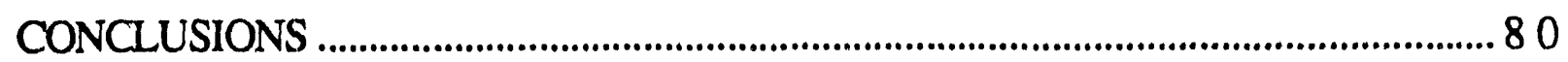

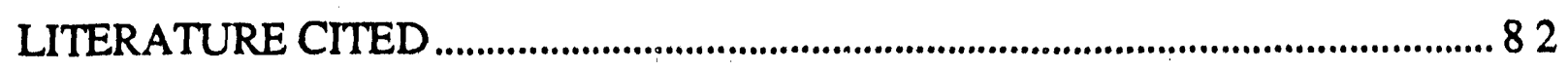

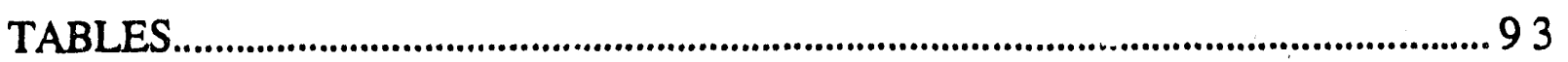

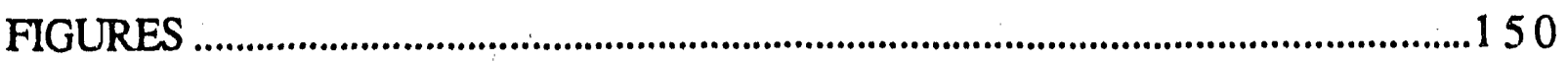

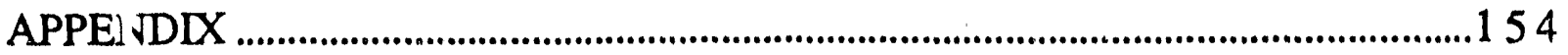




\section{LIST OF TABLES}

Page

Table 1. Geological formations, depths and sites at which isolates were isolated

Table 2. Reproducibility of two chemotaxis assays of isolate A0481 to arginine

Table 3. Reproducibility of three chemotaxis assays of isolate C0397 to lactose

Table 4. Reproducibility of two chemotaxis assays of isolate B 0703 to TCE

Table 5. Chemotaxis of isolate A0481 to carbohydrates.........................99

Table 6. Chemotaxis of isolate A0481 to amino acids..............................98

Table 7. Chemotaxis of isolate A0481 to trichloroethylene (TCE).........99

Table 8. Chemotaxis of isolate A0231 to carbohydrates.......................100

Table 9. Chemotaxis of isolate A0231 to amino acids.............................101

Table 10. Chemotaxis of isolate A0231 to trichloroethylene (TCE) ....102

Table 11. Chemotaxis of isolate B0388 to carbohydrates.....................103

Table 12. Chemotaxis of isolate B0388 to amino acids...........................104

Table 13. Chemotaxis of isolate B0388 to trichloroethylene (TCE).....105

Table 14. Chemotaxis of isolate B0703 to carbohydrates......................106 
Table 15. Chemotaxis of isolate B0703 to amino acids

Table 16. Chemotaxis of isolate B0703 to trichloroethylene (TCE).....108

Table 17. Chemotaxis of isolate B0617 to carbohydrates........................109

Table 18. Chemotaxis of isolate B0617 to amino acids.............................1 1 0

Table 19. Chemotaxis of isolate B0617 to trichloroethylene (TCE).....111

Table 20. Chemotaxis of isolate C0397 to carbohydrates........................112

Table 21. Chemotaxis of isolate C0397 to amino acids ............................113

Table 22. Chemotaxis of isolate C0397 to trichloroethylene (TCE).....114

Table 23. Chemotaxis of isolate C0101 to carbohydrates........................115

Table 24. Chemotaxis of isolate C0101 to amino acids ............................116

Table 25. Chemotaxis of isolate C0101 to trichloroethylene (TCE).....117

Table 26. Chemotaxis of isolate C0464 to carbohydrates.......................118

Table 27. Chemotaxis of isolate C0464 to amino acids ............................119

Table 28. Chemotaxis of isolate C0464 to trichloroethylene (TCE).....120

Table 29. Chemotaxis of isolate CBF 33 to carbohydrates......................121

Table 30. Chemotaxis of isolate CBF 33 to amino acids ..........................1 122 
Table 31. Chemotaxis of isolate CBF 33 to trichloroethylene (TCE)....123

Table 32. Chemotaxis of isolate C0081 to trichloroethylene (TCE)....124

Table 33. Chemotaxis of isolate C0128 to trichloroethylene (TCE).....125

Table 34. Chemotactic response of deep subsurface bacteria to lactose

Table 35. Chemotactic response of deep subsurface bacteria to dextrose

Table 36. Chemotactic response of deep subsurface bacteria to maltose

Table 37. Chemotactic response of deep subsurface bacteria to ribose

Table 38. Chemotactic response of deep subsurface bacteria to sucrose.

Table 39. Chemotactic response of deep subsurface bacteria to arginine

Table 40. Chemotactic response of deep subsurface bacteria to glutamine

Table 41. Chemotactic response of deep subsurface bacteria to proline

Table 42. Chemotactic response of deep subsurface bacteria to threonine

Table 43. Chemotactic response of deep subsurface bacteria to trichloroethylene (TCE) 
Table 44. Comparison of response range, threshold and peak concentrations for chemotaxis experiments toward amino acids, carbolhydrates and TCE of deep subsurface bacteria isolated from the Middendorf geological formation

Table 45. Comparison of response range, threshold and peak concentrations for chemotaxis experiments toward amino acids, carbohydrates and TCE of deep subsurface bacteria isolated from the Black Creek geological formation

Table 46. Comparison of response range, threshold and peak concentrations for chemotaxis experiments toward TCE of deep subsurface bacteria isolated from the McBean geological formation

Table 47. Peak and threshold responses of isolate A0481 to carbohydrates, amino acids and trichloroethylene

Table 48. Peak and threshold responses of isolate A0231 to carbohydrates, amino acids and trichloroethylene

Table 49. Peak and threshold responses of isolate B0388 to carbohydrates, amino acids and trichloroethylene

Table 50. Peak and threshold responses of isolate B0703 to carbohydrates, amino acids and trichloroethylene

Table 51. Peak and threshold responses of isolate B0617 to carbohydrates, amino acids and trichloroethylene

Table 52. Peak and threshold responses of isolate C0397 to carbohydrates, amino acids and trichloroethylene

Table 53. Peak and threshold responses of isolate C0101 to carbohydrates, amino acids and trichloroethylene 145 
Table 54. Peak and threshold responses of isolate C0464 to carbohydrates, amino acids and trichloroethylene

Table 55. Peak and threshold responses of isolate CBF 33 to carbohydrates, amino acids and trichloroethylene

Table 56 Peak and threshold responses of isolates C0081 and $\mathrm{CO} 128$ to carbohydrates, amino acids and trichloroethylen

Table 57. Rates of movement of deep terrestrial subsurface bacteria in sediments 


\section{LIST OF FIGURES}

Page

Figure 1. Map of Savannah River Plant Aiken, South Carolina .............150

Figure 2. Geological profile across the Savannah River Plant and location of the three boreholes (P24, P28, P29) sampled for microbiological analysis..........................151

Figure 3. Chemotactic chamber .......................................................................152

Figure 4. Chambers to study bacterial mobility in sediments.............153 


\section{ABSTRACT}

The chemotactic behavior of deep ierrestria! subsurfaie bacteria toward amino acids, carbohydrates and trichloroethylene was assayed using a modification of the capillary method and bacierial enumeration by acridine orange direct counts. Eleven isolates of bacteria isolated from six different geological formations were investigated. A bimodal response rather than an absolute positive or negative response was observed in most assays. Most of the isolates were positively chemotactic to low concentrations of substrates and were repelled by high concentrations of the same substrate. However, this was not the case for trichloroethylene (TCE) which was mostly an attractant and elicited the highest responses in all the isolates when compared with amino acids and carbohydrates. The movement rates of these isolates in aseptic subsurface sediments in the absence and presence of TCE were also determined using a laboratory model. When exposed to TCE, bacteria increased their migration rates through the sediment chambers, confirming the strong capacity of TCE as an attractant. Since TCE is the most common toxic hydrocarbon contaminant in U. S. aquifers, these findings have important ramifications. All of the isolates showed distinct response range, peak, and threshold concentrations when exposed to the same substrates suggesting that they are possibly different species as has been inferred from DNA homology studies. Even isolates from the same site, geological strata and depth showed different chemotactic behavior. Deep subsurface bacteria moved at about 30 to $180 \mathrm{~cm} /$ day through sediments suggesting that they are 
capable of moving through the geological profile and moreover of finding their optimal conditions for survival in oligotrophic environments by means of chemotaxis. 


\section{INTRODUCTION}

\section{Subsurface and Groundwater Contamination Problem.} According to the Environmental Protection Agency (EPA, 1984), 60,000 chemicals are currently marketed in the United States, and this number increases at a rate of 1,200 per year. This amounts to approximately, 265 metric tons of chemical wastes generated annually (McCormick, 1985). Of the 60,000 products, 20,000 are known to cause severe health problems to humans, eg. high incidence of cancer and other abnormalities (Bitton and Gerba, 1984; Fathepure et al., 1987). According to the U. S. Office of Technology Assessment, more than 100 billion dollars will be needed to cleanup the 93,000 dumping sites used to dispose of these contaminants (McCormick, 1985). One of the most controversial sites is the Love Canal landfill in New York, where over 21,800 tons of toxic wastes containing tetrachloroethylene, trichloroethylene, chloroform, dichloroethane, etc. were once discarded. As a consequence of the severe water and soil contamination which occurred at this site, many families living in nearby homes had to be evacuated from the area. The estimated cleanup costs for this site exceed 45 million dollars (Bitton and Gerba, 1984). Although the cost of cleanup is enormous, the long term health consequences on the exposed community is of greater concern.

For years, landfills were considered a "safe" place to bury toxic substances, mainly because investigators assurned that the soil mantle underneath acted as a "living" filter, leaving underground environments pristine (Bitton and Gerba, 1984). Thus, a common practice followed by many chemical industries was the deposition of 
hazardous wastes in evaporation pits, seepage and retention basins, landfills, and underground tanks (Dean-Ross, 1987). However, recent findings have demonstrated that even artificial barriers between the wastes and the soil do not solve the problem of waste disposal but instead make it worse. Biocorrosion causes toxic compounds to leak from the tanks into the sediments. Thus, the "buried" chemicals end up in soils, sewers, sewage treatment plants, rivers, and groundwater, eventually reaching living organisms (Harvey et al., $1984)$.

Biodegradation as a Solution to the Contamination Problem. Biodegradation; the microbial transformation of organic compounds, is a solution to the cleanup of contaminants from the environment. It was once thought that microorganisms had limited or no ability to degrade xenobiotic or synthetic chemicals (Kilbane et al., 1982; Kuhn et al., 1985). These chemicals are usually toxic, do not occur naturally in the environment, and become recalcitrant in nature (Bouwer and McCarty 1983 a, b). These properties make them less accessible to microorganisms as either energy or carbon sources.

Successful biodegradation studies have demonstrated the removal of toxic chemicals from contaminater environments (Larson and Ventullo, 1983). The exploitation of the ability of micrcbes to transform compounds is a more effective and economical alternative to the $\$ 100$ billion cost for the cleanup and reconditioning of contaminated landfills (McCormick, 1985). Microbial transformation is now being extensively used in the treatment of waters and 
wastewaters from sewage treatment plants and other industrial effluents (Roberts, 1987).

Some of the microorganisms involved in the bioremediation process include not only bacteria but also eucaryotic microorganisms. Currently, the EPA is studying the potential use of fungi to remove hazardous compounds from contaminated sediments. The white rot fungus, Phanerochaete chrysosporium, produces an enzyme that not only decomposes lignin but also pollutants, eg. chlorinated biphenyls, aromatic hydrocarbons and chlorinated dibenzodioxins (Zurer, 1987). Additionally, the controlled use of naturally occurring microbes in their habitat (in situ bioreclamation) has been demonstrated in the removal of petroleum derived hydrosarbons from contaminated soils and groundwater (Wilson et al., 1986). The concept of using microbial transformations is appealing but is not as simple as it may seem. Environmental factors, such as temperature, salinity, pH, redox potential, the presence of other chemicals, and microbial biomass, activity and distribution, can affect the degradation rate and destiny of contaminants in sediments (Spain and Van Veld, 1983). Thus, before bioremediation can be used, a better understanding of the microbiological characteristics of the soil and groundwater is urgently needed (Dean-Ross, 1987).

Common Environmental Pollutants. The organic contaminants most commonly detected in groundwater and sediments are low molecular weight, chlorinated aliphatic hydrocarbons, eg. trichloroethylene (TCE), tetrachloroethylere (PCE), $1,1,1$, trichloroethane, carbon tetrachloride and chloroform (Pye and Ruth, 1983; Bitton and Gerba, 1984). Chlorinated hydrocarbons have 
been widely used as fumigants for insects, in rodent eradication, as fluids for septic tank cleaning, in the production of plastics, in the dry cleaning industry, and as degreasers (Bitton and Gerba, 1984). Now, these $b$ llogenated compounds are of major concern due to their recently documented ability to cause mutations, suspected carcirogenicity, teratogenicity, ubiquity, persistence in nature and toxicity not only to humans but also to microorganisms (Bitton and Gerba, 1984; Fathepure et al., 1987; Kanazawa and Filip, 1986). Even the once popular anesthetic agent, 1,1-trichlcroethane (methyl chloroform), has been responsible for the death of several people (Jones and Winter, 1983).

In general, chlorinated alkenes, like TCE, are more resistant to biotransformation than chlorinated alkanes and are considered the worst pollutants because of their great persistence in the environment (Parsons and Lage, 1985). The maximum contaminant level (MCL) recommended by the U. S. Environmental Protection Agency (EPA, 1984) for TCE, PCE and carbon tetrachloride is $0 \mu \mathrm{g} / \mathrm{l}$ and $200 \mu \mathrm{g} / \mathrm{l}$ for $1,1,1$ trichloroethane with enforceable standards ranging from $5-50 \mu \mathrm{g} / \mathrm{l}$ (Wilson and Wilson, 1985). Concentrations of up to $1000 \mu \mathrm{g} / \mathrm{l}$ of TCE have been found in groundwater wells in New Jersey (Bitton and Gerba, 1984).

Trichloroethylene (TCE) is volatile, slightly soluble in water and a by-product of water chlorination and organic synthesis (Bitton and Gerba, 1984). In only one year, 1973, over 451 million pounds of this compound were produced in the United States. Some major health effects associated with the use of TCE as an anesthetic agent in humans include severe damage to the central nervous system, loss of 
coordination and unconsciousness. In addition, it was discovered that laboratory animals exposed to TCE suffered cardiac dysfunction. TCE also has a strong potential for accumulation in the body (Bitton and Gerba, 1984). These dangerous properties have made TCE a target for many biodegradation studies.

Microbial transformation can be used to remove TCE and other halogenated organic compounds from contaminated sites, although chemical, physical and other environmental factors related with these recalcitrant hydrocarbons make the task difficult (Kilbane et al., 1982). The first report of aerobic microbial degradation of TCE was by Wilson and Wilson (1985). They found that unsaturated columns exposed to a mixture of natural gas and air for three weeks were able to biologically degrade $90 \%$ of the applied TCE to $\mathrm{CO}_{2}$. Further experiments also showed that under aerobic conditions and in the presence of methane, TCE was transformed to $\mathrm{CO}_{2}$ (Fogel et al., 1986). Methanogenic degradation had been previously observed in soil exposed to natural gas (Wilson and Wilson, 1985) and in enriched cultures of methanotrophs obtained from sediments (Bouwer and McCarty, 1983b; Vogel and McCarty, 1985).

Anaerobic degradation has been observed in muck from the Everglades (Barrio-Lage et al., 1985) and other anaerobic soils (Kleopfer et al., 1985). The anaerobic biodegradative pathway is from perchloroethylene, trichloroethylene, dichloroethylene, to vinyl chloride with the rate of transformation decreasing as chlorine is removed (Fathepure et al., 1987). Unfortunately, the end products of this route, eg. vinyl chloride, are more toxic than the parent compounds (Nelson et al., 1987). The major differences between 
aerobic and anaerobic processes are that with methanotrophs no volatile toxic compounds are produced and the rate of degradation increases with less chlorinated hydrocarbons (Fathepure et al., 1987). The first report of a bacterial isolate, G4, capable of using TCE was by Nelson et al. (1986). Biodegradation occurred under aerobic conditions but required the presence of phenol.

Most previous studies have used concentrations of TCE three crders of magnitude lower than those found in contaminated sites. More recently, in a biodegradation study done with concentrations of TCE resembling those found in real life situations, a microbial consortia capable of aerobically degrading more than $99 \%$ of exogenous TCE $(50 \mathrm{mg} / \mathrm{l})$ was described. The consortia was isolated from subsurface sediments contaminated with TCE. Even though the process required an additional source of carbon besides TCE, i.e. yeast extract and methane, it has been the most efficient and least toxic approach reported so far (Fliermans et al., 1988). One of the microorganisms involved in the consortia, CBF 33, was part of this chemotaxis study.

TCE is not the only chlorinated hydrocarbon capable of being biodegraded by microorganisms. PCE has also been found to be degraded by anaerobic bacteria through reductive dechlorination (Fathepure et al., 1987). Pentachlorophenol (PCP) is metabolized by a Elavobacterium spp. strain (Brown et al., 1986) and chloroform is also biodegraded (Stra:d and Shippert, 1986). Biodegradation has proven to be the best approach in the transformation of chlorinated hydrocarbons from the environment. 


\section{Subsurface Microbiology. Subsurace environments are} defined as those which occur beneath soil zones of the earth's crust, including the vadose zone above the water table and saturated zones or aquifers (Bitton and Gerba, 1984; Ghiorse and Balkwill, 1983). Subsurface environments are important reservoirs of groundwater, capable of storing from 33 to 100 quadrillion gallons. Almost $95 \%$ of U. S. freshwater comes from groundwater, nearly half the population uses it as their primary source of drinking water and $75 \%$ of the major cities depend solely on groundwater for their water supply (Bitton and Gerba, 1984). For y'ears, the hazards of groundwater consumption were of no major concern. However, the increasing rate of groundwater contamination by organic pollutants awakened interest in exploring subsurface environments to look for possible solutions to this problem. For years, regions of the earth below the rhizosphere were considered void of life and consequently, remained ignored (Ghiorse and Balkwill, 1985). Microorganisms were thought to live in the earth's top meter, largely in the upper few centimeters (Alexander, 1977), rapidly decreasing in density with increasing depths (Waksman, 1954). It was widely accepted that few, if any, microorganisms resided beneath the topsoil zone of the earth's crust (Bone and Balkwill, 1988). This was mainly because studies by Selman A. Waksman $(1916,1957)$ showed a rapid reduction in the number of microbes with increasing depths. Other evidences against the possibility of finding life forms were the low dissolved organic concentration found in the terrestrial subsurface, $1 \mathrm{mg} / \mathrm{l}$, and the idea of a complete protection of groundwater environments by the soil mantle (Ghiorse and Balkwill, 1985). 
Even though there was evidence that subsurface microbial populations existed, their role was still considered insignificant. It was not until it was established that aquifers and sediments contained diverse, active microbial populations, high in numbers, and capable of influencing groundwater quality, that the interest in these environments developed. Preliminary studies at Lula, Oklahoma disclosed microbial densities of 3 to $9 \times 10^{6}$ cells $/ g$ dry weight between 1.2 and 6 meters in depth and these communities were found to possess the ability to degrade toluene, and chlorobenzene (Wilson and McNabb, 1983). Thus, autochthonous microbial communities can be used to promote biodegradation of subsurface contaminants. Direct enumeration techniques, without the need to culture microorganisms in media, and the development of new aseptic coring devices made the reexamination of microbial distribution and activity in the deep subsurface possible (Ghiorse and Balkwill, 1983).

The high costs involved in the drilling process, unavailability of adequate aseptic sampling techniques, and the problem of adapting standard methods to determine presence, abundance and activity of microorganisms did not facilitate subsurface investigation (Wilson et al., 1983). However, recent studies on water saturated soils, aquifers, and rocks often had microbial population densities higher than those found in surface waters (Wilson et al., 1983). Thus, aquifers, one of the most important sources of water, and the subsurface, are capable of supporting rich communities of microorganisms (Ghiorse and Balkwill, 1985). 
The existing evidence of life in the subsurface encouraged the U. S. Department of Energy (DOE) to establish the Microbiology of the Deep Subsurface Program (Deep Probe) to define microbiological life in the deep subsurface below the Savannah River Plant (SRP) near Aiken, South Carolina (Fig. 1). The major goals of the program are to investigate the presence, abundance, phosiology, ecology and the characterization of subsurface bacteria. Preliminary results indicate a diverse, metabolically active, microbial community as deep as 400 meters below the terrestrial surface (DOE, 1986 a, b). So far, over 3400 bacterial isolates have been isolated including denitrifying, sulfate-reducing, methanogenic bacteria, aerobic heterotrophs, autotrophs and even other microorganisms such as fungi and protozoa (Hazen and Fliermans, personal communication).

Bacterial densities in the core samples, measured by direct counts, revealed up to $10^{7}$ cells/g (Frederickson and Hicks, 1987). Around $90 \%$ of the isolates cannot be classified according to standard biochemical tests, suggesting these bacteria are an entirely new community with unknown capabilities. These results have implications in the use of indigenous microorganisms for biological decontamination of deep aquifers, as a barrier to contaminant movement, reduction of biocorrosion of waste containers planned for storage in deep subsurface environments, and as a source of new organisms with metabolic capabilities for biotechnological applications (DOE, 1986b). Very little is known about the spatial distribution of microorganisms in this environment and their dispersal mechanisms. Transport of cells below ground, cell motility 
and possible chemotaxis are unknown (Girvin et al., 1984; DOE, 1985, 1986a, b).

The study site, SRP, is responsible for producing nuclear materials necessary for the building of nuclear devices for national defense, medical applications and for the space program.

Consequently, one of their major research emphasis is on the detoxification of wastes and other by-products containing contaminated oil, chlorinated hydrocarbons, tributyl phosphate and the concentration or separation of radioactive materials from these compounds. One of the long term goals is to provide techniques for detoxification and degradation of the halogenated hydrocarbons, like TCE, either in situ, in the soil surface, or in vitro, using bioreactors (DOE, 1985). Before biodegradation information can be successfully interpreted and exploited, the ecological conditions of the subsurface microbiota need to be fully understood. Part of these ecological conditions include the distributio of bacteria in the terrestrial subsurface, in which chemotaxis plays a significant role.

It has been demorstrated that chemotaxis is one of the mechanisms by which bacteria become differentially distributed in the environment (Chet and Mitchell, 1976a; Hazen et al., 1984; Kennedy and Lawless, 1985). The chemotactic behavior of deep subsurface bacteria to carbohydrates, amino acids and chlorinated hydrocarbons could provide information about bacterial dispersal mechanisms, distribution and abundance in pristine and contaminated deep subsurface environments. 
Chemotactic Behavior. Cnemotaxis is defined as the bacterial movement toward or away from chemicals. Chemotaxis allows bacteria to find that environment which provides them with the greatest supply of energy (Adler, 1966, 19\%5). Through chemotaxis, bacteria not only seek optimum surroundings but also avoid unfavorable conditions (Ac'er, 1969). Thus, the study of the chemotactic responses of this new terrestrial c'mmunity might help explain their distribution among the different geological strata and sites in the terrestrial subsurface. Chemotaxis, as a form of chemical communication, plays a very important role in sexual behavior, territory definition, migration, and cellular aggregation of microorganisms (Chet et al., 1971). Furthermore, bacterial chemotaxis is important in establishing ponulation interactions such as the colonization of hosts by nitrogen fixing bacteria and predator prey interactions (Chet and Mitchell, 1976a; Galluci and Paerl, 1983). Chemotactic responses are found both in eucaryotic and procaryotic cells. In eucaryotic cells, chemotaxis plays a role in the behavior of white blood cells in the immune response to infections and allergies (Lauffenburguer, 1985).

Chemotactic responses have been investigated in several bacterial genera including A erobacter, Aeromonas, Bacillus, Clostridium, Klebsiella, Leptospira, Pseudomonas, Rhizobium, Vibrio, Serratia, Shigella, Thiobacillus and Escherichia coli (Chet and Mitchell, 1976a; Sjoblad and Coleman, 1980). The chemotaxis phenomenon was first observed by Pfeffer in the 1880's. He observed this bacterial behavior by inserting a capillary tube containing a chemical into a bacterial suspension. Positive chemotaxis resulted in the 
accumulation of bacteria at the mouth and inside the capillary tube, whereas negative chemotaxis promoted movement of bacteria away from the capillary tube (Adler, 1975). In 1881 a similar phenomena, aerotaxis, was discovered by Engelmann (Taylor, 1983). Positive aerotaxis resulted in accumulation of Bacteria termo at the edge of a coverglass, where air bubbles were trapped (Berg, 1975).

The ecological role of chemotaxis can be seen in a wide array of responses by different microorganisms. For example, the cellular slime mold, Dictyostelium discoidium, under nutrient poor conditions, produces cyclic AMP promoting aggregation of the ameboid form of Dictyostelium (Chet and Mitchell, 1976a). Chemotaxis plays in sexual behavior, as demonstrated by Volvox sp. producing a pheromone that induces gonidia to develop into sperm pockets (Chet and Mitchell, 1976a). Likewise, chemotaxis can promote as well as inhibit the initial invasion of mucosal surfaces by bacteria. Allweiis et al. (1977) have shown that pepsin digest of rabbit intestinal mucosa (PMS) neutralizes a positive chemotactic response of several bacterial species to the mucosa, reducing bacterial association with intestinal tissue. Chemoattractants found in fish surface mucus has been shown to stimulate the migration of Aeromonas hydrophila, a bacterium responsible for red sore disease in fish (Hazen ei al., 1982, 1984).

Chemotaxis has been demonstrated to be essential in the survival of certain microbial communities and in the establishment of microbial symbiotic relationships. This type of bacterial interaction has been widely studied in Rhizobia spp. The ability of this rhizobia to locate its host is mediated by a chemotactic response 
(Gaworzewska and Carlile, 1982). Rhizobium is strongly attracted to exudates of leguminous plant roots (Currier and Strobel, 1976; Bowra and Dilworth, 1981; Parke et al., 1985) just as is Azospirillum brasilense to the roots of grasses (Okon et al., 1980). Another example of symbiosis mediated by chemotaxis is Pseudomonas aeruginosa chemoattraction to alanine, serine and other extracellular products of cyanobacteria. Symbiotic nitrogen fixers and other motile chemotactic plant pathogens increase their probability of reaching the host organism by directed rather than by random motility (Soby and Bergman, 1983; Gallucci and Paerl, 1983). The survival of naturally occurring populations of some species of denitrifiers, eg. Pseudomonas, is enhanced by their advantage to successfully compete for $\mathrm{NO}_{3}^{-}$and $\mathrm{NO}_{2}^{-}$(Kennedy and Lawless, 1985).

Most of the attractant chemicals are nutrient sources to the cell (Adler, 1966). Salmonella typhimurium was found to exhibit stronger chemotactic responses to compounds it used as carbon or nitrogen sources and weaker responses toward other substances (Chet and Mitchell, 1976a). Moreover, many attractants signal the presence of other undetected nutrients (Adler, 1974a). Adler (1966, 1969) tested a variety of sugars and their derivatives as chemoattractants to E. coli. The strongest responses were obtained with D-fructose, D-fucose, D-galactose, D-glucose, lactcse, and maltose. E. coli attracted to are was also attracted to the amino acids asparagine, aspartate, cysteine, glutamate, glycine, methionine, serine, and threonine but not to arginine, cysteine, glutamine, histidine, isoleucine, leucine, lysine, phenylalanine, tryptophan, 
tyrosine and valine (Adler, 1974 a, b). However, P. aeruginosa was not attracted to glucose or galactose (Moulton and Montie, 1979).

The mechanisms by which bacteria respond to chemical stimuli are directly related to motility. Bacteria move fast, about ten body lengths per second, by means of a flagellum (Silverman and Simon, 1974). The f agellum is composed of three regions; protein subunits or flagellin filaments (Anderson, 1973), a hook 80-90 nm long, and a basal structure which attaches the hook to the cell membrane (Silverman and Simon, 1974). Motility in bacteria can be described as a smooth swim in a straight line for seconds, a "run" around for a couple of seconds followed by a tumble or abrupt change of direction (Adler, 1974a, b, 1975). In an unstimulated state, bacteria regain swimming in a straight line but to a new and randomly chosen direction. Yet, when bacteria are swimming toward an attractant, cells tumble less frequently than when swimming in opposite directions. If the duration of smooth swimming is longer than the tumbling period it will gradually go in the direction of the substrate. The reverse occurs when bacteria encounter increasing concentrations of repellents. In this case, the tumbles are more frequent so the bacterium gradually moves away from it (Alberts et al., 1983).

In experiments done with E. coli, it was found that the addition of attractants encouraged a counterclockwise rotation of the flagella, whereas addition of repellents caused a clockwise rotation. Therefore, it was concluded that the smooth swimming observed in the presence of an attractant was a result of the counterclockwise rotation of flagella and the tumbling from clockwise rotation. 
Counterclockwise rutation works by allowing all flagella to draw together into a coherent bundle so that bacteria swim in just one direction. However, clockwise rotation causes the flagella to fly apart thus, enhancing tumbling (Adler, 1973, 1974b).

The chemoreceptors involved in the chemotactic signal consist of highly specific soluble periplasmic receptor proteins. A second group of three related transmembrane proteins, the methyl accepting chemotaxis proteins (MCPs) transmit the chemotactic signal across the plasma membrane by means of receptor proteins. The binding of a substrate to the receptor induces conformational changes in the periplasmic receptor protein, which binds and activates the MCP (Alberts et al., 1983). Excitation occurs because the activated MCP generates an intracellular signal (a change in the membrane potential) that causes the motor to continue counterclockwise rotation, tumbling suppression and hence; smooth swimming (Macnab, 1978).

In natural environments, bacteria respond to gradients by monitoring changes in concentration of the substrates over time. In the continued presence of substrates a process of adaptation or desensitization eventually occurs. Bacteria remain in an adapted state as long as no additional gradient is present. Adaptation enables bacteria to respond to changes in concentration rather than steady state levels, thus promoting a chemotactic response when favorable conditions are present (Alberts et al., 1983).

Chemotaxis operates over a limited range of concentrations known as the "response range" (Adler, 1966). On one side is the "threshold concentration," or the lowest concentration of attractant 
that gives a detectable response. On the high extreme is the "saturating concentration" or the concentration of attractant in the bacterial suspension above which the bacteria cannot detect a higher concentration of attractant (Adler, 1973). The knowledge of the range of concentrations that elicit a chemotactic response can be useful for in situ bioreclamation studies when determining the best conditions which stimulate activity in the autochthonous bacterial populations.

The value of motility as a survival factor for bacteria in environments where nutrients or harmful agents are discontinuously present distributed, such as oligotrophic environments, and contaminated sites seems obvious. The survival value of chemotaxis lies in bringing bacteria into favorable and nutritious environments and away from noxious ones (Chet and Mitchell, 1976a). Chemotactic responses involve not only mechanisms by which bacteria move but also imply the possible existence of sensing and transducing devices which direct bacteria toward more suitable conditions for survival and multiplication. The evolution of a system of this complexity indicates that despite the numerous adaptive responses to different environments, its prospects of survival are further enhanced by the ability to select favorable environments by migration.

The ecological irnportance of chemical communication is of great interest especially with the introduction into the environment of xenobiotic, organic and inorganic compounds which may interfere with the normal chemical communication in the subsurface. Chemotaxis has been shown to be inhibited by the presence of xenobiotic chemicals or pollutants in subsurface environments (Chet 
and Mitchell, 1976b). Low concentrations of hydrocarbons, such as toluene, phenol, and oil, inhibit the chemotactic response of certain bacteria. Although bacteria are not killed, their ability to detect nonliving. substrates, nutrients, and prey is lost (Chet and Mitchell, 1976b). In polluted sites, this chemot.ctic inhibition may undermine the natural capacity of the indigenous microbiota to decompose organic matter, xenobiotic compounds and possibly interfere with in situ bioreclamation programs. Moreover, this chemotactic inhibition may result in a decline in the stability of the microbial community. The structure of microbial communities is dependent on a broad biochemical diversity which is maintained by a complex series of interactions between microorganisms within the ecosystem in which chemotaxis plays a significant role.

Importance of Chemotaxis in Subsurface Environments. Very little research has been done in terrestrial subsurface environments. What is known so far is there is an active microbial community present. Whether deep probe bacteria actively move in the subsurface or not is still an enigma. A good way to study bacterial movement through sediments is by chemotaxis, which can account for the differential spatial distribution of bacteria in the different geological formations of the terrestrial subsurface. By positive chemotaxis, soil microbes detect and move toward a nutrient source sparsely distributed in these oligotrophic environments. Since nutrients are usually scarce in soil and subsurface sediments, this mechanism gives them a selective advantage over other competitors, not able to respond to chemical stimuli. In addition, negative chemotaxis give bacteria the advantage of detecting unfavorable 
conditions and avoiding harsh environments. Chemotaxis might help explain why we find only specific types of bacteria in certain sediments and depths.

An understanding of the basic chemotactic behavior of deep subsurface isolates and TCE degrading bacteria toward chlorinated hydrocarbons and nutrient sources, such as carbohydrates and amino acids, will provide useful information for future biotechnological and biodegradation studies. Investigators have proposed that the ability to manipulate cell chemotactic behavior may have great value in a wide range of biotechnological applications (Lauffenburguer, 1985). Bacterial chemotaxis can also be used as a probe to indirectly trace chemical contaminants in subsurface environments and aquifer systems. The presence of a bacteria in a contaminated site might signal the existence of a substrate at concentrations known to elicit a chemotactic response. Another benefit relies on the ability to manipulate substrate concentrations known to enhance bacterial movement, to help target autochthonous bacterial populations into a site of interest for in situ bioreclamation studies. If biodegradation experiments reveal that these microorganisms are capable of metabolizing specific compounds, they could be stimulated by adding substrate concentrations of non-toxic attractants, such as carbohydrates, to promote their chemotactic movement to the source of the compounds to be degraded.

The ability of bacteria to avoid unfavorable conditions by negative chemotaxis, can also be exploited. Chet et al. (1975) were able to demonstrate that organic compounds prevented bacteria from forming biofilms in stainless steel panels submerged in seawater 
when they were coated with paint supplemented with repellents. The use of biological repellents provided a new approach to the control of marine fouling. This idea could be extended to the biocorrosion problem faced in subsurface environments. Considering the enormous problems bacterial corrosion of underground storage tanks causes in the environment, the ability of manipulating negative chemotaxis seems practical. Adding concentrations of repellents around burial sites or including them in the coating of storage tanks could prevent bacteria from attaching to them. The purpose of this investigation was to study the chemotactic behavior of microorganisms isolated from deep terrestrial subsurface environments and determine their relative rate of movement through sediments with no substrate and with sediments exposed to the groundwater contaminant TCE. 


\section{OBJECTIVES}

1. Examine the basic chemotactic behavior of deep terrestrial subsurface bacteria toward sugars and amino acids by determining the peak concentration, threshold concentration and response range.

2. Demonstrate the chemotactic behavior of deep terrestrial subsurface bacteria toward the groundwater contaminant TCE, by determining the peak concentration, threshold concentration and response range.

3. Compare the chemotactic behavior of a TCE degrading bacterium to deep terrestrial subsurface bacteria.

4. Determine rates of bacterial movement for a TCE degrader and deep terrestrial surface bacteria in subsurface sediments using a laboratory model. 


\section{MATERIALS AND METHODS}

Isolates. Bacterial isolates were taken from three boreholes sites on the Savannah River Plant, P24, P28, and P29, with an aseptic coring device developed at the R. S. Kerr Envilonmental Research Laboratory, Ada, OK (Wilson et al., 1983) (Fig. 1). Lyophilized cultures of the isolates were provided by Dr. D. Balkwill, Florida State University, investigator in charge of DOE's Subsurface Microbe Culture Collection (SMCC). Morphological and physiological descriptions of the isolates are in Appendix I. Isolates A0231, and A0481 were obtained from P28 at 440 and $589 \mathrm{ft}$, respectively, corresponding to the Pee Dee and Black Creek geological formations (Table 1). Isolates B0703 and B0617 were obtained from P24 at 851 and $802 \mathrm{ft}$ in the Middendorf formation. Isolate B0388 was taken from the Ellenton formation, at $457 \mathrm{ft}$. From the P29 site, five isolates were used. Isolates C0397 and C0464 were taken at $496 \mathrm{ft}$ and $576 \mathrm{ft}$, respectively, in the Black Creek formation. Isolate C0101 was from a shallower site, the McBean formation at $94 \mathrm{ft}$. Isolates C0081 and C0128 were obtained at $25 \mathrm{ft}$ (Tobacco Road formation) and $94 \mathrm{ft}$ (McBean formation) (Table 1 and Fig. 2). The TCE degrading bacterium, $\mathrm{CBF} 33$, was isolated from a contaminated site, $\mathrm{M}$ area seepage basin borehole at depth of $190 \mathrm{ft}$. and supplied by Dr. Carl B. Fliermans from the Savannah River Laboratory, Aiken, S. C. (patent pending).

Media. Isolates were maintained in PTYG media: $0.5 \mathrm{~g} / \mathrm{l}$ peptone, $0.5 \mathrm{~g} / 1$ tryptone, $1.0 \mathrm{~g} / 1$ yeast extract, $1.0 \mathrm{~g} / 1$ glucose, 0.6 $\mathrm{g} / \mathrm{l} \mathrm{MgSO} 4,0.07 \mathrm{~g} / \mathrm{l} \mathrm{CaCl}$, and $15 \mathrm{~g} / \mathrm{l}$ agar (Ghiorse and Balkwill, 
1983). Motility media (BBL Microbiology Systems, Cockeysville, Md.) and hanging drop method were used to test bacterial motility before the chemotaxis assays. The hanging drop method was also used to confirm motility after centrifugation of the bacterial suspension (Fuentes et al., 1983).

Chemotactic chamber. A chemotactic chamber developed by Palleroni (1976) was used for the assay (Fig. 3). The chamber contains four chambers cut in lexan measuring $5.5 \mathrm{~cm}$ per side and 1 $\mathrm{cm}$ in thickness. Each of these smaller chambers has two cylindrical compartments measuring $7 \mathrm{~mm}$ in diameter and $5 \mathrm{~mm}$ in height, linked by a channel $24 \mathrm{~mm}$ long, $2 \mathrm{~mm}$ wide, and $2 \mathrm{~mm}$ deep.

Chemotaxis Assay. The technique employed was a basic modification of Adler's technique for chemotaxis assay (Adler, 1969; Fuentes, et al., 1983; Hazen et al. 1982, 1984). Motile isolates were grown on PTYG media for $24 \mathrm{~h}$ and harvested by centrifugation at $6,000 \times \mathrm{g}$ for $10 \mathrm{~min}$ at $4^{\circ} \mathrm{C}$. The pellet was resuspended in an equal volume of potassium phosphate buffer (KPB) ( $\mathrm{pH} \mathrm{7)}$ and centrifuged again. The washing step was repeated twice, and the final pellet suspended in KPB. The cell density was adjusted to $10^{8}$ cells $/ \mathrm{ml}$ (Adler, 1969; Hazen et al., 1982, 1984). The chemotaxis buffer consisted of $5.62 \mathrm{~g} / 1 \mathrm{~K}_{2} \mathrm{HPO}_{4}$ and $2.13 \mathrm{~g} / \mathrm{l}$ of $\mathrm{KH}_{2} \mathrm{PO}_{4}$ as described by Gerhardt (1981).

For the chemotaxis assay the capillary method was used. It consisted of a capillary tube containing a substrate solution inserted into the motile bacterial suspension contained in the wells of the lexan chamber. This method was used to assay both positive and negative chemotaxis. Bacteria will be attracted to the mouth of the 
capillay tube in the presence of an attractant. Therefore, more cells will enter the tube containing the chemical than to the tubes in the chemotaxis control (KPB). Whereas, if the chemical is a repellent, fewer cells will be attracted to the experimental tubes than to the KPB control. Each of the four compartments and channels in the chambers, contained $0.4 \mathrm{ml}$ of motile bacterial suspension. As in the method described by Adler (1969), a $3 \mu 1$ disposable micropipette (Drummond Microcaps, Drummond Scientific Co., Broomal, $\mathrm{Pa}$.) was used for each compartment. The $3 \mu \mathrm{l}$ micropipettes, have an internal diameter of $0.35 \mathrm{~mm}$. This diameter is preferred over larger ones because wider capillary tubes promote faster diffusion of the substrates, therefore diminishing the concentration gradient. In contrast to Adler's procedure, both ends were left open. This way, bacteria can enter the tube from any direction. Another convenience of using tubes opened at both ends was that it made manipulations less complicated, filling of capillaries was simplified and moreover, the volume of the solution was more accurate (Palleroni, 1976). The other approach used capillary tubes that had been flamed to seal one end. Flaming the tubes lessened the precision of the measurement. Each capillary was handled with tweezers, filled with $3 \mu 1$ of substrate solution, and placed in a channel of the chamber, containing the bacterial suspension. After incubating the chambers for $1 \mathrm{~h}$ at $23^{\circ} \mathrm{C}$, optimal isolation temperature for deep terrestrial subsurface bacteria (Ghiorse and Balkwill, 1983), the capillary tubes were removed with tweezers and rinsed with distilled water. Care was taken to prevent exposure of the tips of the capillary to the jet of water, so that the contents were not forced out. After washing, 
the capillary was inserted in the holder of the micropipette, the contents released into the wells of a toxoplasmosis slide (Cel-Line Associates, Inc., N. J.), and the cells heat-fixed onto the slide with a slide warmer.

The substrate solutions were prepared from Sigma-grade carbohydrates and amino acids (Sigma Chemical Co., St. Louis, Mo.) dissolved in IRB. Substrates were diluted 10 fold in the chemotaxis buffer to yield concentrations of $1 \mathrm{M}$ to $10^{-5} \mathrm{M}$ or $10^{-6} \mathrm{M}$ depending on the availability of the chambers. In TCE a wider range of concentrations were tested, $1 \mathrm{M}$ to $10^{-10} \mathrm{M}$. Solutions were prepared fresh daily and sterilized by filtration through $0.22 \mu \mathrm{m}$ pore size, $47 \mathrm{~mm}$ diameter membrane filters (Millipore Corp., Bedford, Mass.). Four replicates of each concentration of substrate were used. Lactose, maltose, ribose, glucose, and sucrose were used for carbohydrate tests. The amino acids included proline, threonine, arginine and glutamine. The only chlorinated hydrocarbon used was trichloroethylene, TCE.

A motility control was done by adding the compound to the cell suspension prior to incubation with a capillary tube containing KPB. The motility control was run to determine differences between cell accumulation due to increases in metabolism with alterations in the frequency of flagellar beatings, or motility, and true chemotactic responses and to avoid confusion of negative chemotaxis with motility inhibition. Another control with KPB was used to standardize for bacteria that were attracted to the substrate diluent and/or random movement. The KPB control was as described above except the capillary tubes were filled with KPB instead of the 
experimental substrates (Fuentes et al., 1983; Hazen et al., 1982, 1984). Motility would have significantly increased the counts in the motility control and the numbers would be higher than those in the KPB control capillaries. Each compound was tested at different concentrations and all dilutions made in KPB. To normalize among experiments, the results for the chemotaxis assays were expressed in terms of the chemotactic index $(\mathrm{CI})$, i.e., the ratio of number of bacteria that entered the capillary tubes in the experimental assay to the number of bacteria that entered capillary tubes containing only the chemotaxis buffer.

Total Cell Counts. The contents of the capillary tubes were heat fixed and the cells were stained with Acridine Orange (Difco Laboratories, Detroit, MI) for $1 \mathrm{~min}$ and washed with distilled water. The AODC technique is the most accepted method for determining total number of bacteria and is based on the attachment of the acridine orange fluorochrome to the nucleic acid within the cell (Hobbie et al., 1977). Theoretically, Acridine orange forms red fluorescing dimers only when attached to RNA and single stranded DNA and green fluorescing monomers when only attached to DNA. Cell counts were donf, using a Zeiss epifluorescent microscope.

Rates of bacterial movement in sediments. In an attempt to determine the relative mobility of bacteria in the deep terrestrial subsurface sediments, an assay of bacterial movement in sediments was conducted for each of the isolates for which chemotaxis was studied. The results obtained were then compared and correlated to those obtained in the chemotaxis assays. Rates were assayed using a sample of subsurface sediments from the 
Middendorf geological strata taken at Myrtle Beach, South Carolina at depths of $1214 \mathrm{ft}$, both with and without the presence of TCE.

Sediment chamber were used for this assay (Fig. 4). The chambers consisted of five $\mathrm{ml}$ glass pipettes, $30 \mathrm{~cm}$ long, filled with sediment from the core sample described above and sterilized by autoclaving. Five replicates for each bacterium were used. On one end of the pipet a $30 \mathrm{ml}$ syringe, containing filter sterilized water, was connected with Tygon tubing. The other end of the pipet was inoculated with $25 \mu \mathrm{l}$ of cell suspension prepared in the same way as for the chemotaxis assays. The sediment chambers were then incubated at $23^{\circ} \mathrm{C}$. A $10 \mu \mathrm{l}$ water sample was taken from the water reservoir after $1,2,4,6,8,12,16,20,24 \mathrm{~h}$ of incubation and every other $24 \mathrm{~h}$ for up to 9 days or until bacteria were finally detected. The samples were released into the wells of a toxoplasmosis slide (Cel-Line Associates, Inc., N. J.), and the cells were heat fixed onto the slide. Parallel experiments were done with chambers containing only sterile water in the reservoirs. Two additional experiments were conducted. One control inoculated with a pipet inoculated with formalin fixed bacteria and another with nonmotile cells, to avoid confusing true migration with diffusion of bacteria through sediments due to capillary action or convection.

After 9 days, pipets in which no bacterial migration had been seen were cut into sections. From the sediment contained in this section $1 \mathrm{~g}$ was diluted into $10 \mathrm{ml}$ of sodium pyrophosphate and mixed with vortex for $1 \mathrm{~min}$. After homogenizing, most of the cells were separated from the sediment particles. A $10 \mu \mathrm{l}$ sample of the suspension was fixed onto a toxoplasmosis slide, stained with 
acridine orange for $1 \mathrm{~min}$ and washed with PBS. Slides were immersed in sodium pyrophosphate to help reduce any background fluorescence that resulted from the attachment of acridine orange to remaining particles (Fliermans, personal communication). Samples were taken daily until bacteria were detected in the opposite side of inoculation in the sediment chamber. Acridine orange direct counts (AODC) were done using a Zeiss epifluorescent microscope, recording all fluorescing cells (Hobbie et al., 1977). The rates of movement were reported in $\mathrm{cm} /$ day.

Reproducibility studies. Deep subsurface bacterial cultures were lyophilized with a bench top freeze drier (Labcono). The isolates were resuspended in PTYG broth and incubated for $48 \mathrm{~h}$ at $23^{\circ} \mathrm{C}$. They were streaked on PTYG plates and incubated for $24 \mathrm{~h}$ at $23^{\circ} \mathrm{C}$. Finally, one CFU was grown in PTYG broth for $24 \mathrm{~h}$ at $23^{\circ} \mathrm{C}$ and this culture used for the chemotactic assays. This method was adopted to diminish the day to day differences that may result in the assays, as has been reported in other chemotaxis analysis (Ordal and Gibson, 1977). This way, inoculation from the same bacterial culture ensures almost virtually identical bacteria from experiments days apart.

Several chemotaxis experiments were done using the same isolate and substrate but on different days. Three randomly chosen isolates, one of every site, A0481, B0703 and C0397, were tested for their response to arginine, TCE and lactose in two or three different days and the response range, peak, and threshold concentrations and chemotactic indexes compared. 
Data Analysis. Data was analyzed using prepared programs for Macintosh computers and statistical tests as described by $\mathrm{Zar}$ (1984). All dilutions of each substrate, the KPB control, and motility test were examined for differences using analysis of variance. Tukey Tests were performed for significant analysis of variances to determine which groups or dilutions were different. Any probability less than or equal to 0.05 was considered significant. 


\section{RESULTS}

None of the isolates showed significant reduction in motility after centrifugations and incubation period as indicated by microscopic observations and motility controls. All the motility controls showed an index not significantly different from 1 (Tables 2-33, Appendix II). Therefore, the bacterial true chemotactic response was not affected by addition of substrates. If the addition of a compound to the bacterial suspension diminished bacterial motility, the value would have been significantly less than the KPB control i.e., a chemotactic index less than 1 would have been obtained in the motility control. If on the contrary, motility increased, the chemotactic index would have significantly exceeded the KPB control, i.e., a chemotactic index significantly greater than 1 would have been obtained in the motility control.

Reproducibility. Randomly chosen isolates and substrates were tested for reproducibility. For isolate A0481, the threshold on both assays for arginine was at $10^{-6} \mathrm{M}, \mathrm{CI}=2.38$ on the first assay and $\mathrm{CI}=2.07$ on the second assay. The peaks were both at $10^{-4} \mathrm{M}, \mathrm{CI}$ of 3.03 on the first experiment and 2.70 on the second (Table 2). Similar threshold ard peak responses were obtained also in three different assays of isolate $\mathrm{C} 0397$ at $10^{-5} \mathrm{M}$ lactose (Table 3). The chemotactic indexes corresponding to the threshold concentrations of these three different assays were $1.63,1.51$, and 1.57. Isolates $\mathrm{B} 0703, \mathrm{~A} 0481$, and $\mathrm{C} 0397$ gave good reproducible results in different days. The threshold for isolate B0703 and TCE 
was at $10^{-10} \mathrm{M}, \mathrm{CI}$ of 1.89 on the first assay and 1.77 on the second, repectively (Table 4). The peak response was seen for both experiments at $10^{-7} \mathrm{M}, \mathrm{CI}=3.53$ on the first experiment and $\mathrm{CI}=3.43$ on the second experiment. Day to day differences in chemotaxis experiments were reduced following the procedure for the preparation of the cell suspension, as described in the reproducibility section in the Materials and Methods. Cell suspensions from clones of the same age lyophilized cultures ensured almost identical results.

Isolate A0481. A bimodal response curve was obtained for isolate A0481 with substrates like lactose, dextrose and sucrose (Table 5). The peak concentration for the negative response to lactose was at $1 \mathrm{M}$ with an index of 0.15 and the threshold at $10^{-2} \mathrm{M}, \mathrm{CI} 0.82$. For the positive chemoattraction of lactose, the peak concentration was at $10^{-3} \mathrm{M}, \mathrm{CI}$ of 1.50 and the threshold at $10^{-5} \mathrm{M}, \mathrm{CI}$ of 1.28 (Table 5). For sucrose, the response range for the negative chemoattraction was from $1 \mathrm{M}$ to 10-2 $\mathrm{M}$ (Table 5). The peak concentration was at $1 \mathrm{M}$ with an index of 0.15 with the threshold concentration at $10^{-2} \mathrm{M}$ with $\mathrm{Cl}=0.49$. The response range for the positive chemotaxis of isolate A0481 towards sucrose was between $10^{-3} \mathrm{M}$ and 10-5 $\mathrm{M}$. The highest positive response was seen at $10^{-5} \mathrm{M}$ with an index of 1.48. This value corresponds to both the peak and threshold concentrations (Table 5). Dextrose, on the contrary, elicited a positive response at high concentrations and a negative one at lower concentrations (Table 5). Indexes of 1.39 and 0.64 were obtained for dextrose suggesting that isolate A0481 was attracted 
to $1 \mathrm{M}$ but repelled by $10^{-1} \mathrm{M}$ of that sugar. Maltose elicited a negative response at all the concentrations tested (Table 5). The peak response was seen at $1 \mathrm{M}$ with an index of 0.53 and the threshold at $10^{-5} \mathrm{M}$ with an index of 0.70 . Ribose elicited a positive response at all the concentrations used except at $10^{-1} \mathrm{M}$. The peak concentration was at $1 \mathrm{M}, \mathrm{CI}=1.76$ and the threshold at $10^{-5} \mathrm{M}, \mathrm{CI}=1.25$ (Table 5).

Threonine did not generate any significant chemotactic response (Tables 5 and 6). Regarding the other amino acids, isolate A0481 was positively chemotactic to glutamine with the peak response at $10^{-4} \mathrm{M}, \mathrm{CI}$ of 1.54 and a threshold concentration of $10^{-5} \mathrm{M}, \mathrm{Cl}$ of 1.34 (Table 6). Isolate A0481 was repelled only by glutamine $10^{-3} \mathrm{M}, \mathrm{CI}=0.86$. Proline was a repellent to isolate A0481 from concentrations of $1 \mathrm{M}$ to $10^{-3} \mathrm{M}$ (Table 6). Lesser concentrations were not significantly different from the motility control. The peak response was at $1 \mathrm{M}$ with a $\mathrm{Cl}$ of 0.32 and the threshold at $10^{-3} \mathrm{M}$ with a $\mathrm{Cl}$ of 0.77 . Arginine elicited the highest positive responses for isolate A0481 (Table 6) being attracted to ail the concentrations of arginine used and with chemotactic indexes above 2 in most cases. The highest response for arginine was obtained at $10^{-4} \mathrm{M}$ with an index of 2.87 and the threshold was at the lowest concentration tested, $10^{-6} \mathrm{M}, \mathrm{Cl}$ of 2.45 .

In general, isolate A0481 was repelled by maltose, proline and high concentrations of sucrose, dextrose, glutamine and lactose, while it was attracted to ribose, some concentrations of glutamine, arginine and low concentrations of lactose and sucrose. 
Threonine did not elicit any response at any of the concentrations tested. Almost all the concentrations of TCE used, except $10^{-9} \mathrm{M}$, were attractants to isolate A0481 (Table 7). The highest response was at $10^{-8} \mathrm{M}$ with an index of 3.10 . The threshold, as with other isolates, was the lowest concentration of TCE used, $10^{-10} \mathrm{M}, \mathrm{CI}$ of 1.88 (Table 7).

\section{Isolate A0231. Isolate A0231 showed a strong} chemoattraction to dextrose with a response range from $1 \mathrm{M}$ to 10-6 M (Table 8). Its peak response was obtained at 10-6 M with a chemotactic index of 2.17 , which also corresponded to the threshold concentration. For maltose, ribose, sucrose, and lactose a bimodal response curve was seen (Table 8). At the highest concentration tested, $1 \mathrm{M}, \mathrm{A} 0231$ was highly negatively chemotactic to maltose ( $\mathrm{CI}$ of 0.35 ), ribose ( $\mathrm{CI}$ of 0.54$)$, and sucrose (CI of 0.47 ). For lactose, a lower concentration elicited the highest negative response, $10^{-3} \mathrm{M}, \mathrm{CI}=0.65$ (Table 8). At lower concentrations, A0231 was positively chemotactic to the substrates mentioned above. For maltose the positive threshold and peak concentrations were obtained at $10^{-6} \mathrm{M}$ with a $\mathrm{Cl}$ of 2.38. For ribose the peak concentration was at $10^{-5} \mathrm{M}$ with a $\mathrm{CI}$ of 1.59. The threshold was at $10^{-6} \mathrm{M}$ with an index of 1.36. For sucrose the peak was also at $10^{-5} \mathrm{M}$ with an index of 1.65 and the threshold at $10^{-6} \mathrm{M}$ with an index of 1.57. The highest positive response for lactose was seen at $10^{-6} \mathrm{M}, \mathrm{CI} 1.81$ which also corresponded to the threshold concentration (Table 8).

For amino acids a bimodal response was observed toward arginine (Table 9). Chemotactic indexes of 0.69 (highest negative 
response) and 1.14 (highest positive response) were observed at $10^{-1} \mathrm{M}$ and $10^{-4} \mathrm{M}$ (peak responses), respectively. The thresholds were at $10^{-2} \mathrm{M}, \mathrm{Cl}=0.74$ and at $10^{-4} \mathrm{M}, \mathrm{Cl}=1.14$. In contrast, glutamine showed a high positive response at low concentrations. At $10^{-5} \mathrm{M}$, the peak concentration, an index of 2.38 was observed. The threshold was at $10^{-6} \mathrm{M}, \mathrm{CI}$ of 2.10 (Table 9). Concentrations from $1 \mathrm{M}$ to $10^{-3} \mathrm{M}$, were not significantly chemotactic. Proline elicited a significant negative chemotactic response at all concentrations tested (Table 9). The highest negative response was seen at $10^{-2} \mathrm{M}$ with an index of 0.16. At the threshold concentration, $10^{-6} \mathrm{M}$, a chemotactic index of 0.62 was obtained. Threonine also acted as a repellent (Table 9). The peak concentration was at $10^{-2} \mathrm{M}, \mathrm{CI}$ of 0.54 . The threshold occurred at $10^{-4} \mathrm{M}, \mathrm{CI}=0.76$.

Isolate A0231 responded chemotactically to all the carbohydrates and amino acids tested. Isolate A0231 was attracted to dextrose, glutamine and to low concentrations of lactose, maltose, ribose, arginine, and sucrose. Proline, threonine and high concentrations of maltose, ribose, arginine, and sucrose (1 M) repel this bacteria. Isolate A0231 responded positively to all the concentrations of trichloroethylene used (Table 10). The response ranged from $10^{-2} \mathrm{M}$ to $10^{-10} \mathrm{M}$. The highest response was obtained at $10^{-6} \mathrm{M}$ with a chemotactic index of 2.95 . The threshold concentration corresponded to the lowest concentration tested, $10^{-10} \mathrm{M}, \mathrm{Cl}$ of 2.21 . 
Isolate B0388. All the carbohydrates tested elicited a positive and high chemotactic response on B0388 (Table 11). The response range for dextrose ranged from $1 \mathrm{M}$ to $10^{-6} \mathrm{M}$. The highest response was obtained at $10^{-6} \mathrm{M}, \mathrm{CI}$ of 2.69 . This value also corresponds to the threshold concentration. Also all lactose, ribose, and sucrose concentrations used were attractants. The highest response for lactose was seen at $10^{-5} \mathrm{M}, \mathrm{CI}=2.09$ and the threshold concentration at $10^{-6} \mathrm{M}$ with an index of 1.97 . The peak concentration for sucrose was at $10^{-6} \mathrm{M}$ with an index of 2.72 , corresponding also to the threshold concentration. The maximum response for ribose occurred at $10^{-4} \mathrm{M}, \mathrm{Cl}$ of 3.28 and the threshold at $10^{-6} \mathrm{M}, \mathrm{CI}$ of 3.20 (Table 11). The positive for maltose response ranged from $10^{-1} \mathrm{M}$ to $10^{-6} \mathrm{M}$. The maximum response and the threshold concentration coincide i.e., $10^{-6} \mathrm{M}, \mathrm{CI}$ of 2.69 .

For amino acids, arginine was an attractant at $10^{-4} \mathrm{M}$ and 10-6 M. This last concentration corresponds to both the threshold and peak concentration, $\mathrm{CI}$ of 1.74 (Table 12). Arginine at $1 \mathrm{M}$ elicited a negative response, $\mathrm{Cl}=0.69$ (peak and threshold response). Proline elicited a bimodal response. The maximum positive response for proline was at $10^{-4} \mathrm{M}, \mathrm{CI}$ of 1.69 and the threshold at $10^{-6} \mathrm{M}, \mathrm{CI} 1.66$. An index of 0.44 was obtained at $10^{-1} \mathrm{M}$ (maximum and threshold response), suggesting a bimodal response curve. Isolate $\mathrm{B} 0388$ responded positively to threonine at concentrations between $1 \mathrm{M}$ and $10^{-4} \mathrm{M}$ with the maximum chemotactic index and threshold of 2.15 at $10^{-4} \mathrm{M}$. The only amino acid to which isolate B0388 was completely repelled, was 
glutamine (Table 12), Glutamine at $1 \mathrm{M}$ concentration repelled the most bacteria producing a chemotactic index of 0.26 . The threshold concentration was at $10^{-5} \mathrm{M}$ with an index of 0.71 (Table 12). Isolate B0388 was attrarted to all concentrations of TCE used in the experiment (Table 13). The highest response was seen at $1 \mathrm{M}, \mathrm{Cl}$ of 2.70 . The threshold was at $10^{-10} \mathrm{M}, \mathrm{CI}$ of 2.17 . In conclusion, isolate B0388 was attracted to dextrose, lactose, maltose, ribose, sucrose, TCE, threonine and low concentrations of arginine, and, proline. The only substrate to which B0388 was totally repelled was glutamine. The highest positive responses were to ribose and sucrose. Motility controls for isolate B0388 were slightly more variable than for other assays (Table 13). Even though arginine and proline slightly decreased bacterial motility, significant chemotactic responses were obtained (Table 13).

Isolate B0703. Isolate B0703 responded chemotactically to all the sugars tested (Table 14). Dextrose promoted a bimodal response in isolate $\mathrm{B} 0703$. However, the response was the opposite of what we had previously seen for other bacteria. Dextrose was an attractant to the bacteria but only at high concentrations, eg., $1 \mathrm{M}, \mathrm{Cl}=1.75$, and a repellent at lower, eg. 10-5 $M(\mathrm{CI}=0.58)$. Ribose had the highest positive response, with the peak at $1 \mathrm{M}$ and an index of 2.38. The threshold concentration was at $10^{-2} \mathrm{M}, \mathrm{CI}=1.35$. These were the only concentrations significantly different from the motility control (Table 14). Isolate B0703 was negatively chemotactic to sucrose and maltose (Table 14). Concentrations as high as $1 \mathrm{M}$ of maltose gave an index of 
only 0.12 (maximum negative response). The threshold concentration was at $10^{-6} \mathrm{M}, \mathrm{CI}=0.63$. Similar to maltose, all concentrations of sucrose were repellents (Table 14). At $10^{-5} \mathrm{M}$ of sucrose an index as low as 0.09 was obtained. This value corresponds to the peak and threshold concentrations.

Proline, arginine and the lowest concentration of threonine are the amino acids to which isolate $\mathrm{B} 0703$ was attracted to (Table 15). A maximum response of 2.09 was obtained with proline at $10^{-4} \mathrm{M}$. At $10^{-5} \mathrm{M}$ an index of 1.56 was obtained, corresponding to the threshold concentration. The response range of $\mathrm{B} 0703$ for arginine was between $10^{-2} \mathrm{M}$ and $10^{-4} \mathrm{M}$. The highest response for arginine was at $10^{-3} \mathrm{M}$ with a $\mathrm{CI}$ of 1.43 . The threshold concentration was at $10^{-4} \mathrm{M}, \mathrm{CI}=1.23$. Glutamine acted as a repellent to isolate $\mathrm{B} 0703$. Glutamine at $10^{-1} \mathrm{M}$ repelled the most bacteria, $\mathrm{CI}=0.72$. The threshold was at $10^{-4} \mathrm{M}, \mathrm{CI}=0.77$. No other concentration elicited a significant chemotactic response. Lactose and threonine promoted a bimodal response. Isolate B0703 was more negatively chemotactic towards these two substrates at high concentrations. A chemotactic index of 0.17 was obtained for $1 \mathrm{M}$ of lactose and an index of 0.16 for $1 \mathrm{M}$ threonine. The threshold concentration for the negative response of these two substrates was $10^{-1} \mathrm{M}$ with an index of 0.54 for lactose and 0.77 for threonine. Isolate B0703 responded positively to lactose at $10^{-2}$ $\mathrm{M}$ and $10^{-4} \mathrm{M}$. The highest response gave an index of 1.30 in lactose $10^{-2} \mathrm{M}$ and an index of 1.62 in threonine at $10^{-5} \mathrm{M}$. Isolate B0703 was attracted to ribose, proline, arginine and to low concentrations of threonine, lactose, and high concentrations of 
dextrose while it was repelled by maltose, sucrose, glutamine, high concentrations of threonine and lactose, and low concentrations of dextrose. Isolate B0703 was also attracted to all the concentrations of TCE used (Table 16). The highest response was at $10^{-7} \mathrm{M}, \mathrm{Cl}=3.47$. The threshold was at $10^{-10} \mathrm{M}, \mathrm{CI}$ of 1.83 .

Isolate B0617. Isolate B0617 showed no significant chemotactic response towards sucrose (Table 17). Isolate B0617 moved away when exposed to maltose $10^{-1} \mathrm{M}$ concentration $(\mathrm{CI}=0.63)$ while it was attracted to $10^{-3} \mathrm{M}$ (peak response) and 10-5 $\mathrm{M}$ (threshold concentration) of that same sugar. Dextrose promoted the highest response at $10^{-6} \mathrm{M}$ with an index of 1.41 This value also corresponds to the threshold concentration. Dextrose was a significant attractant at concentrations of $10^{-2} \mathrm{M}$ and $10^{-3} \mathrm{M}$. Dextrose at $10^{-5} \mathrm{M}$ was a repellent, $\mathrm{CI}=0.73$. Lactose elicited the highest response of all the carbohydrates (Table 17) with a peak concentration at $10^{-2} \mathrm{M}$ and an index 2.40 . The threshold concentration was at $10^{-6} \mathrm{M} \mathrm{Cl}$ of 1.43. As with dextrose, only one concentration was a repellent, $10^{-3} \mathrm{M}, \mathrm{CI}=0.78$. Ribose elicited a negative response at $1 \mathrm{M}, \mathrm{Cl}$ of 0.56 (peak) and at $10^{-1} \mathrm{M}$ (threshold), while being an attractant at $10^{-5} \mathrm{M}, \mathrm{CI}=1.21$. The threshold for the positive response was at $10^{-6} \mathrm{M}, \mathrm{CI}=1.19$. At low concentrations proline and threonine attracted isolate B0617 (Table 18). The response range for proline was from 10-3 $M$ to $10^{-6} M$ while the maximum response and the threshold concentration were at $10^{-6} \mathrm{M}$ with an index of 2.67 . At $1 \mathrm{M}$, proline was a repellent, $\mathrm{CI}=0.66$. Glutamine, arginine and high concentrations of threonine and proline are repellents to isolate 
B0617 (Table 18). In the bimodal response observed for threonine, $10-3 \mathrm{M}$ elicited the highest negative response, $\mathrm{CI}$ of 0.50. This value also corresponded to the threshold concentration for the negative response towards threonine. At lower concentrations, a significant positive chemotaxis was observed. The concentration that gave the highest positive chemotactic index was $10^{-5} \mathrm{M}, \mathrm{CI} 1.70$, which also corresponded to the threshold concentration. The highest negative response was seen with arginine at $10^{-5} \mathrm{M}, \mathrm{CI}$ of 0.003 . The threshold concentration was at $10^{-6} \mathrm{M}, \mathrm{CI}$ of 0.01 . Isolate B0617 responded to concentrations of glutamine, between $1 \mathrm{M}$ and $10^{-3} \mathrm{M}$. For glutamine the highest negative response was at $1 \mathrm{M}$ with an index of 0.42 and the threshold at $10^{-3} \mathrm{M}, \mathrm{CI} 0.72$. Isolate $\mathrm{B} 0617$ responded chemotactically to all the substrates except sucrose. Isolate B0617 had the highest chemotactic index for TCE, 4.69 (Table 19). This was observed at $1 \mathrm{M}$. The response range for TCE was from $1 \mathrm{M}$ $10^{-10} \mathrm{M}$. The threshold concentration occurred at $10^{-10} \mathrm{M}, \mathrm{Cl}$ of 2.10 .

Isolate C0397. The response range for dextrose was between $1 \mathrm{M}$ and $10^{-6} \mathrm{M}$ (Table 20). The maximum response was obtained at $10^{-4} \mathrm{M}$ with a.t index of 2.12 and the threshold at $10^{-}$ $6 \mathrm{M} \mathrm{Cl}=1.41$. The response range for lactose was between $1 \mathrm{M}$ and $10^{-5} \mathrm{M}$. The peak and the threshold concentrations were at $10^{-5} \mathrm{M}, \mathrm{Cl}$ of 1.57 . Maltose was a repellent to isolate $\mathrm{C} 0397$ but at limited concentrations, $1 \mathrm{M}$ and $10^{-1} \mathrm{M}$. The maximum response occurred at $i \mathrm{M}, \mathrm{CI}=0.42$ and the threshold comesponded to $10^{-1} \mathrm{M}, \mathrm{CI}=0.63$. Isolate $\mathrm{C} 0397$ was negatively chemotactic 
only at $1 \mathrm{M}$ of ribose, $\mathrm{CI}$ of 0.55 . The rest of the ribose and maltose concentrations gave no significant chemotactic response. Sucrose promoted a bimodal response in isolate $\mathrm{C} 0397$, being repelled at $10^{-2} \mathrm{M}(\mathrm{Cl}=0.70)$ and attracted at $10^{-5} \mathrm{M}(\mathrm{Cl}=1.35)$ (Table 20).

Arginine, glutamine and one concentration of proline elicited negative chemotactic responses on C0397 (Table 21). The maximum response for arginine was at $10^{-2} \mathrm{M}$ with a $\mathrm{CI}$ of 0.60 and the threshold concentration at $10^{-3} \mathrm{M}$. $\mathrm{CI}=0.84$. The same index was obtained at the peak and threshold for glutamine but at a different concentration, i.e. $10^{-4} \mathrm{M}$. Glutamine elicited a positive response at $10^{-1} \mathrm{M}, \mathrm{CI}=1.30$. No other concentration of arginine or glutamine was a significant attractant. Proline gave a bimodal response with the highest positive response at $1 \mathrm{M}$, $\mathrm{CI}=1.46$ and the highest negative one at $10^{-2} \mathrm{M}, \mathrm{Cl}=0.53$. The threshold for the positive response occurred at $10^{-5} \mathrm{M}, \mathrm{CI}=1.36$. Isolate C0397 was positively chemotactic only to threonine, lactose, dextrose, sucrose $10^{-5} \mathrm{M}$, and $1 \mathrm{M}$ of proline and negatively chemotactic to maltose, ribose, arginine, $10^{-4} \mathrm{M}$ glutamine and $10^{-1} \mathrm{M}$, and $10^{-2} \mathrm{M}$ of proline. Isolate $\mathrm{C} 0397$ was also attracted to TCE (Table 22). The positive response range for TCE was from $10^{-2} \mathrm{M}$ to $10^{-9} \mathrm{M}$. The peak was at the highest concentration tested, $10^{-2} \mathrm{M}, \mathrm{CI}$ of 2.26 . The threshold was at $10^{-}$ ${ }^{9} \mathrm{M}, \mathrm{CI} 1.61$. TCE at $10^{-10} \mathrm{M}$ was a repellent, $\mathrm{CI}=0.79$.

Isolate C0101. Ribose was an attractant to isolate C0101 at all concentrations tested (Table 23). The highest response was obtained at $10^{-5} \mathrm{M}$ with a chemotactic index of 2.70 . The 
threshold concentration was at $10^{-6} \mathrm{M}, \mathrm{Cl}, 2.58$. Dextrose was a significant attractant but only at $10^{-3} \mathrm{M}, \mathrm{CI} 1.58$. Dextrose was an attractant from $10^{-1} \mathrm{M}$ to $10^{-6} \mathrm{M}$. The highest response was at 10-3 M, CI=1.58. The threshold concentration was at $10^{-6} \mathrm{M}$, $\mathrm{CI}=1.28$. Sucrose positive chemotactic response ranged from $10^{-1}$ $\mathrm{M}$ to 10-6 M. The maximum response was obtained at $10^{-5} \mathrm{M}$ with an index of 1.82 . The threshold was at $10^{-6} \mathrm{M}, \mathrm{CI} 1.59$. High concentrations of sucrose, eg. $1 \mathrm{M}$, repel isolate C0101. Of the carbohydrates, lactose, sucrose, and maltose provoked a bimodal response (Table 23). At $1 \mathrm{M}$, lactose promoted a chemotactic index of only 0.23 but at $10^{-5} \mathrm{M}$ the index was 1.68 (peak and threshold response). The same occured with maltose, only the highest negative response was at $10^{-1} \mathrm{M}, \mathrm{CI}=0.19$. The threshold occurred at $10^{-2} \mathrm{M}, \mathrm{CI}=0.51$. The highest positive index was at $10^{-5} \mathrm{M}, 1.58$. The positive threshold occurred at $10^{-6} \mathrm{M}, \mathrm{CI}=1.33$. The range of maltose that promoted a negative chemotaxis was between $1 \mathrm{M}$ and $10^{-2} \mathrm{M}$ and the positive between $10^{-3} \mathrm{M}$ and $10^{-6} \mathrm{M}$ (Table 23). The range of concentrations of lactose that promoted a positive chemotaxis included $10^{-1} \mathrm{M}, 10^{-2} \mathrm{M}, 10^{-4} \mathrm{M}$ and $10^{-5} \mathrm{M}$.

Isolate C0101 was highly attracted to almost all the amino acids (Table 24). For both threonine and proline the maximum response was obtained at $10^{-3} \mathrm{M}$ with an index of 2.42 and 2.72 . The threshold concentration was the same for both, $10^{-6} \mathrm{M}$ with an index of 1.81 for threonine and 2.02 for proline. The response range of proline was broader, from $10^{-1} \mathrm{M}$ to $10^{-6} \mathrm{M}$. Arginine was a chemoattractant at concentrations between $10^{-2} \mathrm{M}$ and $10^{-}$ 
6 M. An index of 1.45 was obtained at the peak concentration and a $\mathrm{Cl}$ of 1.16 at $10^{-6} \mathrm{M}$, the threshold concentration. A bimodal response of $\mathrm{C} 0101$ to arginine was also seen. At high concentrations it was repelled. The maximum response was at 1 $\mathrm{M}, \mathrm{Cl}=0.66$ and the threshold at $1 \mathrm{M}, \mathrm{Cl}=0.74$. Glutamine did not elicit any significant response (Table 24).

Isolate C0101 was positively chemotactic to most of the substrates tested including ribose, dextrose, threonine, proline, and some concentrations of lactose, sucrose, arginine and maltose but negatively chemctactic to high concentrations of all of them. Isolate C0101 did not respond significantly to glutamine but was attracted to TCE (Table 25). The response range was from $1 \mathrm{M}$ to $10^{-10} \mathrm{M}$. The maximum response was at $10^{-2} \mathrm{M}$ with a chemotactic index of 3.11 and the threshold at $10^{-10} \mathrm{M}$ with an index of 2.14 .

Isolate C0464. Isolate $\mathrm{C} 0464$ was strongly attracted to concentrations between $10^{-1} \mathrm{M}$ and $10^{-6} \mathrm{M}$ of ribose. The peak was at $10^{-6} \mathrm{M}, \mathrm{CI}=1.66$ (Table 26). This value also corresponded to the peak and threshold concentrations. Ribose at $1 \mathrm{M}$ was a repellent, $\mathrm{CI}=0.76$. Maltose also acted as a repellent at high concentrations at $10^{-2} \mathrm{M}$ (maximum response) and $10^{-3} \mathrm{M}$ (threshold concentration) with an index of 0.60 for both. Lactose and sucrose also elicited a bimodal response showing a negative chemotaxis for lactose at $1 \mathrm{M}(\mathrm{CI} 0.32)$ and $10^{-1} \mathrm{M}(\mathrm{CI} 0.73)$ for sucrose but a positive response at lesser concentrations. The maximum response for the positive chemotaxis of lactose occurred at $10^{-3} \mathrm{M}$ with an index of 1.47 , and the threshold value at $10^{-6}$ 
$\mathrm{M}, \mathrm{CI}=1.34$. For sucrose the threshold and maximum responses on the positive chemotaxis occurred at $10^{-5} \mathrm{M}$ with an index of 1.58 . Other positive responses were observed for sucrose at concentrations of $10^{-3} \mathrm{M}$ to $10^{-5} \mathrm{M}$. Dextrose highest positive response was at $10^{-1} \mathrm{M}, \mathrm{CI}=1.30$ and the threshold at $10^{-6} \mathrm{M}$, $\mathrm{CI}=1.25$. Concentrations as low as $10^{-4} \mathrm{M}$ (peak response) and 10-5 M (threshold) elicited a negative response. Glutamine, on the contrary, did not promote any type of response (Table 27). Arginine was positively chemoattractant at concentrations between $10^{-2} \mathrm{M}$ and $10^{-5} \mathrm{M}$ with the highest response of 1.46 (Table 27). The threshold occurred at $10^{-6} \mathrm{M}, \mathrm{CI}=1.34$. Threonine elicited also a positive response. The response was between $10^{-1}$ $\mathrm{M}$ and $10^{-6} \mathrm{M}$. The maximum response and the threshold were at $10^{-5} \mathrm{M}, \mathrm{Cl}=1.95$. Proline, on the other hand, was a repellent to isolate C0464. The maximum response for proline was at $1 \mathrm{M}, \mathrm{CI}$ 0.33 and the threshold at $10^{-1} \mathrm{M}, \mathrm{CI} 0.56$.

C0464 was positively chemotactic to ribose, arginine, threonine maltose, dextrose, lactose and sucrose. Glutamine did not promote any chemotactic behavior. Isolate C0464 was also attracted to TCE (Table 28). The response range was between $1 \mathrm{M}$ and $10^{-9} \mathrm{M}$. The highest index was seen at $10^{-1} \mathrm{M}, 3.40$. The threshold was at $10^{-9} \mathrm{M}, \mathrm{CI}=1.61$.

Isolate CBF 33. Isolate CBF 33 was repelled by ribose, being $1 \mathrm{M}$ the concentration where the maximum negative response was obtained, $\mathrm{Cl}=0.53$ (Table 29). The threshold for this carbohydrate was at $10^{-6} \mathrm{M}, \mathrm{Cl}=0.77$. The response ranged from $1 \mathrm{M}$ to $10^{-6} \mathrm{M}$. Sucrose was also a repellent at $1 \mathrm{M}$, with an index 
of 0.43 (peak concentration). The threshold was at the lowest concentration used, $10^{-6} \mathrm{M}, \mathrm{Cl}=0.61$. Dextrose promoted a bimodal response with a negative index of 0.32 at $1 \mathrm{M}$ (peak and threshold response) and a maximum positive index of 2.09 at $10^{-}$ $4 \mathrm{M}$. The threshold for the positive response was at $10^{-5} \mathrm{M}$, $\mathrm{CI}=1.79$. Lactose was also a repellent at $1 \mathrm{M}, \mathrm{CI}=0.83$ but a chemoattractant at $10^{-1} \mathrm{M}, \mathrm{Cl}=1.29$ (peak response) and $10^{-2} \mathrm{M}$, $\mathrm{CI}=1.22$ (threshold response). Maltose was a repellent at $10^{-3} \mathrm{M}$, $\mathrm{CI}=0.71$ (peak) and at $10^{-5} \mathrm{M}, \mathrm{CI}=0.75$ (threshold).

Threonine was a repellent at $1 \mathrm{M}, \mathrm{Cl}$ of 0.42 (Table 30). The rest of the concentrations were not significantly different from the motility control. Proline was also a repellent at all concentrations, except $10^{-3} \mathrm{M}$. The maximum response for proline was at $1 \mathrm{M}$ with an index of 0.19 . The threshold was at $10^{-6} \mathrm{M}, \mathrm{Cl}=0.46$. Isolate CBF 33 was highly attracted to glutamine at concentrations as high as $1 \mathrm{M}$. This concentration corresponds to maximum response with a chemotactic index of 2.29. The threshold was observed at $10^{-2} \mathrm{M}$ with an index of 1.52 . It was repelled by low concentrations of glutamine. At $10^{-4} \mathrm{M}$, maximum response, an index of 0.58 was obtained and at $10^{-6} \mathrm{M}$, an index of 0.71 , threshold response. Arginine also promoted a bimodal response, isolate $\mathrm{CBF} 33$ was repelled by concentrations of $1 \mathrm{M}$, index of 0.07 (maximum response). The threshold for the negative chemotaxis of arginine was at $10^{-1} \mathrm{M}, \mathrm{Cl}=0.23$ whereas a positive response was obtained at $10^{-4} \mathrm{M}$, CI of 1.16 , positive peak and threshold response (Table 30 ). 
CBF 33 was attracted to glutamine and low concentrations of dextrose, lactose, and arginine. Ribose, sucrose, maltose, threonine, proline and high concentrations of dextrose and arginine repel isolate CBF 33. TCE also promoted a bimodal response by isolate CBF 33 (Table 31). Concentrations as high as 1 $\mathrm{M}$ of TCE promoted negative chemotaxis of isolate CBF 33, CI of 0.53 . In contrast, positive responses were seen between $10^{-2} \mathrm{M}$ and $10^{-7} \mathrm{M}$. The peak positive response was at $10^{-5} \mathrm{M}, \mathrm{CI}$ of 1.45 and the threshold at $10^{-7} \mathrm{M}, \mathrm{CI}$ of 1.23 . The rest of the concentrations did not differ significantly from the motility control (Table 31).

Isolates $\mathrm{C0081}$ and $\mathrm{C0128}$. Only chemotaxis assays with TCE were conducted on isolates C0128 and C0081. For isolate C0081 a positive response was obtained in almost all concentrations except $10^{-4} \mathrm{M}$ and $10^{-7} \mathrm{M}$ (Table 33). The maximum response was at $10^{-3} \mathrm{M}, \mathrm{CI}$ of 2.11 and the threshold at $10^{-10} \mathrm{M}, \mathrm{CI}$ of 1.40 . For isolate $\mathrm{C} 0128$ the only significant positive response observed was at $1 \mathrm{M}$ of TCE with an index of 1.70 (Table 32). Thus, these values also corresponded to the peak and threshold concentrations for the positive response. At lower concentrations, TCE was a repellent and the maximum negative response and threshold were seen at $10^{-10} \mathrm{M}, \mathrm{CI}=0.74$.

Comparison of substrates. Lactose elicited the highest positive response in isolate $B 0617$ and the highest negative in isolate A0481 (Table 34). Most of the isolates, eg. B0703, A0231, A0481, C0101, B0617, CBF 33, and C0464, showed a bimodal response to lactose. The threshold for the responses occurred 
primarily at the lowest concentration of chemical tested. Dextrose elicited a positive response in isolates A0231, C0397, and B0388 (Table 35). The highest responses were those of B0388 (Table 35). Isolate CBF 33 had the highest negative response of all the isolates. Half of the isolates used were negatively chemotactic to maltose, i.e. A0481, C0397, B0703, and CBF 33, while just one was highly attracted to it, B0388 (Table 36). Isolates A0231, B0617 and C0464 responded negatively at high concentrations of maltose but positively to lower concentrations. All the isolates responded to ribose (Table 37). The highest positive response was by $\mathrm{B} 0388$. Ribose was also an attractant to isolates B0703, A0481, and C0101. Negative responses were obtained for isolates C0397 and CBF 33, whereas A0231, B0617 and C0464 reflected a bimodal response. The highest response was seen at $1 \mathrm{M}$ ribose for most of the isolates. Isolate B0388 had the highest positive response for sucrose, followed by $\mathrm{C} 0101$ (Table 38). In contrast, isolates CBF 33 and B0703 were highly repelled by sucrose. Bimodal responses were obtained by A0231, A0481, C0397, and C0464 while B0617 did not respond to this carbohydrate. The highest response was primarily seen at $10^{-5} \mathrm{M}$, or the lowest concentration of substrate used.

For amino acids, arginine elicited the highest positive response in isolate A0481 (Table 39). Isolates B0703, and C0464 were also attracted to arginine but to a lesser extent. Isolates B0617, and C0397, were repelled by this amino acid while isolates A0231, B0388, C0101 and CBF 33 showed a bimodal response toward this amino acid. The only isolate that did not respond significantly to 
arginine was A0231. Glutamine was an attractant for isolate A0231 and a repellent to isolates B0703, B0388, and, B0617 (Table 40). Isolates A0481, C0397 and CBF 33 were attracted to it at high concentrations and repelled by low concentrations. Isolates C0464 and $\mathrm{C} 0101$ did not show any significant response to it. Proline elicited positive responses in isolates B0703 and C0101 whereas it was a repellent to isolates A0231, A0481, C0464, and, CBF 33 (Table 41). The highest positive responses were those of C0101 and B0617 with bimodal responses by $\mathrm{C} 0397, \mathrm{~B} 0388$ and $\mathrm{B} 0617$. Threonine attracted B0388, C0101, and C0464 (Table 42). High concentrations of threonine in isolates B0703, B0617, and CBF 33 acted as repellents. Isolate A0231 was repelled by all threonine concentrations. Isolate A0481 did not respond significantly to any of the concentrations of threonine tested.

In general, the highest positive chemotactic responses for all the tested compounds were obtained for TCE (Table 43). All the isolates assayed were attracted to it, even at very high concentrations. Surprisingly, isolate CBF 33 showed a bimodal response and lower chemotactic indexes than other isolates. An index of only 0.53 was observed at $1 \mathrm{M}$ TCE while a greater index was seen at $10^{-5} \mathrm{M}, 1.45$. The positive threshold was at $10^{-7} \mathrm{M}$, $\mathrm{Cl}=1.23$ and the negative threshold at $1 \mathrm{M} \mathrm{Cl}=0.53$. The highest response for isolate $\mathrm{A} 0231$ was at $10^{-6} \mathrm{M}, \mathrm{CI} 2.95$ and the threshold at $10^{-10} \mathrm{M}, \mathrm{CI}=2.21$. The highest response for isolate $\mathrm{A} 0481$ was at $10^{-8} \mathrm{M}$ with an index of 3.10 and the threshold at $10^{-10} \mathrm{M}, \mathrm{Cl}$ of 1.88. The maximum response for isolate $\mathrm{B} 0703$ was at $10^{-7} \mathrm{M}$, $\mathrm{Cl}=3.47$ and a threshold at $10^{-10} \mathrm{M}, \mathrm{Cl} 1.83$. The peak response for 
isolate $\mathrm{C} 0397$ was at $10^{-2} \mathrm{M}, \mathrm{CI}=2.26$ and a threshold at $10^{-9} \mathrm{M}$ with an index of 1.61 . At $10^{-10} \mathrm{M}$, an index of 0.79 was measured. Isolate $\mathrm{B} 0388$ had the highest response at the highest concentration tested, $1 \mathrm{M}, \mathrm{CI} 2.70$ as did B0617. The chemotactic index for isolate B0617 was 4.69 and the threshold at $10^{-10} \mathrm{M}, \mathrm{CI}=2.10$. The peak concentration for isolate $\mathrm{C} 0081$ was at $10^{-3} \mathrm{M}, \mathrm{CI}=2.11$ and the threshold at $10^{-10} \mathrm{M}, \mathrm{Cl}=1.40$. Isolate $\mathrm{C} 0101$ highest response was at $10^{-2} \mathrm{M}, \mathrm{Cl}=3.11$. The threshold was at $10^{-10} \mathrm{M}$ with a chemotactic index of 2.14. Isolate $\mathrm{C} 0464$ peak concentration was at $10^{-1} \mathrm{M}, \mathrm{Cl}=3.40$ and the threshold at $10^{-9} \mathrm{M}, \mathrm{CI}=1.63$. Isolate $\mathrm{C} 0128$ responded positively to only $1 \mathrm{M}$ of TCE with an index of 1.70 . Therefore, this value corresponded to both the peak and threshold concentrations.

Morphological changes. Besides differences in the chemotactic response of deep subsurface bacteria toward substrates, a behavior which altered the morphology of the cell was also observed whenever the isolates were exposed to TCE. Although positive chemotactic responses with indexes as high as 4.69 were seen at $1 \mathrm{M}$ for isolate B0617, this concentration affected its morphology of B0617. Bacteria attracted to high concentrations of TCE suffered reduction in their cell volume. Shorter rods and an irregular surface were seen. This phenomena was most noticeable in isolate B0617 and in isolate B0388. In addition, some isolates, like A0481 were not distributed as single cells but formed small clumps or aggregates when exposed to high concentrations to TCE.

Rates of bacterial movement in sediments. No cells were seen in the samples taken from the autoclaved, killed and non-motile 
controls. Bacterial movement through sediments was observed without bacteria being transported by diffusion, capillary action or convection. The first isolates to be detected at the end of the diffusion shambers distal to the original place of inocula were B0617, B0703 and B0388 (Table 48). They appeared after $8 \mathrm{~h}$ of incubation in sterile sediments and after 4 to $6 \mathrm{~h}$ of incubation in the presence of TCE. The rate of migration in sediments without TCE was 90 $\mathrm{cm} /$ day. During TCE exposure the rate increased to $180 \mathrm{~cm} /$ day for isolate B0388 and $120 \mathrm{~cm} /$ day for isolate B0617 and B0703. Isolate B0388 has both the fastest migration rate in sediments and one of the highest chemotactic responses. These three isolates were taken from the same borehole P24, but not all from the same geological formation. Isolate B0388 was from the Ellenton formation and the other two from the Middendorf formation. Isolates B0703 and B0617 were from the same geological strata and showed the same and fast migration rates in subsurface sediments. A0481 appeared after $12 \mathrm{~h}$ in sterile sediments and after $8 \mathrm{~h}$ in the presence of TCE (Table 48). The rates were 60 and $90 \mathrm{~cm} /$ day in sterile and TCE exposed sediments, 'respectively. Isolate C0081 was detected after $20 \mathrm{~h}$ in the presence of TCE and after $24 \mathrm{~h}$ in its absence, migrating at rates of 36 and $30 \mathrm{~cm} /$ day, respectively. The rest of the isolates, C0101, C0397, C0464 and CBF 33 migrated at a slower rate, 20 $\mathrm{cm} /$ day in sterile sediments. Almost all the isolates from the same borehole migrated at the same rate. However, when they were exposed to TCE, all, except isolate C 0464 , migrated faster. Isolate C0464 migrated at the same rate regardless of the presence or absence of TCE. Isolates $\mathrm{C} 0397$ and $\mathrm{C} 0464$ were from the same 
geological formation and migrated at similar rates when not exposed to TCE.

Comparison of isolates from the Middendorf geological formation. Isolates B0617 and B0703 were botri collected from P24 site in the Middendorf geological strata, $802 \mathrm{ft}$ and $851 \mathrm{ft}$ deep, respectively. Their migration rates in sterile sediments and in the presence of TCE were the same as previously discussed (Table 43). However, when the response ranges, threshold and peak concentrations for the substrates used in the chemotaxis experiments were compared, differences were observed (Table 44). The positive response range for lactose was between $10^{-2} \mathrm{M}, 10^{-4} \mathrm{M}$ and $10^{-6} \mathrm{M}$ for isolate $\mathrm{B} 0617$ and $10^{-2} \mathrm{M}$ and $10^{-4} \mathrm{M}$ for isolate B0703: The peak and threshold values were also different. For dextrose, the positive response range of isolate $\mathrm{B} 0617$ was $10^{-2} \mathrm{M}, 10^{-3} \mathrm{M}$ and $10^{-6} \mathrm{M}$ while that of isolate $\mathrm{B} 0703$ was only at $1 \mathrm{M}$ and $10^{-2} \mathrm{M}$. Lower concentrations were repellents for both, but their peal:s differed. Isolate B0617 was repelled by maltose at $1 \mathrm{M}$ while $\mathrm{B} 0703$ was repelled by all the concentrations of maltose used. Different responses were observed for ribose. Isolate B0703 was attracted to it while B0617 was repelled from it. Also, B0617 did not respond significantly to any of the concentrations of sucrose used while B0703 was repelled (Tables 44 and 47). Arginine also had opposite effects among these two isolates. Isolate B0703 was attracted to it while B0617 was not (Table 47). Glutamine was a repellent for both of them but their response ranges were different. Isolate B0617 was repelled by high concentrations of glutamine $\left(1 \mathrm{M}\right.$ to $\left.10^{-3} \mathrm{M}\right)$ while the range for isolate B0703 was one order of magnitude lower, i.e. 
10-4 M. Threonine elicited a bimodal response for both. Proline was an attractant for both isolates but the maximum response occurred at different concentrations, $10^{-4} \mathrm{M}$ for isolate B0703 and $10^{-6} \mathrm{M}$ for isoiate B0617. At $1 \mathrm{M}$, proline repelled isolates B0617. TCE elicited a different response. Although both isolates were attracted to it, the peak concentration or the maximum response occurred at very different concentrations. For isolate B0617 the peak was at $1 \mathrm{M}$ with an index of 4.69 versus the peak of B0703 which occurred at a lower concentration, $10^{-7} \mathrm{M}$, with an index of 3.31 (Tables 44 and 47).

Comparison of isolates from the Black Creek geological formation. Isolates A0481, C0397 and C0464 were isolated from the same geological strata at $589 \mathrm{ft}, 496 \mathrm{ft}$ and $576 \mathrm{ft}$, respectively. Isolate A0481 and C0397 were attracted to $1 \mathrm{M}$ dextrose (Table 45). The difference was the index of the maximum response observed, 1.39 and 2.06, respectively. Isolates A0481 and C0464 showed a bimodal response to lactose and both, the peak concentration for the negative and the positive chemotaxis were the same. Isolate C0397 was only repelled by lactose. Maltose was a repellent for all of the three isolates. The peak response was the same for isolate A0481 and $\mathrm{C} 0397,1 \mathrm{M}$, but at $10^{-2} \mathrm{M}$ for isolate C0464. Ribose was a repellent to isolates $C 0397$ and A04B1. On the contrary, A0481 was attracted to ribose. Sucrose promoted a similar bimodal response among A0481 and C0464. Isolate C0397 was attracted to it but at lower concentrations, $10^{-5} \mathrm{M}$. Of these isolates, A0481 had the highest responses towards arginine when compared to isolate C0397 which was repelled by it. Isolate $\mathrm{C} 0464$ also was attracted to arginine and had similar responses. Glutamine was an attractant 
only to isolate A0481, and at higher concentrations, to isolate C0397 while glutamine was a repellent to isolate C0397. Glutamine elicited no significant response in isolate C0464. Isolates A0481 and C0464 were both repelled by proline but the response range for isolate A0481 was broader. Isolate C0397 was attracted to proline. Isolate A0481 did not respond significantly to threonine while C0464 was attracted at low concentrations. Although the three isolates were highly attracted to TCE, their peak and response ranges varied (Table 43). Isolates A0481 and C0464 had similar chemotactic indexes in their peak values for TCE but they occurred at different concentrations, $10^{-8} \mathrm{M}$ and $10^{-1} \mathrm{M}$, respectively. The peak concentration for isolate $\mathrm{C} 0397$ was at $10^{-2} \mathrm{M}$ with a 2.26 index.

Comparison of isolates from the McBean geological formation. Isolates $\mathrm{C} 0101$ and $\mathrm{C} 0128$ were cultured from the P29 site at $94 \mathrm{ft}$ deep in the McBean strata. The only results that can be compared for these two isolates are those of TCE because no other substrate was tested for isolate C0128 (Table 46). Isolate C0128 was positively chemotactic to TCE but only at $1 \mathrm{M}$ with an index of 1.70 as compared to 2.11 at $10^{-2} \mathrm{M}$ observed for isolate $\mathrm{C} 0101$. At concentrations of $10^{-9} \mathrm{M}$ and $10^{-10} \mathrm{M}$, TCE was a repellent to isolate C0128 but an attractant to isolate C0081. Furthermore, higher chemotactic indexes were observed for isolate C0101.

Comparison of bacteria from P28. The peak and threshold data for isolates A0231 and A0481 are shown in Tables 47 and 48. Isolate $\mathrm{A} 0481$ was repelled by high concentrations of lactose, while A0231 was repelled at lower concentrations. Lactose was an attractant for isolate $A$ is 231 but at lower concentrations than to 
isolate $\mathrm{A} 0481$, while the highest positive responses toward lactose were those of A0231. Dextrose elicited a bimodal response for isolate A0481 and had a broader and higher positive effect on A0231 (Tables 47 and 48). Maltose also elicited different responses; bimodal in isolate A0231 and a negative one in isolate A0481. Ribose gave a bimodal response for isolates A0231 and a chemoattraction by A0481. Sucrose elicited similar responses for both isolates. Arginine was a better attractant to isolate A0481 than to isolate A0231 which was repelled. Glutamine, on the other hand, was a better chemoattractant for isolate A0231 than for isolate A0481. Proline was a repellent for both, but mostly to isolate A0231. Threonine did not elicit any significant response from isolated A0481 but it was a repellent to isolate A0231. TCE was an attractant for both.

Comparison of bacteria from P24. Isolates B0703, B0388 and B0617 were from P24. The concentrations that elicited the highest chemotactic responses, the threshold, and the chemotactic indexes for the substrates are shown in Tables 49,50 and 51 . Isolate B0388 was attracted to lactose while the other two isolates responded bimodally to it. The highest positive response for lactose and dextrose was by isolate B0617 and the highest negative by B0703. Maltose was an attractant to isolate B0388, a repellent to isolate B0703 and elicited a bimodal response from B0617 (Table 36). Isolates $\mathrm{B} 0388$ and $\mathrm{B} 0703$ were attracted to ribose but the responses of B0388 were higher and over a broader range of concentrations (Table 37). A bimodal response was seen with Bû́óit. Sucrose elicited very different responses on the three isolates from 
P24. Isolate B0388 was attracted to it, B0703 repelled and B0617 did not respond to at any of the sucrose concentrations used (Table 38). Isolate $\mathrm{B} 0703$ was attracted to arginine, B0617 repelled and B0388 attracted to it at low concentrations (Table 39).

Concentrations as high as $1 \mathrm{M}$ arginine, repelled B0388. Glutamine was the only substrate that elicited the same response among the isolates from the P24 site, and that was negative chemotaxis (Table 40). Isolate B0703 was highly attracted to proline while B0388 and B0617 were attracted to it only at low concentrations (Table 42). Isolates B0703 and B0617 responded bimodally to threonine while B0388 was attracted (Table 42). TCE elicited the same high positive response among the three isolates but the intensity was highest in isolate B0617 and lower in isolate B0388 (Table 43).

Comparison of bacteria from P29. Isolates C0397, C0101 and C0464 were isolated from P29. The peak and threshold responses are shown in Tables 52-54. Lactose and dextrose elicited a positive response in isolate $\mathrm{C} 0397$ and a bimodal response in isolates C0101 and C0464 (Tables 34 and 35). Maltose was a repellent to isolate $\mathrm{C} 0397$ at very low concentrations. A bimodal response towards maltose was seen with C0101 and C0464 (Table 36) while ribose elicited very distinct responses among the three isolates. Isolate C0101 was attracted to ribose, C0397 was repelled and C0464 was attracted to it but only at low concentrations (Table 37). Sucrose elicited a bimodal response among the three isolates with the maximum positive response at $10^{-5} \mathrm{M}$ (Table 38). Arginine was a repeilent to isolaté $\mathrm{C} 0397$, añ atitactant to isolate C0464 and both a repellent and an attractant to isolate $\mathrm{C} 0101$ (Table 39). Glutamine 
elicited a bimodal response from isolate C0397 while nn significant chemotaxis was observed in isolates C0464 or C0101 (Table 40). Proline was a repellent for isolate $\mathrm{C} 0464$, an attractant to isolate C0101 and both, for isolate C0397 (Tat'e 41). Threonine and TCE were attractants for all the isolates of P29 (Table 42).

Comparison between sites. Not only did the isolates from the same geological formation respond differently to the compounds used for the chemotaxis experiments but also there were differences in bacterial behavior among isolates from different sites. Bacteria isolated from different sites responded differently when exposed to the same sugars, amino acids and even TCE (Table 48). Those differences included the intensity of the response, their maximum and the threshold concentrations, and the range of concentrations to which they responded. What was mostly common to all sites were the threshold concentrations, the lowest concentration of a substrate that elicit a significant response. In most cases, the threshold for the positive response was at the lowest concentration of substrate used, i.e., $10^{-5} \mathrm{M}$ or $10^{-6} \mathrm{M}$ (Table 48 ). Another similiarity between isolates from different sites was the ability to move away from high concentrations of substrates and move toward lower concentrations of that same compound (Tables 47-56). 


\section{DISCUSSION}

To the surprise of many, microbial densities comparable to those found in surface soil were present in the core samples collected at the three sites on the Savannah River Plant, confirming predictions made from results seen in shallower aquifers. Still, many factors regulating these microbial communities are unknown. The Microbiology of the Deep Subsurface or Deep Probe program of the DOE focuses on the biomass, community structure, and environmental factors that control microbial communities at depths (DOE, 1986b). Of special interest to the program are those factors which permit deep subsurface bacteria to adapt to low oxygen, low nutrients and low moisture environments, and the mechanisms involved in their distinct distribution among the different geological strata at which they were found.

There are three hypothesis as to the origins of this organisms at depth. Either they leaked from the surface, moved with the water from the recharge zone or were deposited with the sediments when they were first laid down, millions of years ago. This study was the first to concentrate on the motility and chemotactic behavior of motile subsurface bacteria available from the culture collection established from the Deep Probe program.

Analysis done on the core samples have shown that the subsurface is low in nutrients and carbon sources and therefore, can be classified as an oligotrophic environment. Oligotrophic environments are by definition, those which contain between 1-15 $\mathrm{mg}$ organic- $\mathrm{C} / \mathrm{l}$ and are considered the most common habitats found 
in nature (Poindexter, 1981). Thorn and Ventullo (1988) have suggested that the slow growth of subsurface bacteria is a reflection of their oligotrophic environment. Later findings, confirmed that subsurface microorganisms were nutrient stressed in situ, and therefore, are specially adapted for growth under the near starvation conditions that prevail in their oligotrophic environment (Beloin et al., 1988; Bone and Balkwill, 1988).

Bacteria have been recognized to have efficient mechanisms to take up carbon, nitrogen and other elements necessary for growth and reproduction when in an environment which has these compounds at very low concentrations (Chet and Mitchell, 1976a). Wilson et al. (1983) had proposed that bacterial communities subsist under these stringent conditions by metabolizing residual organic carbon which filters down from the surface. Other mechanisms have been suggested to explain how bacteria in general, survive under those conditions and most of them involve physiological and morphological adaptations (Roszak and Colwell, 1987). These strategies help maximize the ability of the cell to gather nutrients across a gradient and over extended periods of time. Among the mechanisms, are reduction of surface to volume ratio, chemotaxis, and conservative utilization of nutrients once they are inside the cell (Roszak and Colwell, 1987; Torella and Morita, 1982; Morita, 1988). These adaptations have been proposed as explanation for the survival of aquatic and terrestrial microorganisms but few, if any, have been confirmed to exist among deep terrestrial bacteria. Bacterial motility and chemotaxis in subsurface microbial populations is an important function that has not been adequately addressed. 
Until now, bacterial chemotaxis has been assayed through viable counts. The first attempts added substrates directly in nutrient media and then the response was analyzed by observing accumulation of bacteria across the substrate gradient formed in the plate (Adler, 1969). Later, Adler (1973) developed the "chemical in capillary method" in which bacteria attracted to the inside of a capillary tube containing a specific concentration of a compound were plated. This approach provided more reproducible esults but still required the growth of bacteria in nutrient media (Adler, 1973). Unfortunately, plate counts are deficient in that no single medium will culture all bacteria in a sample (Roszak and Colwell, 1987). In this study, acridine orange direct counts (AODC) instead of viable counts were used to enumerate bacteria. This assay provided several advantages over the dilution plating technique developed by Adler (1973) in that direct enumeration has proven to be a better and more accurate way to enumerate bacteria. Since AODC does not require the growth of cells in nutrient media, all the bacteria in a sample are enumerated (Roszak and Colwell, 1987). Additionally, with the describedmethod, bacteria are always kept in suspension, thus the suppression of bacterial motility is avoided. It has been demonstrated that the presence of solid media, even semisolid, provides resistance for bacterial movement and eventually prevents bacteria from forming flagella (Adler, 1973).

Chemotaxis depends on motility (Adler, 1973) so, if the cells are prevented from forming flagella, their chemotactic behavior can not be accurately assayed. Moreover, viable counts done with subsurface bacteria have shown the best incubation period to be 
approximately 5 days (Ghiorse and Balkwill, 1983). With our assay, bacteria are enumerated immediately following one hour incubation thus avoiding the need to wait extensive periods of time to obtain results. More accurate and reproducible results are obtained because the reduction in bacterial motility is less likely to occur in such a short time and conditions (Adler, 1973). Since these bacteria are oligotrophic, with special nutrient requirements whose properties are not yet fully understood, a method which required the cells to spend less time in culture and uses direct enumeration seemed to be the best approach in studying their chemotactic behavior.

The experimental design also diminished the standard errors commonly seen in other chemotaxis experiments. Adler (1973) and other investigators have reported standard deviations of $20 \%$ or more between assays done on different days. In general, our chemotactic indexes of assays done with the same isolates and substrates on different days varied less than $10 \%$. Thus, one can conclude that the procedures used for the preparation of the bacterial cultures prior to the chemotaxis assays and the experimental design were successful in giving significant reproducible results.

Only in the case of A0481 and arginine were differences of even $15 \%$ observed (Table 2). These slightly variable results were be attributed to fluctuations in the incubation temperature observed during the second experiment. Differences in temperature are known to affect bacterial motility and chemotaxis (Adler, 1973). Since the chemicals used in the assay were not purified in the laboratory, these variations may be attributed to contamination of 
substrates. However, previous efforts in purifying chemicals prior to chemotaxis assays do not show any significant difference between thresholds or peak responses in E. coli and B. subtilis (Adler, 1973; Ordal and Gibson, 1977). The purification of substrates used on this investigation would not have altered the results. Our results would not have been significantly altered if the substrates used were purified once more in the laboratory.

Chemotaxis is generally defined as a response by a motile organism which results in a directed movement toward a particular nutrient source or away from a harmful one. A bacterium capable of migrating from an area of no nutrients to an area in which a particular attractant is concentrated will be favored in oligotrophic environments over others which do not posses this capability. This was demonstrated in marine systems by Bell and Mitchell (1972) who showed that marine bacteria capable of chemotaxis toward extracellular products of marine algae were selected over non chemotactic bacteria. Marine environments as well as the terrestrial subsurface are very low in nutrient concentration. Therefore, it is suggested that those subsurface bacteria which are capable of responding to a potential nutrient source, will be favored over those which lack chemotactic behavior. These isolates are likely to prevail and to be the most abundant in the geological profiles. Chemotaxis might not only provide one understanding of the survival mechanism of deep subsurface bacteria but also may help explain the abundance of certain types of isolates in the study site.

The ability of these bacteria to survive under extreme oligotrophic conditions is not the only unusual aspect of these 
isolates. Efforts to taxonomically describe the subsurface community have failed. The isolates used in this chemotaxis study could not be classified according to standard biochemical tests, suggesting that deep subsurface communities may be an entirely new microbial community with special capabilities and nutrient requirements. If this were indeed a new community, their chemotactic mechanisms and/or responses will probably diffor substantially from those of commonly found bacteria, like E. coli and B. subtilis. For this reason, it was not only of special interest to know if these microorganisms could exhibit chemotactic behavior, but also see how their behavior resembled those of other bacteria. None of the isolates studied completely resembled chemotactically the organisms used for the

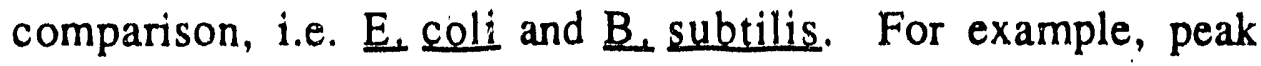
concentrations reported by Ordal and Gibson (1977) for proline, arginine, threonine and glutamine for Bacillus subtilis are $10^{-1} \mathrm{M}$ or above with thresholds of $10^{-9} \mathrm{M}, 10^{-8} \mathrm{M}$ and $10^{-6} \mathrm{M}$. Of the deep probe isolates, only $\mathrm{C} 0397$ had peak positive responses toward proline and threonine at a concentration similar to the one seen in $\underline{B}$. subtilis. Concentrations of $10^{-1} \mathrm{M}$ and $1 \mathrm{M}$, which elicited positive responses in $\underline{B}$. subtilis, were repellents to these subsurface isolates. Furthermore, the peak for the rest of the amino acids tested with isolate C0397 occurred at lower concentrations than 10-1 M. Also, other substrates instead of being attractants, were repellents to the isolates. The fact the isolates responded at lower concentrations of nutrients than B. Subtilis may be evidence of the low nutrient conditions at which they are found in situ. Another similar isolate was A0481 which showed a threshold for arginine equal to that of B. 
subtilis, $10^{-6} \mathrm{M}$, but different peak responses. Bacillus subtilis showed positive chemotaxis to all 20 natural amino acids, with glutamate being the poorest attractant and alanine the best (Van der Drift and de Jong, 1974). From the amino acids in this study, arginine was the best attractant. In these experiments, none of the subsurface isolates were positively chemotactic to all the substrates assayed as was B. subtilis. Only isolate B0388 was attracted to all the carbohydrates but not to all the amino acids. Glutamine, proline, and $1 \mathrm{M}$ arginine were repellents to isolate $\mathrm{B} 0388$, while they were attractants to B. Subtilis. Thus, it is conclude that none of the isolates had a behavior similar to the gram positive rod B. subtilis, suggesting these isolates possess a different chemotactic mechanism than $\underline{B}$. subtilis for the substrates used in the comparison.

Many mechanisms involved in the chemotactic response and receptor have been elucidated through the study of E. celi and other enteric bacteria such as Salmonella typhimurium. The first suggestions about the receptors involved in the chemotactic response of a particular bacterium came from studying and comparing threshold and peak responses toward different substrates. The isolation of mutants and further analysis helped discern the different sensory mechanisms involved in chemotaxis. As a result of these

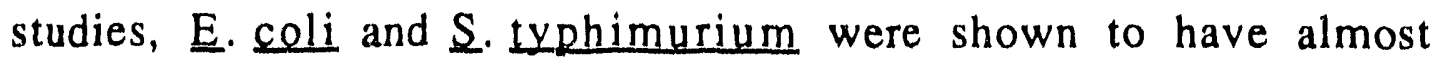
identical chemosensors (Hazelbauer and Parkinson, 1977). Later, descriptions of the chemosensory systen in gram positive bacteria indicated that the number and specificity of chemosensors varied drastically among different species (Hazelbauer and Parkinson, 1977). One difference between chemotaxis toward amino acids for 
B. subtilis and E. coli is that the response curve for attractants, have a lower threshold in B. subtilis than in E. coli (Ordal and Gibson, 1977). Ordal and Gibson (1977) suggested the existence of different chemoreceptors in B. subtilis each having a different disassociation constant for certain amino acids. Therefore, the study and comparison of chemotaxis in deep subsurface bacteria with other bacteria could provide information on the mechanisms involved in the response of oligotrophic bacteria. Differences in chemotactic response may assist in defining general or species specific features of chemosensors (Hazelbauer and Parkinson, 1977).

The most powerful sugar attractants for $\mathrm{E}$ coli, include ribose, galactose, dextrose, and mannose among others (Adler, 1966). The threshold concentration observed for dextrose, and maltose in E. coli was $3 \times 10^{-6} \mathrm{M}$, and for ribose it was $7 \times 10^{-6} \mathrm{M}$. The threshold for the repellent glutamine was $3 \times 10^{-3} \mathrm{M}$ (Mesibov and Adler, 1972; Adler, 1974b). Of the deep subsurface isolates attracted to ribose and dextrose, B0388, B0703, and C0101 exhibited the highest responses. The lowest concentration of dextrose and ribose that elicited a significant chemotactic response in isolates B0388 and $\mathrm{C} 0101$ was $10^{-6} \mathrm{M}$. Isolate B0703 responded differently for dextrose and ribose, $10^{-1} \mathrm{M}$ and $10^{-2} \mathrm{M}$, respectively. Similar thresholds obtained for E. coli were observed with isolates B0388, and $\mathrm{C} 0101$ but not with isolate B0703. These responses occurred with ribose and glucose but not with other carbohydrates. When comparing amino acids, glutamine was a repellent for $\underline{E}$. coli and for isolates B0703, C0397, B0617 and B0388, but the responses were one or two orders of magnitude lower for the subsurface bacteria. The 
chemoreception of ribose and dextrose by isolates B0388 and C0101 seem to be similar to that of $E_{u}$ coll. The subsurface isolates were more sensitive than E. coli and able to detect harmful and beneficial conditions at lower concentrations of substrates.

Other inferences can be made about the chemoreceptors of isolate B0388. Isolate B0388 responded to all the sugars almost with the same intensity. The carbohydrates were attractants at all the concentrations used, with most of their peak and threshold responses, at 10-6 M. Remarkably similar was the data demonstrated that glucose and maltose (a disaccharide of glucose) elicited the same maximum response at $10^{-6} \mathrm{M}, \mathrm{Cl}=2.69$. Sucrose, a disaccharide of glucose and fructose, elicited a response very close to this $(\mathrm{CI}=2.72)$ at the same con antrations. At least one receptor of isolate B0388 appears to be involved in the recognition of glucose and its derivatives. E. coli have different receptors for fructose, mannose, ribose, maltose and glucose and the same receptor that recognizes galactose, recognizes glucose and fructose (Adler, 1969; 1975). The results presented in this study suggests that isolated B0388 probably has a receptor for ribose that is similar to the one in E. coli but that it also possesses a different one capable of recognizing glucose and its derivatives. Isolate A0231 provided data relating to its mechanism of chemotaxis. Isolate A0231 has a very similar response towards ribose and sucrose. Both were repellents at $1 \mathrm{M}$ ribose and sucrose; $\mathrm{CI}=0.54$ and $\mathrm{CI}=0.47$ respectively, while they were attractants at lower concentrations. Their positive peak response was at 1()$^{-5} \mathrm{M}$, with an index of 1.59 for ribose and 1.65 for sucrose. The threshold in both cases was at $10^{-6} \mathrm{M}$. Thus, there is 
probably one chemoreceptor in isolate A0231 involved in the recognition of both ribose and sucrose and that receptor is different from those suggested for isolate B0388. Substrates that were attractants to isolate $\mathrm{B} 0388$ were repellents to isolate $\mathrm{A} 0231$.

Salmonella spp. are positively attracted to ribose, galactose, glucose and serine (Adler, 1975). Isolates A0231, C0397, and B0388 were also attracted to glucose but of these, only B0388 attracted to ribose. Thus, of the isolates, only B0388 responded toward carbohydrates, similar to Salmonella. Isolate B0388 also had the most similar responses toward ribose and glucose. This is not surprising since E. coli and Salmenella have been shown to have almost identical chemosensors (Adler, 1975).

Chemoautotrophic bacteria possess distinct chemotactic responses when compared with these subsurface isolates. Thiobacillus thioparus showed no attraction to D-glucose, ribose, mannose or galactose nor to any amino acid (Sjoblad and Coleman, 1980) as do most heterotrophic bacteria. All the subsurface isolates were attracted to either amino acids or sugars and sometimes to both. This is further indication of the heterotrophic nature of the studied isolates which use organic carbon sources like carbohydrates, and responded chemotactically to them. Threonine elicits a positive response in Pseudomonas aeruginosa with the threshold response between $10^{-4} \mathrm{M}$ and $10^{-5} \mathrm{M}$ and the peak at $10^{-1} \mathrm{M}$ (Gallucci and Paerl, 1983). Isolate B0388 was similarly attracted to threonine and exhibited a similar threshold as Pseudomonas, but different peak response. The peak response for isolate B0388 occurred at lower concentration, while high concentrations of threonine eg. 10-1 $\mathrm{M}$, 
were mostly repellents to B0388 and not an attractant as it was for Pseudemenas. The other isolates which were highly attracted to threonine had peak and threshold responses at much lower concentrations. Again, this might be a result of the low nutrient conditions at which the subsurface bacteria were exposed in situ. High concentrations of nutrients are rarely encountered in the terrestrial subsurface and thus, no positive response towards them will be elicited.

Although the differences in the response of deep subsurface bacteria when compared to other strains_the might be attributed to the different enumeration techniques used, i.e. AODC vs, viable counts, the results can still be compared because the chemotactic response was reported as a ratio and not as total cell density. The relationship of the number of cells in the experimental and the number of cells in the control remained constant no matter which enumeration technique was used. The intensity of the response may vary but not the concentration at which the maximum response and the threshold occurred.

Interestingly, of all the substrates used, TCE elicited the most positive responses among terrestrial subsurface bacteria as opposed to the amino acids and carbohydrates, which were both, attractants and repellents to the cells. Moreover, the responses for TCE were stronger over a very wide range of concentrations. Higher chemotactic indices were obtained with TCE than with any of the tested sugars and amino acids. The different responses to amino acids, carbohydrates and TCE observed in deep subsurface bacteria suggested the existence of different chemoreceptors 
involved in their reception. The chemoreceptor of deep subsurface bacteria involved in the TCE response might be able to detect only hydrophobic and smaller molecules than the receptors for the carbohydrates. If we think of the receptor-ligand associatio ${ }_{i}$, like an en yme-substrate interaction, we might be able to suggest that there is a very high degree of specificity involved in the TCE receptor which allows only molecules of TCE to bind it. In addition, its transport inside the cell is probavly eased by the hydrophobic nature of the molecule which makes it more soluble in the membrane than the hydrophilic sugars and amino acids. Another difference in the response might be related to the toxic nature of this contaminant. Although trichloroethylene is a coxic chemical, deep subsurface bacteria probably derive more benefit from attraction to it instead of moving away from the TCE. The benefit of some isolates may rely on the formation of clumps or aggregates which helps reduce the surface to volume ratio of the cell. This phenomena is usually seen when they are exposed to high concentrations of TCE. This reduction in cell size and formation of aggregates might be a protection mechanism to diminish the area of the cell exposed th the contaminant and reduce the chances of suffering additional deleterious effects. Isolated migrate towards the contaminant, and once they are grouped together, their cells become protected. They probably lack a chemotactic mechanism that enables them to move away from the toxic source but compensate this by possessing a positive mechanism which facilitates the formation of groups of cells thus, diminishing the number of bacteria exposed to it. 
The chemotactic response towards TCE was higher than for the carbohydrates and amino acids. The increase in chemotax is intensity is of special importance and concern. The presence of toxic contaminants, like TCE, in aquifers and sediments could significantly alter the immediate microbial community structure. Chet and Mitchell (1976b) showed that hydrocarbons such as toluene, phenol and crude oil had a harmful effect on the marine microbial population. Bacteria when exposed to these substances, lost their ability to locate substrates, prey and their ability to degrade organic matter. Similarly, the presence of TCE in terrestrial sediments can also have a negative effect on the microbial population, probably interfering with the normal chemical response and metabolism of the subsurface community. This investigation demonstrated that the presence of TCE promotes a higher chemotaxis and motility among the subsurface bacteria. Further experiments should address bacterial chemotaxis towards substrates, in the presence of TCE to confirm these hypothesis.

Isolate CBF 33 showed the lowest response to TCE even though it is capable of met bolizing it. This is possibly due to the factor that isolate CBF 33 alone is not capable of degrading TCE but requires other microorganisms of the consortia. Moreover, isolate CBF 33 might be adapted to TCE, unlike the other isolates which had never been previously exposed to the chemical. Desensitization or the loss of the ability to respond to further chemical stimuli, occurs when bacteria remain exposed to an attractant for certain periods of time (Alberts et al., 1983) and 
prevents bacteria from responding to further stimuli. Adaptation of isolate CBF 33 to TCE might have occurred preventing the cell to highly respond to its presence. The difference in the intensity of the response might also be a result of the nutrient status of the cell. It is known that starving bacteria increase chemotaxis with increasing periods of nutrient stress (Morita, 1982; 1988). Since the subsurface isolates probably have never been exposed to TCE before, they might be able to perceive it as a ptential energy source and highly respond to it. The reason that one may not observe the same strong response with more nutrient sources to the cell might be directly correlated to the nature of the receptors involved in the detection, as we have previously discussed.

Generally, most of the isolates exhibited significant chemotactic behavior to some amino acids and carbohydrates at concentrations as low as $10^{-6} \mathrm{M}$ and at concentrations as low as $10^{-10} \mathrm{M}$ for TCE. These were compared to results obtained for $\underline{E}$. coli by other researchers; who have reported sensitivities as low as $10^{-6} \mathrm{M}$ for $\underline{E}$. coli and other bacteria (Adler, 1966, 1974 and 1975). However, since most of these thresholds were at the lowest substrate dilution, it cannot conclusively determine a definitive threshold. There might be lower concentrations of chemicals capable of eliciting a chemotactic response in deep subsurface bacteria that were not assayed in these investigations. The possibility of a chemotaxis mechanism so sensitive that permits deep subsurface bacteria detect nutrient sources at extremely limited concentrations is valid. Also both high concentrations and low concentrations of a substrate can promote maximal responses in subsurface bacteria, not just one 
concentration. The positive responses towards the different substrates were not limited to one concentration. This pattern is similar to that observed by Adler (1973) for different substrates in E. coli. The most common trend observed through all the assays, was that subsurface bacteria were attracted to low concentrations of a substrate, while they were repelled by high concentrations of that same substrate. This bimodal response could be attributed to the oligotrophic nature of deep subsurface bacteria which results in an adaptation of survival at low nutrient concentrations. When bacteria are exposed to concentrations of substrate too high to be found in nature which might be harmful to the cell, they move away from it. However, that same substrate can be used as a nutrient source at lower concentrations thus, eliciting the positive response. This is more obvious when comparing their behavior with other bacteria not as nutrient stressed as the subsurface isolates. Deep subsurface bacteria have lower peak and threshold responses than the others, allowing them to detect nutrients at concentrations similar to the ones they find in nature. Their chemotaxis mechanism is more sensitive than those of terrestrial and aquatic bacteria, the reason it can be suggested they have a very special adaptative chemotaxis mechanism that allows them to survive under extreme conditions. The possibility of that apparent negative chemotaxis seen on the bimodal response being due to motility inhibition due to high substrate concentrations was discarded because the motility controls done did not show any significant difference from the experimental. The audition of substiates into the bacterial suspension did not increased or decreased bacterial motility. 
The function of negative chemotaxis appears to allow the bacteria to escape from harmful or crowded environments; thus, negative chemotaxis must have a survival value for bacteria (Adler, 1975). In an oligotrophic environment, where nutrients are limited, the sudden appearance of high concentrations of substrates can promote their dispersal mechanism. This may be the case of most of the deep subsurface bacteria which show a bimodal response to most of the substrates tested. High concentrations of a chemical repel the bacteria while lower concentrations promote a high positive response. This phenomena was observed earlier by Pffefer with isolates of Spirillum undula which were attracted by $1 \%$ meat extract but repelled by $4 \%$ (Berg, 1975). Substrates which proved attractants at one concentration were repellents at another. It is clear that these bacteria possess a unique chemotactic mechanism which may involve dual chemoreceptors that can detect and respond to a chemical stimuli in different ways.

The majority of the peak and threshold concentrations for the repellents were higher than those obtained for attractants as reported by Adler (1974b) for E. coli. This mechanism may provide a selective advantage to the bacteria, since the repellents studied may be harmful only at high concentrations, whereas as attractants they may be used even at low concentrations (Adler, 1974b). Morita (1982) suggested that the threshold level for inducible systems should be low so that nutrient uptake capacity could be expanded promptly in response to the appearance of an utilizable substrate. In contrast, the threshold for repression of uptake systems should be fairly high, so that only in the presence of an abundant or sustained 
supply of the repressing substance would the high affinity systems not be synthesized (Geesey and Morita, 1979). When bacteria meet low nutrient concentrations, they shift to a high affinity active transport system. This, during a starvation process in natural waters, they shifted to that higher affinity system to scavenge as much nutrient as they could from the seawater (Geesey and Morita, 1979). Since chemotaxis serves the bacteria primarily as a food finding device (Hazelbauer and Parkinson, 1977), chemotaxis among subsurface bacteria might involve high affinity systems between receptors and ligand which help the cell takes as much nutrient as possible from around their environment. When those nutrient concentrations are high, the affinity lowers, since they do not need those concentrations for survival. Moreover, those concentrations may be harmful to the cell so the affinity system may shift and generate a negative response.

Although it seems obvious that it is an advantage for bacteria to migrate toward sugars or amino acids there are still some excellent carbon sources that are not attractants to the cell. It is very possible that a representative selection of substrates can act as a signal for other biological nutrient sources in the surroundings. This is the case for aspartate whose presence has been suggested to be an indicator of a hydrolyzing protein and of the availability of other amino acids that may be used as nutrient sources (Macnab, 1978). However, repellents are harder to explain. The fact that they operate at higher concentrations than attractants, but well below toxic levels, is reasonable. Repulsion from trace quantities, might mislead them away from a nutrient 
source. This is probably why most of the observed positive thresholds were at the lowest concentrations used and that the negative ones were at higher concentrations. The same way positive chemotaxis may signal the presence of other nutrient sources, negative chemotaxis may signal the presence of other adverse conditions. For example, high concentrations of fatty acids and other excretion products, may signal overcrowding in the area therefore, stimulating migration away from it (Chet and Mitchell, 1976a). Thus, one cannot discard the possibility of other nutrient or harmful sources in the subsurface to which these isolates may be able to respond indirectly by responding to the substrates tested in this study.

When comparing the chemotactic behavior of deep subsurface bacteria taken from the same source, the isclates from the same site and strata i.e. McBean, Middendorf and the Black Creek did not show any similarity in their threshold and peak responses toward the different substrates. In the Middendorf, isolate B0703 had peak responses at higher concentrations than t'lose of isolate B0617 (Table 44). Isolate B0703 might be adapted to use higher concentrations of nutrients than B0617, a mechanism which can reduce microbial competition among species inhabiting the same area. However, chemotaxis in isolate B0617 was not limited to those peak concentrations in that solate B0617 was also capable of detecting lower concentrations of substrates. By always responding to low nutrient concentrations, isolate B0617 can survive in oligotrophic sediments both in the presence and in the absence of a competitor. In the Black Creck, opposite responses were observed towards the 
same substrate. For example, lactose and ribose were attractants to isolate A0481 while they were repellents to isolate C0397. These isolates probably possess different nutrient requirements and hence, the development of different adaptation mechanisms may reduce competition among species.

Bacterial motility has been neglected by microbial ecologists (Carlile, 1980). Very few investigations have been done to determine the rate of movement of bacteria in sediments. Motility and chemotaxis of various microorganisms have been demonstrated in liquid media, and agar plates but very few studies have been conducted with sediments (Stotzky, 1965; Hunter and Fahring, 1980). Studies of bacterial mobility have been conducted for several species, but most have failed to differentiate between spread due to diffusion and spread due to the active effort of a motile chemotactic system (Soby and Bergman, 1983).

Once it was established that deep subsurface bacteria had the ability to respond to chemical stimuli by either moving to or away from the sources we proceeded to investigate if similar results were seen when they were inoculated in sediments exposed to TCE. Bacterial movement in sediments is influenced by many environmental factors, difficult to define completely. Among these factors is the presence of toxic contaminants, like TCE, which might affect or interfere with the chemical response of bacteria in the subsurface, and intervene with their rates of movement. This study attempted to determine the relative rates of movement of deep terrestrial bacteria in sediments with and without TCE and correlated these with the results obtained in the chemotaxis experiments. 
The rate of movement of bacteria through sediments and into groundwater is extremely important. The monitoring movement of microorganisms with percolating water through soil systems, assessing new sites for land application of wastewater, septic tank drain fields and investigating sources of waterborne diseases outbreaks, are but a few examples of the importance of bacterial movement in sediments (Bitton and Gerba, 1984). Also, the ability to trace microbial movement in groundwater is essential in recognizing the potential for transmission of disease causing microorganisms. For example, coliform bacteria, such as E. coli, are used for monitoring groundwater quality. Coliform bacteria are assumed to be excreted in fecal wastes of man and other animals, and thus, can be used to monitor the movement of septic and sewage wastes in groundwater (Bit on and Gerba, 1984). Several investigations have looked at their rate of movement in septic fields, sewage disposal sites and agricultural fields (Wallace, 1978) and found that these bacteria moved at approximately $150 \mathrm{~m} /$ day. Based on this rate of movement fecal coliforms were traceable for at least $2.5 \mathrm{~km}$ from their source. Knowing the rate of movement of deep subsurface bacteria can be very useful in determining the extent to which they can be traced in the subsurface. If they possess special properties, the extent to which they could be traced on the subsurface is needed and hence, their migration rates. As biological tracers, they could also be used to determine direction and velocities of subsurface flow. Antibiotic resistant isolates of $\underline{E}$. coli and Streptococcus faecalis are being used to monitor movement of subsurface water flow in Oregon (Bitton and Gerba, 1984). They are easily distinguished from other 
microbes and were found to travel $500 \mathrm{~cm} /$ day under saturating conditions. The deep subsurface isolates may have unique properties that will facilitate their use in subsurface environments. One of the applications could be their use in subsurface transport programs to monitor the groundwater flow and destiny of toxic chemicals.

In other experiments done, rates of $200 \mathrm{~m} /$ day were reported for strains of E. coli and Bacillus staerothermophilus. Streptococcus faecalis and Serratia marscenses have been reported to travel 220$240 \mathrm{~m} /$ day while Bacillus subtilis traveled only at $150 \mathrm{~m} /$ day (Bitton and Gerba, 1984). The rates of movement of the deep subsurface bacteria are significantly lower than these, ranging from about 30 to $180 \mathrm{~cm} /$ day. The movement rates mentioned above for surface soil bacteria are two orders of magnitude higher than the ones we reported for subsurface bacteria. Differences could be attributed to the methodology employed, the nature of the sediments, and the saturating conditions of the soil used in thes experiments. Bacterial movement through saturated soils depends o1 its water content (Hamdi, 1971; Bitton et al., 1974; Madsen anc Alexander, 1982). Moreover, difference: might be due to the nature of the bacteria we studied. Subsurface bacteria are probably not as motile as some terrestrial isolates. Deep terrestrial subsurface bacteria moved at a rate of 20 to $60 \mathrm{~cm} /$ day in sediments in the absence of chemical stimuli. They do not move as actively as E. coli, B. staerothermophilus, $\underline{S}$. faecalis, or Serratia marscenses but possess more efficient chemotaxis mechanisms which might compensate for their slow movement. 
In other experiments done with $\mathrm{B}$. melileti, rates of 0.53 $\mathrm{cm} /$ day were reported in peat and sand. The lowest rates were in clay, in which no bacterial migration was observed (Soby and Bergman, 1983). In these experiments, the highest spread was 2-5 times less than the rate of bacterial spread in soil reported by Kellerman and Fawcett (1907). In soils saturated with water, Bacillus ochraceus, Pseudomonas and Bacillus coli were found to progress $60 \mathrm{~cm}$ per day. In barely moist soils, they moved at $2.5 \mathrm{~cm}$ in $72 \mathrm{~h}$ to $2.5 \mathrm{~cm}$ in 8 days (Kellerman and Fawcett 1907). These rates were lower than those reported for subsurface bacteria, but the differences were largely due to the experimental design. In Kellerman and Fawcett's experiments, it was not clear how the rates were measured and furthermore, no controls were mentioned.

Correlations between chemotactic responses and migration rates showed that isolates with a stronger response to TCE had the fastest migration rates through the soil. Isolate B0388 moved at 180 $\mathrm{cm} /$ day and had chemotaris indices around 3, while isolates B0703 and B0617 moved at $120 \mathrm{~cm} /$ day and also had the highest responses towards TCE. Bacteria took less time to migrate through the sediments under the presence of an attractant than only through random motility. There was even a twofold increase in their rate of movement in sediments exposed to TCE. The only exception was A0231 which took 11 days to be detected and moved at a rate of 2 $\mathrm{cm} /$ day. This could be due to the fact that the sediments contained in these chambers were not as moist as the rest. In general, the rate of bacterial spreading is affected by physical or chemical differences among soils and by changes in water content (Jensen, 1961). Dryness 
of the sediments may prevent bacteria from migrating efficiently through the substrate. This has been reported in Rhizobia spp. (Parke et al., 1985). The rate of bacterial movement with TCE was faster, correlating with the high responses observed in the chemotaxis assays with pure cultures. Soby and Bergman (1983) have demonstrated that Rhizobium meliloti also exhibit greater migration rates when exposed to substrate concentrations of an attractant.

It is known that the number of microorganisms appear to be more influenced by the geologic formation and the presence of water than by depth (Alexander, 1977). Sandy layers which contain the most water, are prolific in cell density. Clay layers, more impermeable to water, contain fewer microbes. The isolates which migrated faster through the sediments, B0703 and B0617, were isolated from the same geological strata, Middendorf. This formation is composed of saturated gray sand high in moisture content.

Bacteria which live in the presence of moisture are expected to move faster than those found in barely moist sediments. The fact that the fastest isolates were those naturally found in the Middendorf, might be related also to the sediments used in the experimental design.

The sediment chambers were filled with sediments corresponding to the Middendorf formation. Those isolates naturally occurring in these sediments will give the best and highest migration rates. However, the other strata with the isolate with the strongest chemotactic responses and movement rates, isolate $\mathrm{B} 0388$, was also composed of saturated gray sand, i.e., Ellenton. The migration rates might have been affected by the type of sediments used in the 
chambers but still bacteria from the other strata high in moisture content migrated at fast rates. The slowest isolate, A0231, was from the Pee Dee formation which is composed of dry light clay. The marked difference in the rates of movement of these isolates in sediments may reflect the natural conditions which they are exposed. The slowest bacterial migrations occured in clays and in unsaturated sediments and the fastest in saturated sand particles (Soby and Bergman, 1984; Bitton and Gerba, 1984). Bacteria generally do not move large distances in fine-textured soil (less than a few meters) like clay particles, but they can migrate much larger distances in coarse-textured or fractured materials like sand (Bitton and Gerba, 1984).

Many unanswered questions still remain about the origin, identity, and hundreds of other factors in the microbial ecology of the deep terrestrial subsurface bacteria. What was demonstrated in this study was that these microbes were capable of responding chemotactically to carbohydrates, and amino acids and moreover, to a common contaminant found in groundwater and sediments, trichloroethylene (TCE). Not only were they chemotactic to TCE in laboratory conditions but also in subsurface sediments.

The origin of bacteria in the subsurface is still unknown. They could have been deposited with sediments millions of years ago or they may have migrated recently into the formations with water or during construction of wells (Bitton and Gerba, 1984). The possibility of transportation of these bacteria through sediments by groundwater movement also exists. However, experiments done with groundwater samples taken from wells within $15 \mathrm{~m}$ of the core 
sampling sites at the Savannah River Plant concluded that microbial communities found in groundwater are not representative of the epilithic community found in sediments (Lopez-de-Victoria et al., 1988). Microbial diversity and activity were low, and bacterial densities were up to five orders of magnitude lower in the groundwater. Even biochernical tests and genetic analysis done on these isolates do not seem sufficient to determine their origin. So far they show very little homology with known bacterial species and even isolates with very different gram reactions and morphology have the same phenotype by API - Rapid NFT profile index. It is suggested that this microbial community, possibly millions of years old, is able to survive in extreme oligotrophic environments by their ability to detect favorable conditions through chemotaxis. This chemotactic mechanism allows them to respond positively to concentrations of substrates similar to those naturally occurring in the environment and negatively to those never seen in situ. Additionally, this chemotaxis mechanism might be altered by the presence of toxic contaminants in the subsurface. 


\section{CONCLUSIONS}

1. Deep subsurface bacteria respond chemotactically to carbohydrates, amino acids and trichloroethylene.

2. Deep subsurface bacteria can detect concentrations between $1 \mathrm{M}$ and $10^{-6} \mathrm{M}$ of sugars and amino acids and concentrations of TCE as low as $10^{-10} \mathrm{M}$.

3. The TCE degrader isolate, $\mathrm{CBF} 33$, had the lowest responses to the substrates tested, including TCE.

4. A bimodal response was observed for a variety of substrates (except for TCE) in a majority of the isolates. High concentrations of a potential nutrient repelled the bacteria while low concentrations of that same compound were an attractant. Selective adaptation to the oligotrophic environment of the deep terrestrial subsurface is suggested.

5. TCE elicited an abnormally high positive response in all isolates except a TCE degrader. This attraction appears to be a fatal non specific response.

6. Deep subsurface bacteria are capable of moving through sediments at rates, ranging from $2 \mathrm{~cm} /$ day to $90 \mathrm{~cm} /$ day. 
7. For most of the isolates, these migration rates were higher when exposed to TCE, $30 \mathrm{~cm} /$ day to $180 \mathrm{~cm} /$ day. The isolates with the highest chemotactic responses to TCE were also the fastest to move through the sediments in response to TCE. 


\section{LITERATURE CITED}

Adler, J. 1966. Chemotaxis in bacteria. Science 153:708-716.

Adler, J. 1969. Chemoreceptors in bacteria. Science 166:1588-1597.

Adler, J. 1973. A method for measuring chemotaxis and use of the method to determine optimum conditions for chemotaxis by Escherichia coli. J. Gen. Microbiol. 74:77-91.

Adler, J. 1974a. "Decision" making in bacteria: chemotactic response of Escherichia coli to conflicting stimuli. Science 184:12921294.

Adler, J. 1974b. Negative chemotaxis in Escherichia coli. J. Bacteriol. $118: 560-576$.

Adler, J. 1975. Chemotaxis in bacteria. Ann. Rev. Biochem. 44:341356.

Alberts, B., D. Bray, J. Lewis, M. Raff, K. Roberts, and J. D. Watson. 1983. Molecular Biology of the Cell. Garland Publishing, Inc. New York, N. Y. pp. 757-763.

Alexander, M. 1977. Introduction to Soil Microbiology. 2nd ed.

John Wiley and Sons, Inc. New York.

Allweiss, B., J. Dostal, K. E. Carey, T. F. Edwards, and R. Freter. 1977. The role of chemotaxis in the ecology of bacterial pathe gens of mucosal surfaces. Nature 226:448-450.

Anderson, R. A. 1973. Bacteria swim by rotating their flagellar filaments. Nature 245:380-382.

Barrio-Lage, G., F. Z. Parsons, R. S. Nassar, and P. A. Lorenzo. 1985. Sequential dehalogenation of chlorinated ethenes. Environ. Sci. Technol. 20:96-99. 
Beloin, R. M., J. L. Sinclair and W. C. Ghiorse. 1988. Distribution and activity of micioorganisms in subsurface sediments of a pristine study site in Oklahoma. Micro. Ecol. 16:85-97.

Bell, W., and R. Mitchell. 1972. Chemotactic and growth responses of marine bacteria to algal extracellular products. Biol. Bull. $143: 265-277$.

Berg, H. C. 1975. Chemotaxis in bacteria. Ann. Rev. Biophys: Bioeng. $4: 119-136$.

Bitton G., and C. P. Gerba. 1984. Groundwater Pollution Control. John Wiley and Sons, N. Y.

Bitton, G., N. Lahav, and Y. Henis. 1974. Movement and retention of Klebsiella aerogenes in soil columns. Plant Soil 40:373-380.

Bone, T. L. and D. L. Balkwill. 1988. Morphological and cultural comparisons of microorganisms in surface soil and subsurface sediments at a pristine study site in Oklahoma. Microbial Ecol. $16: 49-64$.

Bouwer, E. J., and P. L. McCarty. 1983a. Transformations of 1 - and 2-carbon halogenated aliphatic organic compounds under methanogenic conditions. Appl. Environ. Microbiol. 45:12861295 .

Bouwer, E. J., and P. L. McCarty. 1983b. Transformations of halogenated organic compounds under denitrification conditions. Appl. Environ. Microbiol. 45:1295-1299.

Bowra, B. J., and M. J. Dilworth. 1981. Motility and chemotaxis towards sugars in Rhizobium leguminosarum. J. Gen. Microbiol. $126: 231-235$. 
Brown, E., J. J. Pignatello, M. M. Martinson, and R. L. Crawford. 1986. Pentachlorophenol degradation: a pure bacterial culture and an epilithic microbial consortium. Appl. Environ. Micrubiol. 52:9297.

Carlile, M. J. 1980. Position mechanisms- the role of motility, taxis and trophism in the life of microorganisms. In: Contemporary Microbial Ecology. D. C. Ellwood, N. J. Hedger, M. J. Latham, J. M. Lynch, and J. H. Slater (eds.). pg. 54-74. Academic Press, London.

Chet, I., S. Fogel, and R. Mitchell. 1971. Chemical detection of microbial prey by bacterial predators. J. Bacteriol. 106:863867.

Chet, I., P. Asketh, and R. Mitchell. 1975. Repulsion of bacteria from marine surfaces. Appl. Environ. Microbiol. 30:1043-1045.

Chet, I., and R. Mitchell. 1976a. Ecological aspects of microbial chemotactic behavior. Ann. Rev. Microbiol. 30:221-239.

Chet, I., and R. Mitche!?. 19760. Petroleum hydrocarbons inhibit decomposition of organic matter in seawater. Nature 261:308309.

Currier, W. W., and G. A. Strobel. 1976. Chemotaxis of Rhizobium spp. to plant root exudates. Plant Physiol. 57:820-823.

Dean-Ross, D. 1987. Biodegradation of toxic wastes in soil. ASM News 53:490-492.

DOE. 1985. Anaerobic bingeochemical processes in the subsurface. Scientific results of an ISIS seminar held at Pennsylvania State University, State College, Pennsylvania on May 13-15, 1985. DOE/ER-0252 
DOE. 1986a. Microbiology of subsurface environments. First investigators meeting. Savannah River Laboratory June 4-5, 1986. DOE/ER-0280.

DOE. 1986b. Proceedings second investigators' meeting Savannah River exploratory Deep Probe. DOE/ER-0312.

Fathepure, B. Z., J. P. Nengu, and S. A. Boyd. 1987. Anaerobic bacteria that dechlorinate perchloroethene. Appl. Environ. Microbiol. 53:2671-2674.

Fliermans, C. B., T. J. Phelps, D. Ringelberg, A. T. Mikell, and D. C. White. 1988. Mineralization of trichloroethylene by heterotrophic enrichment cultures. Appl. Environ. Microbiol. 54:1709-1714.

Fogel, M. M., A. R. Taddeo, and S. Fogel. 1986. Biodegradation of chlorinated ethenes by, a methane-utilizing mixed culture. Appl. Environ. Microbiol. 51:720-724.

Frederickson, J. K., anci R. J. Hicks. 1987. Probing reveals many microbes beneath earth's surface. ASM New's 53:78-79.

Fuentes, F. A., E. J. Biamón, and T. C. Hazen. 1983. Bacterial chemotaxis to effluent from a rum distillery in tropical nearshore coastal waters. Appl. Environ. Microbiol. 46:1438-1441.

Gallucci, K. K., and H. W. Paerl. 1983. Pseudomonas aeruginosa chemotaxis associated with blooms of $\mathrm{N}_{2}$-fixing blue-green algae (Cyanobacteria). Appl. Environ. Microbiol. 45:557-562.

Gaworzewska, E. T., and M. J. Carlile. 1982. Positive chemotaxis of Rhizobium leguminosarum and other bacteria towards root exudates from legumes and other plants. J. Gen. Microbiol. 128:1179-1188. 
Geesey, G. G., and R. Y. Morita. 1979. Capture of arginine at low concentration by a marine psychrophilic bacterium. Appl. Environ. Microbiol. 46:1258-1262.

Gerhardt, P. (ed.) 1981. Manual of Methods for General Bacteriology. American Society for Microbiology, Washington D. C.

Ghiorse, W. C., and D. L. Balkwill. 1983. Enumeration and morphological characterization of bacteria indigenous to subsurface environments. Dev. Ind. Microbiol. 24:213-224.

Ghiorse, W. C., and D. L. Balkwill. 1985. Microbiological characterization of subsurface environments. C. H. Ward, W. Giger, and P. L. McCarty (eds.). Ground Water Quality. John Wiley and Sons, Inc., N. Y. pg. 387-400.

Girvin, D. C., J. M. Zachara, C. T. Kincaid, and F. J. Wobber. 1984. Transport of energy-related organic compounds and mixtures in subsurface environments. U.S. Dept. of Energy. DOE/ER0229.

Hamdi, Y. A. 1971. Soil-water tension and the movement of rhizobia. Soil Biol. Biochem. 3:121-126.

Harvey, R. W., R. L. Smith, and L. George. 1984. Effect of organic contamination upon microbial distributions and heterotrophic uptake in a Cape Cod, Massachusets aquifer. Appl. Environ. Microbiol. 48:1197-1202.

Hazelbauer, G. L. and J. S. Parkinson. 1977. Bacterial chemotaxis. In: Receptors and Recognition. Ed. by J. L. Reissing. Chapman and Hall, London. p. 59-98. 
Hazen, T. C., G. W. Esch, R. V. Dimock Jr., and A. Mansfield. 1982. Chemotaxis of Aeromonas hydrophila to the surface mucus of fish. Curr. Microbiol. 7:371-375.

Hazen, T. C., R. V. Dimock Jr., G. W. Esch, A. Mansfield, and M. L. Raker. 1984. Chemotaxis behavior of Aeromonas hydrophila. Curr. Microbiol. 10:13-18.

Hobbie, J. E., R. J. Daley, and S. Jasper. 1977. Use of nuclepore filters for counting bacteria by fluorescent microscopy. Appl. Environ. Microbiol. 33:1225-1228.

Hunter, W. J. and C. J. Fahring. 1980. Movement of Rhizobium and nodulation of legumes. J. Biol. Biochem 12:537-542.

Jensen; H. L. 1961. Survival of Rhizobium meliloti in soil culture. Nature 192:682-682.

Jones, R. D., and D. P. Winter. 1983. Two case reports of deaths on industrial premises attributed to 1,1,1,-trichloroethane. Arch. Environ. Health 38:59-61.

Kanazawa, S., and Z. Filip. 1986. Microorganisms and enzymatic activity in soil as affected by TCE, PCE and dichloroethylene. A Short Communication. V. Jensen, A. Kjoller and L. H. Sorensen, (eds.). Microbial Communities in Soil. Elsevier Applied Science Publishers, N. Y. pg. 207-209.

Kellerman, K. F. and E. H. Fawcett. 1907. Movement of certain bacteria in soils. Science 25:806.

Kennedy, M. J., and J. G. Lawless. 1985. Role of chemotaxis in the ecology of denitrifiers. Appl. Environ. Microbiol. 49:109-114. 
Kilbane, J. J., D. K. Chattergee, J. S. Karns, S. T. Kellog, and A. M. Chakrabarty. 1982. Biodegradation of 2,4,5,trichlorophenoxyacetic acid by pure culture of Pseudomonas cepacia. Appl. Environ. Microbiol. 44:72-78.

Kleopfer, R. D., D. M. Easley, B. B. Hass, Jr., and T. G. Dehil. 1985. Anaerobic degradation of trichloroethylene in soil. Environ. Sci. Technol. 19:277-280.

Kuhn E. P., P. J. Colberg, J. L. Schnoor, O. Wanner, A. J. B. Zehnder, and R. P. Schwarzenback. 1985. Microbial transformations of substituted benzenes during infiltration of rinse water to groundwater: Laboratory Column Studies. Environ. Sci. Technol. $19: 961-968$.

Larson, R. J., and R. M. Ventullo. 1983. Biodegradation potential of ground-water bacteria. Proceedings of the Third National Symposium on Aquifer Restoration and Groundwater Monitoring. National Water Well Assoc., Ohio. 402-209. Lauffenburguer, D. A. 1985. Chemotaxis: analysis for quantitative studies. Biotechnology Progress 1:151-160.

López-de-Victoria, G., L. Jiménez, T. C. Hazen and C. B. Fliermans. 1988. Comparison of bacteria from water and sediment cores in the terrestrial subsurface. Abstract ASM Annual Meetin: Miami, Fla.

Macnab, R. M. 1978. Bacterial motility and chemotaxis: the molecular biology of a behavioral system. CRC Crit. Rev. Biochem. 5:291-341.

Madsen, E. L. and M. Alexander. 1982. Transport of Rhizobium and Pseudomonas through soil. Soil Science 46:557-560. 
McCormick, D. 1985. One Bug's Meat... Biotechnology 3:429-435. Mesibov, R. and J. Adler. 1972. Chemotaxis toward amino acids in Escherichia coli. J. Bacteriol. 112:315-326.

Morita, R. Y. 1982. Starvation survival of heterotrophs in the marine environment. Adv. Microbial Ecol. 6:171-198.

Morita, R. Y. 1988. Bioavailability of energy and its relationship to growth and starvation survival in nature. Can, J. Microbiol. $34: 436-441$.

Moulton, R. C., and T. C. Montie. 1979. Chemotaxis by Pseudomonas aeruginosa. J. Bacteriol. 137:274-280.

Nelson, M. J., S. O. Montgomery, E. J. O'Neill, and P. H. Pritchard. 1986. Aerobic metabolism of trichloroethylene by a bacterial isolate. Appl. Environ. Microbiol. 52:383-384.

Nelson, M. J., S. O. Montgomery, W. R. Mahaffey, and P. H. Pritchard. 1987. Biodegradation of trichloroethylene and involvement of an aromatic biodegradative pathway. Appl. Environ. Microbiol. $53: 949-954$.

Okon, Y., L. Cakmacki, I. Nur, and I. Chet. 1980. Aerotaxis and chemotaxis of Azospirillum brasilense. Microb. Ecol. 6:277-280.

Ordal, G. W. and K. J. Gibson. 1977. Chemotaxis toward amino acids by Bacillus subtilis. J. Bacteriol. 129:151-155.

Palleroni, N. J. 1976. Chamber for bacterial chemotaxis experiments. Appl. Environ. Microbiol. 32:729-730.

Parke, D., M. Rivelli, and L. N. Ornston. 1985. Chemotaxis to aromatic and hydroaromatic acids: comparison of Bradyrhizobium japonicum and Rhizobium trifoli. J. Bacteriol. 163:417-422. 
Parsons, F., and G. B. Lage. 1985. Chlorinated organics in simulated groundwater environments. J. Am. Water Works Assoc. 5:5259.

Poindexter, J. S. 1981. Oligotrophy: fast and famine existence. Adv. Microb. Ecol. 5:63-89.

Pye, V. I., and P. Ruth. 1983. Ground water contamination in the United States. Science 221:713-718.

Roberts, L. 1987. Discovering microbes with a taste for PCB's. Science 237:975-977.

Roszak, D. B. and R. R. Colwell. 1987. Survival strategies of bacteria in natural environments. Microbiol. Rev. 51:365-379.

Silverman, M., and M. Simon. 1974. Flagellar rotation and the mechanism of bacterial motility. Nature 249:73-74.

Sjoblad, R. D., and B. A. Coleman, 1980. Chemotactic responses of Thiobacillus thioparus. Microb. Ecol. 6:147-151.

Smith, J., and R. N. Doetsch. 1969. Studies on negative chemotaxis and the survival value of motility in Pseudomonas fluorescens. J. Gen. Microbiol. 55:379-391.

Soby, S., and K, Bergman. 1983. Motility and chemotaxis of Rhizobium meliloty in Soil. Appl. Environ. Microbiol. 46:995998.

Spain, J. C., and P. A. Van Veld. 1983. Adaptation of natural microbial communities to degradation of xenobiotic compounds: Effects of concentration, exposure time, inoculum and chemical structure. Appl. Environ. Microbiol. 45:428-435.

Stotzky, G. 1965. Replica plating technique for studying microbial interactions in soil. Can. J. Microbiol. 11:629-640. 
Strand, S. E., and L. Shippert. 1986. Oxidation of Chloroform in an anaerobic soil exposed to natural gas. Appl. Environ. Microbiol. $52: 203-205$.

Taylor, B. L. 1983. How do bacteria find the optimal concentration of oxygen? TIBS 438-442.

Thorn, P. M. and R. M. Ventullo. 1988. Measurement of bacterial growth rates in subsurface sediments using the incorporation of tritiated thymidine into DNA. Microbial Ecol. 16:3-16.

Torella F., and R. Y. Morita. 1982. Starvation induced morphological changes, motility and chemotaxis patterns in a psychrophilic marine vibrio. Publ. Centr. Natl. Exploit. Actes Colloq. (Fr.) Oceans 13:45-60.

U. S. Environmental Protection Agency. 1984. National revised primary drinking water regulations; volatile synthetic organic chemicals; proposed rule making. Fed. Reg. 49:24329-24355.

Van der Drift, C. and M. H. de Jong. 1974. Chemotaxis toward amino acids in Bacillus subtilis. J. Bacteriol, 96:83-92.

Vogel, T. M., and P. L. McCarty. 1985. Biotransformation of tetrachloroethylene trichloroethylene, dichloroethylene, vinyl chloride and carbon dioxide under methanogenic conditions. Appl. Environ. Microbiol. 49:1080-1083.

Waksman, S. A. 1916. Bacterial numbers in soil at different depths, and in different seasons of the year. Soil Sci. 1:363-380.

Waksman, S, A. 1954. My life with the microbes. Simon and Schuster Inc. N. Y., N. Y. 
Wallace, H. R. 1978. Dispersal in time and space: soil pathogens. In: Plant disease: an advanced treatise. J. G. Horsfall and E. B. Cowlin (eds.). Vol II. Academic Press, New York. pg. 181-202. Wilson, J. T., and J. F. McNabb. 1983. Riological transformation of organic pollutants in groundwater. EOS 64:47-50.

Wilson, J. T., J. F. McNabb, D. L. Balkwill, and W. C. Ghiorse. 1983. Enumeration and characterization of bacteria indigenous to a shallow water-table aquifer. Ground Water 21:134-142.

Wilson, J. T., and B. H. Wilsun. 1985. Biotransformation of trichloroethyl $n$ ne in soil. Appl. Environ. Microbiol. 49:242-243.

Wilson, J. T., L. E. Leach, M. Henson, and J. N. Jones. 1986. In situ biorestoration as a ground water remediation technique. Ground Water Microbiol. Rev. 3:56-64.

Zar, J. H. 1984. Biostatistical Analysis. Prentice Hall, Inc. Englewood Cliifs, N. J.

Zurer, P. S. 1987. Fungus shows promise in hazardous waste treatment. Chem. and Eng. News. 34:17-19. 
Trable 1. Geological formations, depths and sites at which isolates were collected.

\begin{tabular}{llll}
\hline ISOLATE & SITE & DEPTH & $\begin{array}{l}\text { GEOLOGICAL } \\
\text { FORMATION }\end{array}$ \\
& & $(\mathrm{ft})$ & \\
\hline A0231 & P28 & 440 & PeeDee \\
A0481 & P28 & 589 & Black Creek \\
B0388 & P24 & 457 & Ellenton \\
B0703 & P24 & 851 & Middendorf \\
B0617 & P24 & 802 & Middendorf \\
C0101 & P29 & 94 & McBean \\
C0397 & P29 & 496 & Black Creek \\
C0464 & P29 & 576 & Black Creek \\
C0081 & P29 & 25 & Tobacco Road \\
C0128 & P29 & 94 & McBean \\
\hline
\end{tabular}


Table 2. Reproducibility of two chemotaxis assays of isolate A0481 to arginine.

CONCENTRATION

FIRST ASSAY

$$
1.01 \pm 0.11
$$

$2.35 \pm 0.22$

$1.52 \pm 0.12$

$2.22 \pm 0.02$

$2.65 \pm 0.07$

$\underline{3.03} \pm 0.13$

$2.60 \pm 0.11$

$10^{-5} \mathrm{M}$

$10^{-6} \mathrm{M}$
SECOND ASSAY

$1.05 \pm 0.08$

$2.17 \pm 0.16$

$1.41 \pm 0.09$

$2.10 \pm 0.10$

$2.38 \pm 0.06$

$2.70 \pm 0.11$

$2.30 \pm 0.10$

$2.07^{*} \pm 0.03$

Mean chemotactic index \pm one standard error $(n=4)$, chemotactic index $=$ experimental density/control density, bold $P<0.05$, underlined $=$ peak, asterisked $=$ threshold. 
Table 3. Reproducibility of three chemotaxis assays of isolate C0397 to lactose.

\section{CONCENTRATION}

FIRST ASSAY

SECCND ASSAY

THIRD ASSAY

\begin{tabular}{|c|c|c|c|}
\hline MiÓTILITY & $1.01 \pm 0.08$ & $0.97 \pm 0.04$ & $1.01 \pm 0.02$ \\
\hline $1 \mathrm{M}$ & $1.27 \pm 0.02$ & $1.13 \pm 0.02$ & $1.13 \pm 0.03$ \\
\hline $10^{-1} \mathrm{M}$ & $1.22 \pm 0.05$ & $1.10 \pm 0.04$ & $1.20 \pm 0.03$ \\
\hline $10^{-2} \mathrm{M}$ & $1.37 \pm 0.07$ & $1.22 \pm 0.04$ & $1.33 \pm 0.03$ \\
\hline $10^{-3} \mathrm{M}$ & $1.42 \pm 0.05$ & $1.29 \pm 0.02$ & $1.37 \pm 0.02$ \\
\hline $10^{-4} \mathrm{M}$ & $1.47 \pm 0.08$ & $1.28 \pm 0.06$ & $1.38 \pm 0.02$ \\
\hline $10^{-5} \mathrm{M}$ & $1.63^{*} \pm 0.10$ & $1.51^{*} \pm 0.04$ & $1.57^{*} \pm 0.02$ \\
\hline $10^{-6} \mathrm{M}$ & $0.95 \pm 0.04$ & $0.85 \pm 0.05$ & $0.95 \pm 0.03$ \\
\hline
\end{tabular}


Table 4. Reproducibility of two chemotaxis assays of isolate B0703 to TCE. CONCENTRATION FIRST ASSAY SECOND ASSAY

$\begin{array}{lll}\text { MOTLITY } & 1.03 \pm 0.12 & 1.02 \pm 0.09 \\ 10^{-2} \mathrm{M} & \mathbf{1 . 7 4} \pm 0.10 & \mathbf{1 . 6 7} \pm 0.10 \\ 10^{-3} \mathrm{M} & \mathbf{2 . 1 5} \pm 0.10 & \mathbf{2 . 0 8} \pm 0.09 \\ 10^{-4} \mathrm{M} & \mathbf{2 . 2 3} \pm 0.05 & \mathbf{2 . 1 3} \pm 0.10 \\ 10^{-5} \mathrm{M} & \mathbf{2 . 3 4} \pm 0.04 & \mathbf{2 . 1 6} \pm 0.05 \\ 10^{-6} \mathrm{M} & \mathbf{3 . 3 2} \pm 0.14 & \mathbf{3 . 3 5} \pm 0.10 \\ 10^{-7} \mathrm{M} & \mathbf{3 . 5 3} \pm 0.11 & \mathbf{3 . 4 3} \pm 0.08 \\ 10^{-8} \mathrm{M} & \mathbf{1 . 9 7} \pm 0.05 & \mathbf{1 . 9 7} \pm 0.10 \\ 10^{-9} \mathrm{M} & \mathbf{1 . 3 0} \pm 0.05 & \mathbf{1 . 6 2} \pm 0.04 \\ 10^{-10} \mathrm{M} & \mathbf{1 . 8 9} \pm 0.09 & \mathbf{1 . 7 7} \pm 0.04\end{array}$

Mean chemotactic index \pm one standard error $(n=4)$, chemotactic index $=$ experimental density/control density, bold $\mathrm{P}<0.05$, underlined $=$ peak, asterisked $=$ threshold. 
$a$

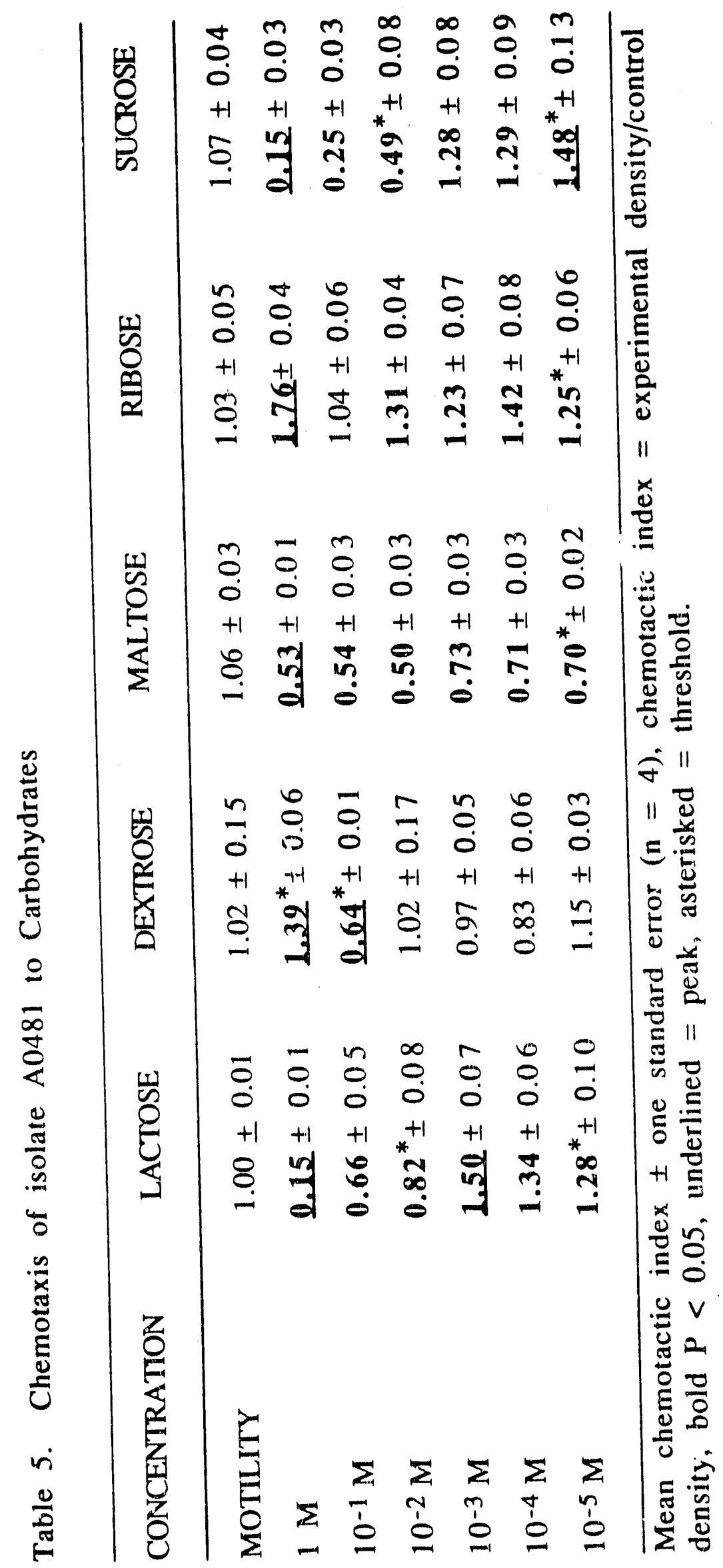




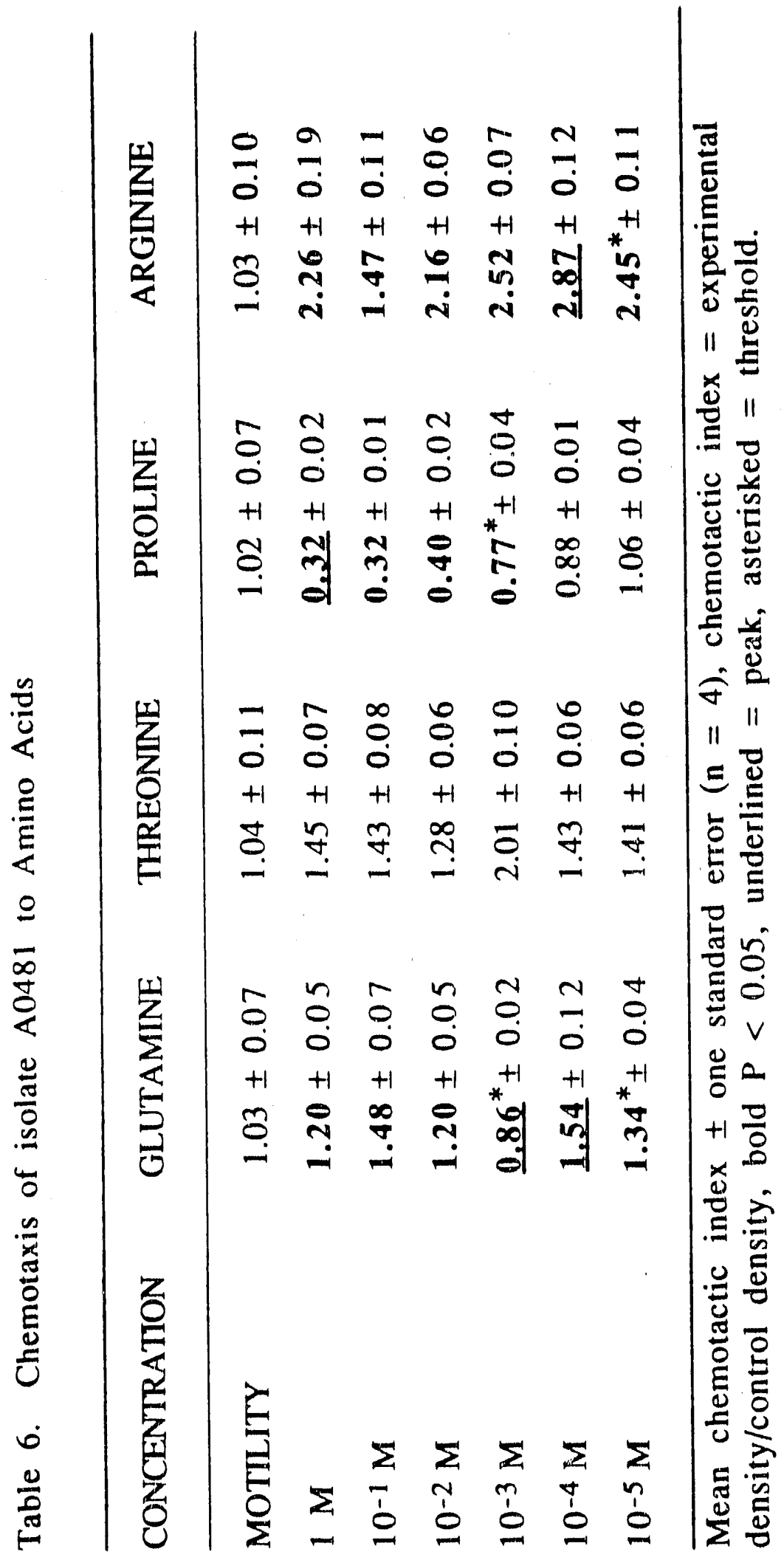


Table 7. Chemotactic Behavior of isolate A0481 to TCE

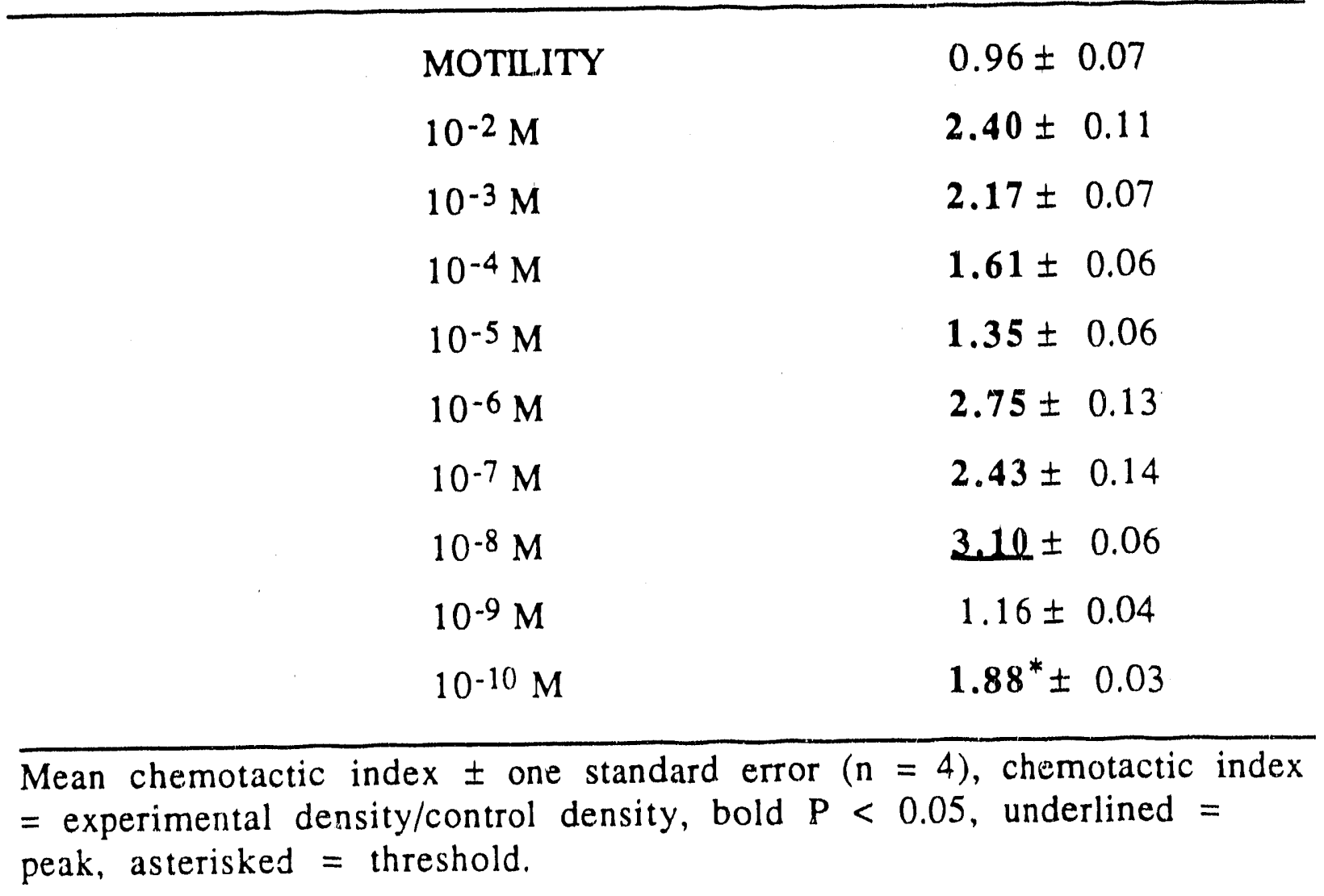


:

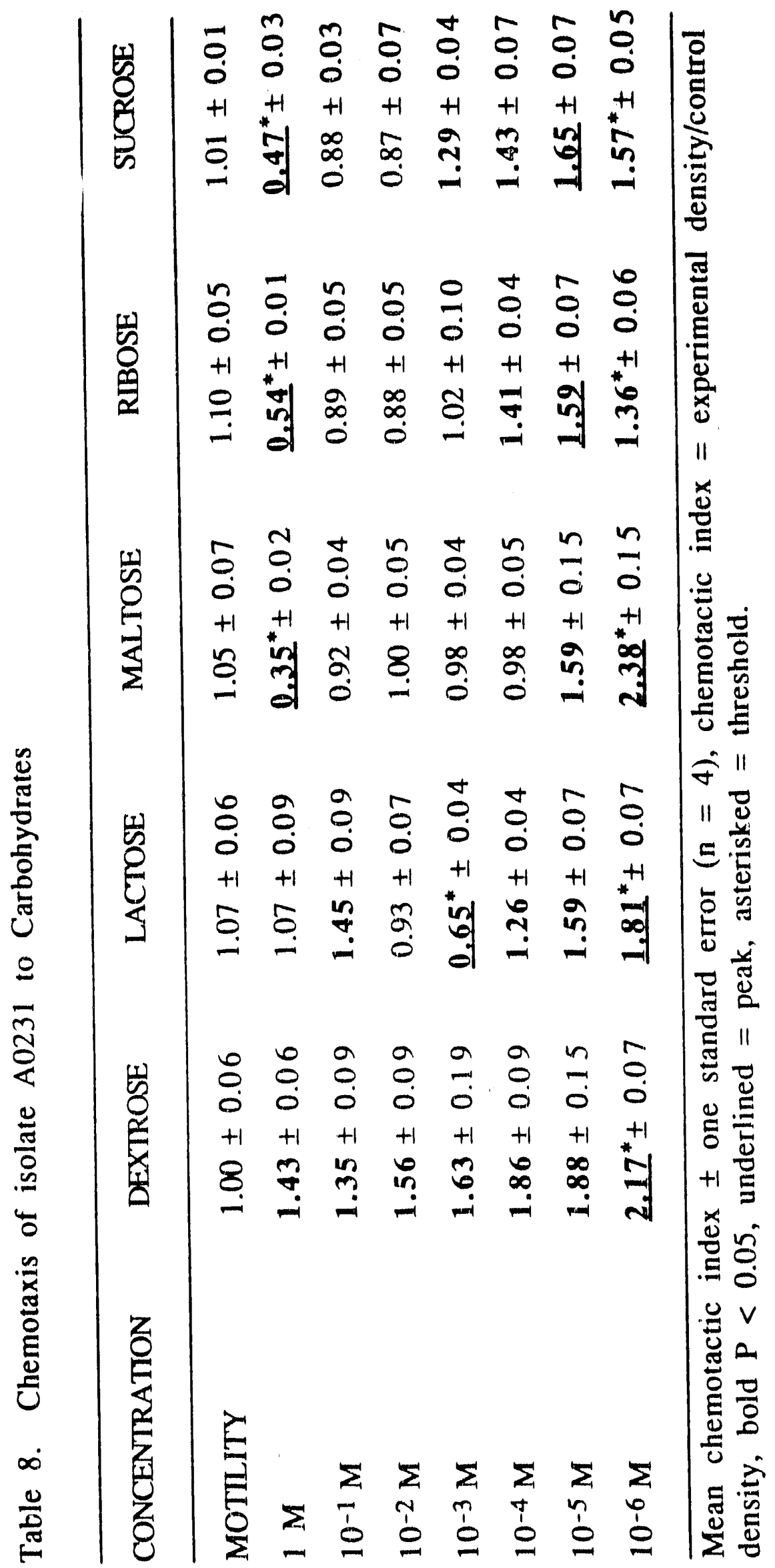




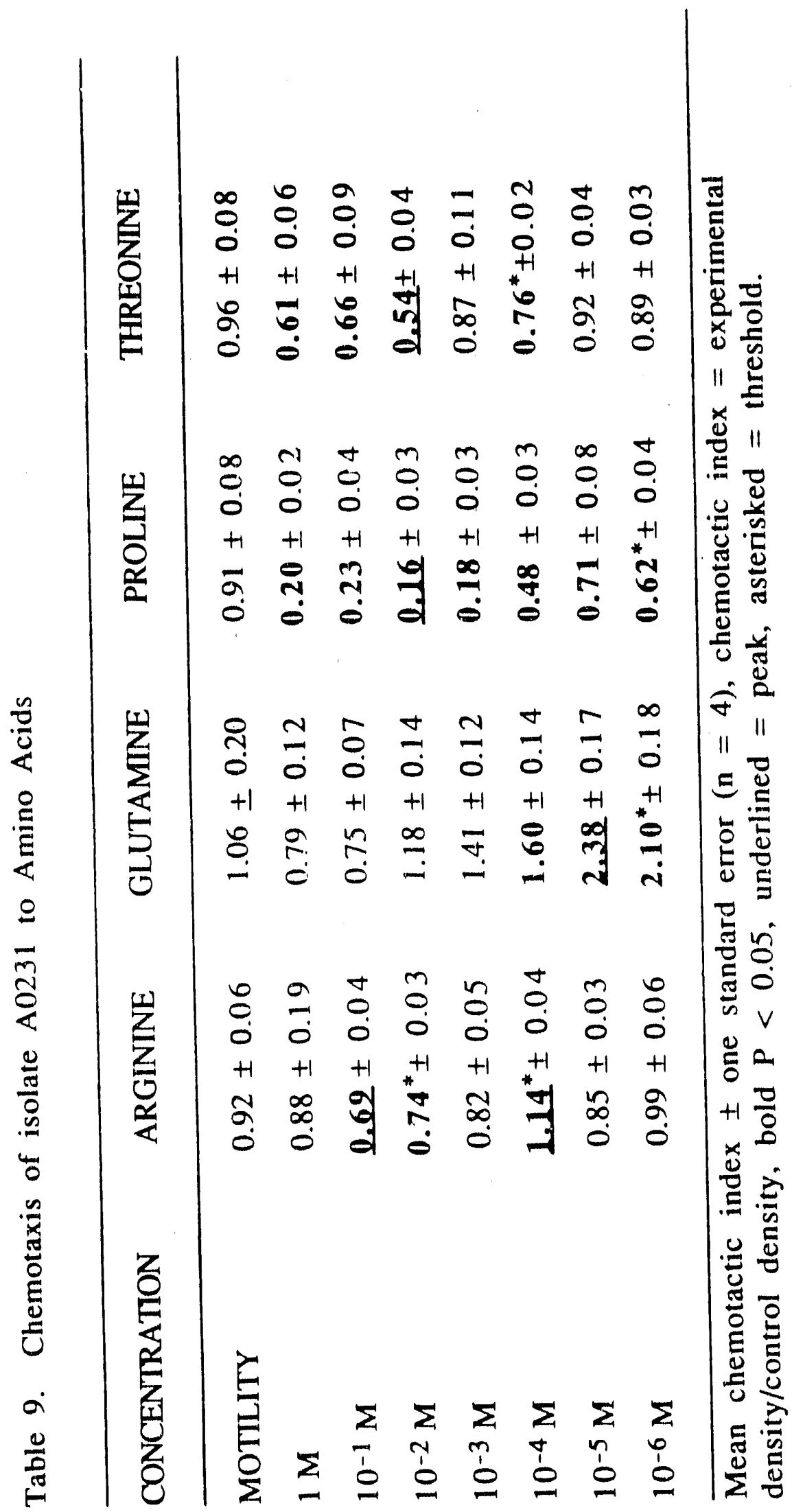


Table 10. Chemotactic Behavior of isolate A0231 to TCE

CONCENTRATION

\section{CHEMOTACTIC INDEX}

$\begin{array}{ll}\text { MOTILITY } & 0.98 \pm 0.04 \\ 10^{-2} \mathrm{M} & \mathbf{1 . 6 8} \pm 0.08 \\ 10^{-3} \mathrm{M} & \mathbf{2 . 0 2} \pm 0.07 \\ 10^{-4} \mathrm{M} & \mathbf{2 . 3 2} \pm 0.09 \\ 10^{-5} \mathrm{M} & \mathbf{2 . 2 0} \pm 0.06 \\ 10^{-6} \mathrm{M} & \mathbf{2 . 2 5} \pm 0.12 \\ 10^{-7} \mathrm{M} & \mathbf{2 . 6 5} \pm 0.05 \\ 10^{-8} \mathrm{M} & \mathbf{2 . 4 0} \pm 0.23 \\ 10^{-9} \mathrm{M} & \mathbf{1 . 5 0} \pm 0.04 \\ 10^{-10} \mathrm{M} & \mathbf{2 . 2 1} \pm 0.06\end{array}$

Mean chemotactic index \pm one standard error $(n=4)$, chemotactic index = experimental density/control density, bold $P<0.05$, underlined $=$ peak, asterisked $=$ threshold. 


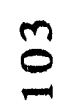

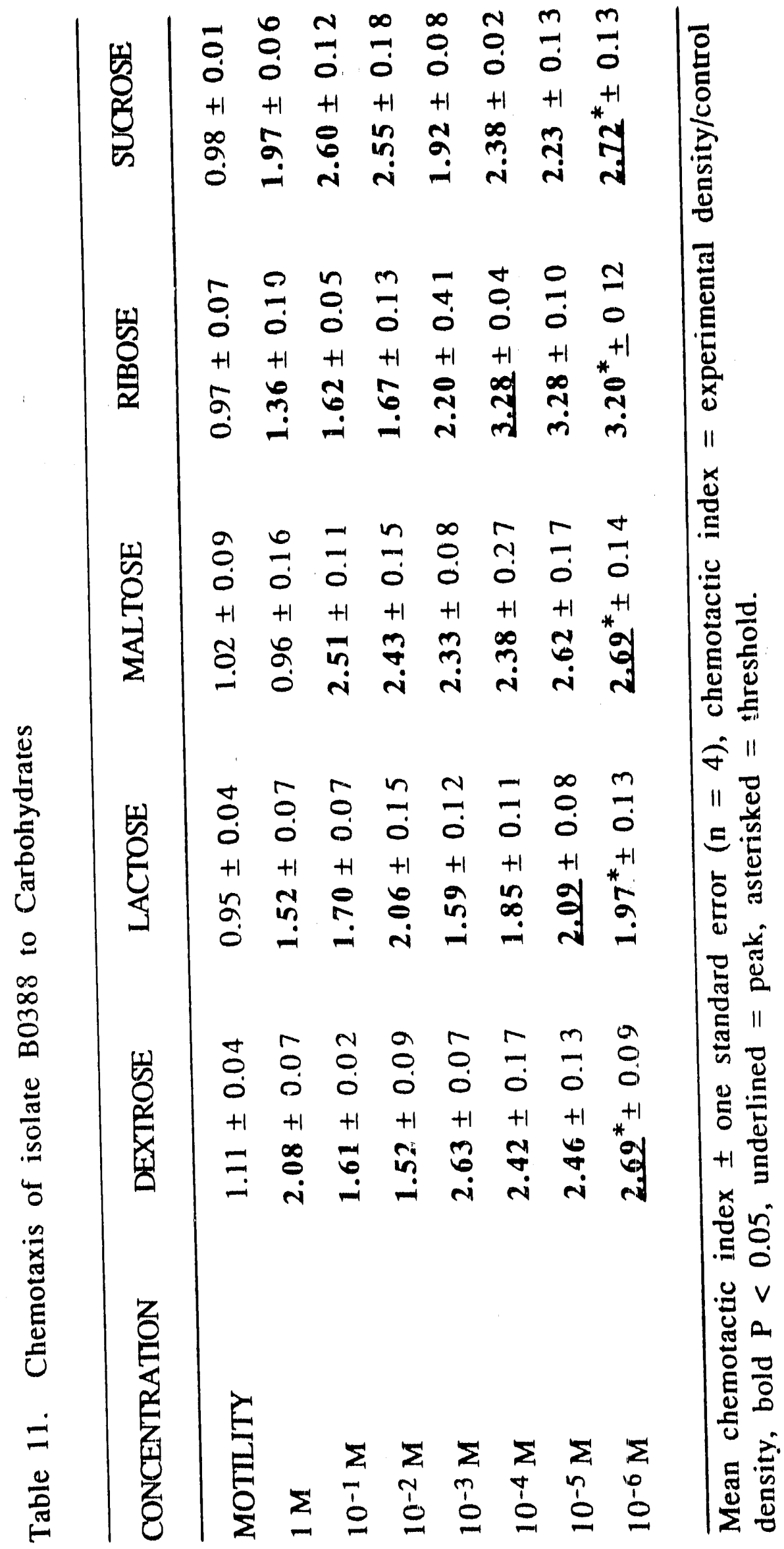


$\stackrel{ \pm}{ }$

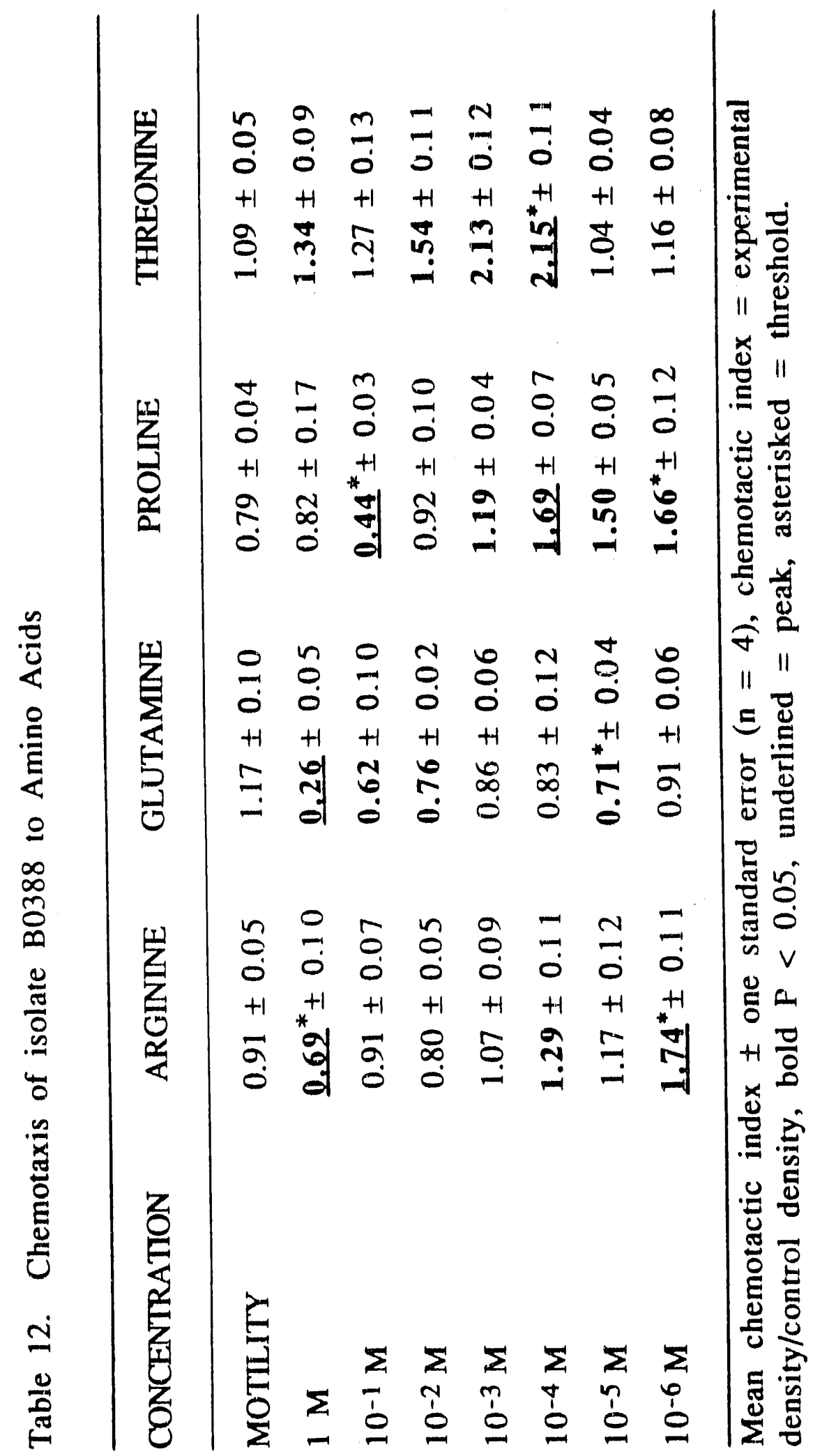


Table 13. Chemotactic Behavior of isolate B0388 to TCE

\begin{tabular}{ll}
\hline CONCENTRATION & CHEMOTACTIC INDEX \\
\hline MOTILITY & $1.01 \pm 0.13$ \\
$1 \mathrm{M}$ & $\mathbf{2 . 7 0} \pm 0.36$ \\
$10^{-1} \mathrm{M}$ & $\mathbf{2 . 0 3} \pm 0.29$ \\
$10^{-2} \mathrm{M}$ & $\mathbf{1 . 5 3} \pm 0.09$ \\
$10^{-3} \mathrm{M}$ & $\mathbf{1 . 7 0} \pm 0.13$ \\
$10^{-4} \mathrm{M}$ & $\mathbf{1 . 6 1} \pm 0.17$ \\
$10^{-5} \mathrm{M}$ & $\mathbf{1 . 9 2} \pm 0.21$ \\
$10^{-6} \mathrm{M}$ & $\mathbf{2 . 2 4} \pm 0.13$ \\
$10^{-7} \mathrm{M}$ & $\mathbf{2 . 2 4} \pm 0.20$ \\
$10^{-8} \mathrm{M}$ & $\mathbf{1 . 9 3} \pm 0.09$ \\
$10^{-9} \mathrm{M}$ & $\mathbf{1 . 9 4} \pm 0.22$ \\
$10^{-10} \mathrm{M}$ & $\mathbf{2 . 1 7} \pm 0.14$ \\
\hline
\end{tabular}

Mean chemotactic index \pm one standard error $(n=4)$, chemotactic index $=$ experimental density/control density, bold $\mathrm{P}<0.05$, underlined $=$ peak, asterisked $=$ threshold. 


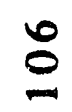

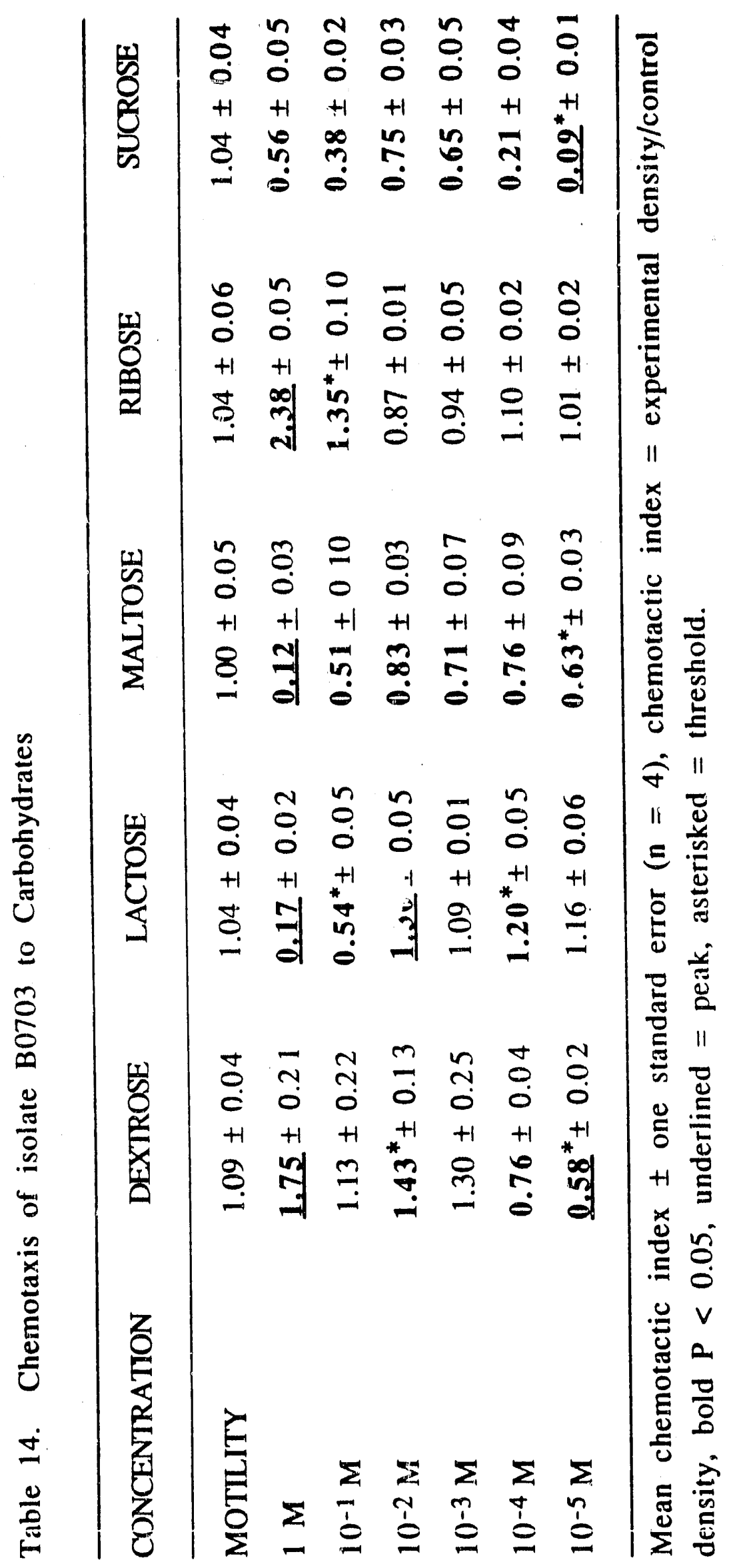


Table 16. Chemotactic Behavior of isolate B0703 to TCE CONCENTRATION CHEMOTACTIC INDEX

\begin{tabular}{ll}
\hline MOTILITY & $1.02 \pm 0.11$ \\
$10^{-2} \mathrm{M}$ & $1.71 \pm 0.11$ \\
$10^{-3} \mathrm{M}$ & $\mathbf{2 . 1 2} \pm 0.10$ \\
$10^{-4} \mathrm{M}$ & $\mathbf{2 . 1 8} \pm 0.07$ \\
$10^{-5} \mathrm{M}$ & $\mathbf{2 . 2 5} \pm 0.04$ \\
$10^{-6} \mathrm{M}$ & $\mathbf{3 . 3 3} \pm 0.13$ \\
$10^{-7} \mathrm{M}$ & $\mathbf{3 . 4 7} \pm 0.10$ \\
$10^{-8} \mathrm{M}$ & $\mathbf{1 . 9 7} \pm 0.08$ \\
$10^{-9} \mathrm{M}$ & $\mathbf{1 . 4 6} \pm 0.04$ \\
$10^{-10} \mathrm{M}$ & $\mathbf{1 . 8 3} \pm 0.07$ \\
\hline
\end{tabular}

Mean chemotactic index \pm one standard error $(n=4)$, chemotactic index $=$ experimental density/control density, bold $\mathrm{P}<0.05$, underlined $=$ peak, asterisked $=$ threshold. 


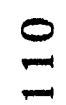

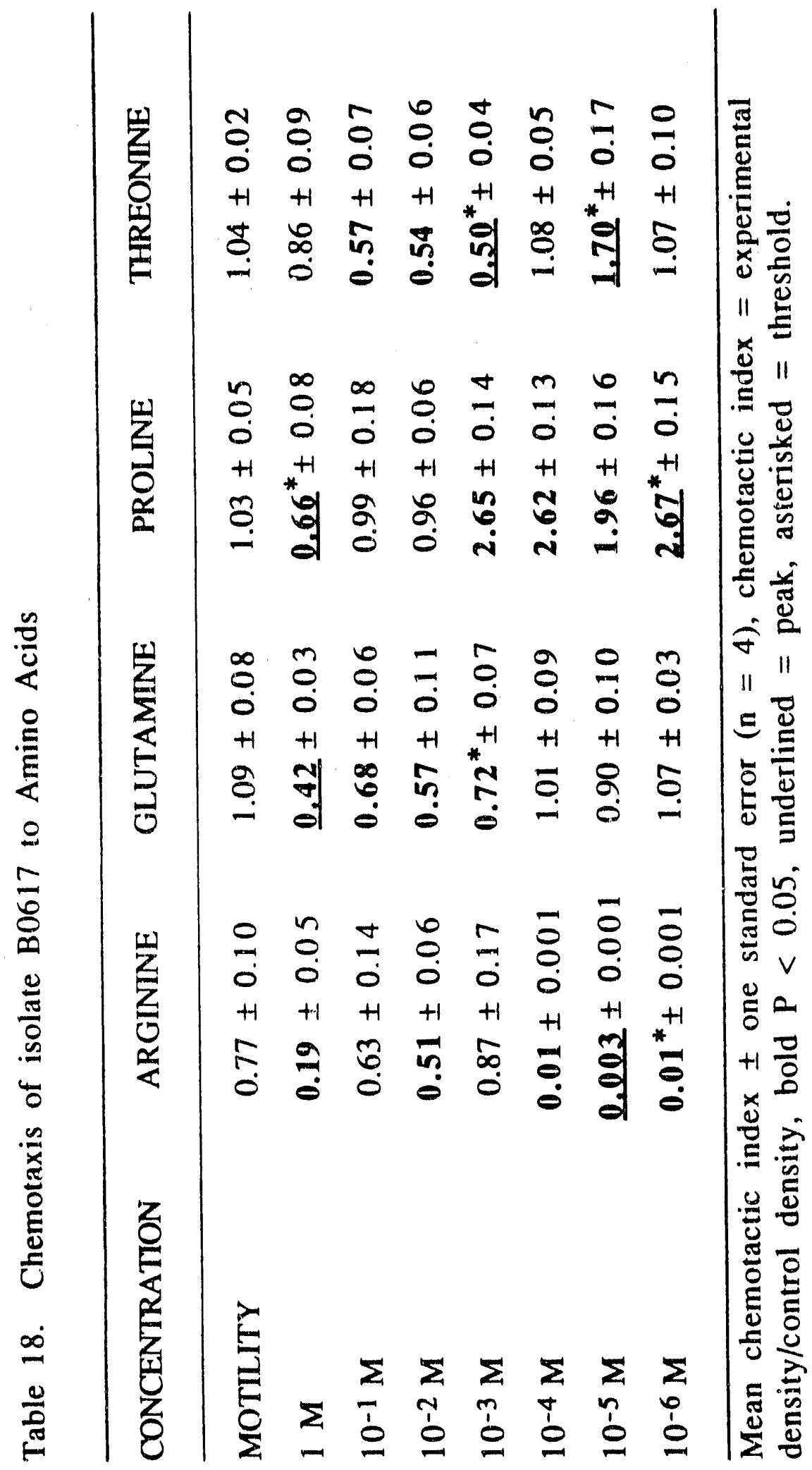


Table 19. Chemotactic Behavior of isolate B0617 to TCE

CONCENTRATION

MOTILITY

$1 \mathrm{M}$

$10^{-1} \mathrm{M}$

$10^{-2} \mathrm{M}$

$10^{-3} \mathrm{M}$

$10^{-4} \mathrm{M}$

$10^{-5} \mathrm{M}$

$10^{-6} \mathrm{M}$

$10^{-7} \mathrm{M}$

$10^{-8} \mathrm{M}$

$10^{-9} \mathrm{M}$

$10^{-10} \mathrm{M}$

\section{CHEMOTACTIC INDEX}

$1.15 \pm 0.08$

$4.69 \pm 0.30$

$3.47 \pm 0.50$

$2.48 \pm 0.32$

$1.95 \pm 0.18$

$1.57 \pm 0.12$

$2.23 \pm 0.17$

$2.36 \pm 0.10$

$1.83 \pm 0.23$

$2.20 \pm 0.12$

$1.63 \pm 0.15$

$2.10^{*} \pm 0.23$

Mean chemotactic index \pm one standard error $(n=4)$, chemotactic index $=$ experimental density/control density, bold $P<0.05$, underlined $=$ peak, asterisked $=$ threshold. 
$N$

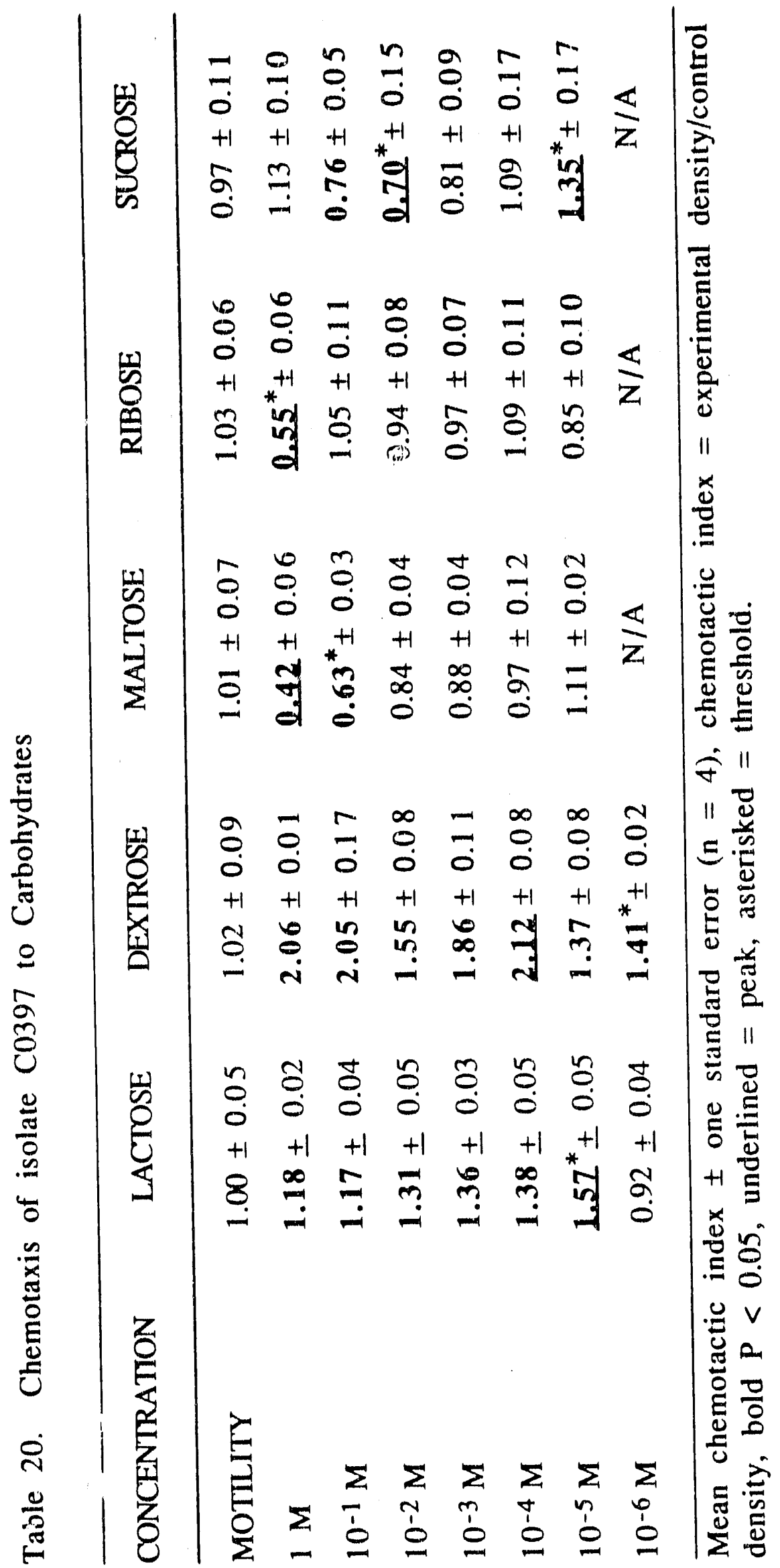




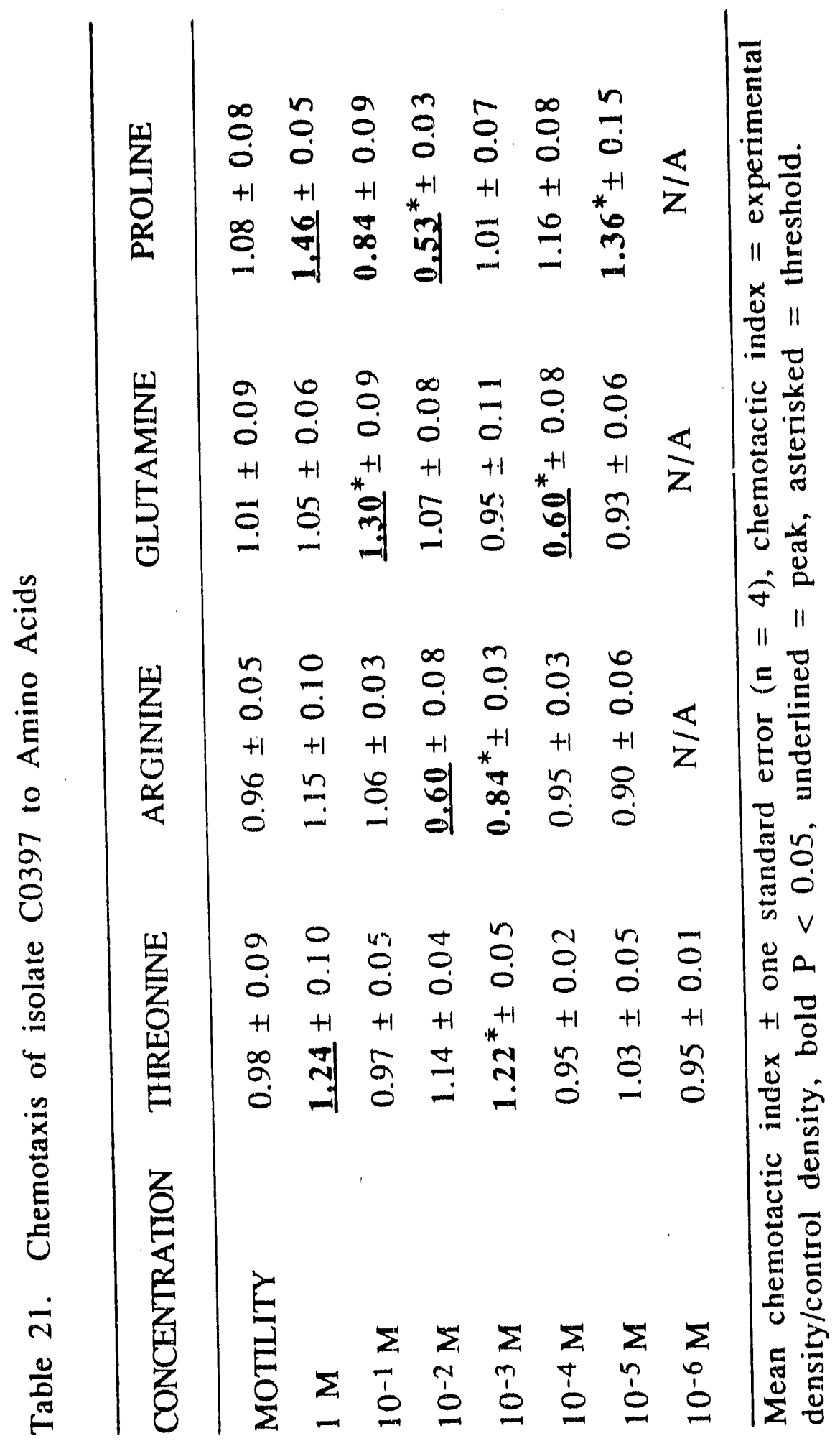


Table 22. Chemotactic Behavior of isolate C0397 to TCE

CONCENTRATION

\section{CHEMOTACTIC INDEX}

$\begin{array}{ll}\text { MOTILITY } & 0.97 \pm 0.04 \\ 10^{-2} \mathrm{M} & \mathbf{2 . 2 6} \pm 0.09 \\ 10^{-3} \mathrm{M} & \mathbf{1 . 6 0} \pm 0.17 \\ 10^{-4} \mathrm{M} & \mathbf{1 . 4 5} \pm 0.11 \\ 10^{-5} \mathrm{M} & 1.10 \pm 0.07 \\ 10^{-6} \mathrm{M} & 1.57 \pm 0.20 \\ 10^{-7} \mathrm{M} & \mathbf{1 . 3 4} \pm 0.04 \\ 10^{-8} \mathrm{M} & 1.29 \pm 0.11 \\ 10^{-9} \mathrm{M} & \mathbf{1 . 6 1} \pm 0.03 \\ 10^{-10} \mathrm{M} & \mathbf{0 . 7 2}^{*} \pm 0.03\end{array}$

Mean chemotactic index \pm one standard error $(n=4)$, chemotactic index $=$ experimental density/control density, bold $P<0.05$, underlined $=$ peak, asterisked $=$ threshold. 


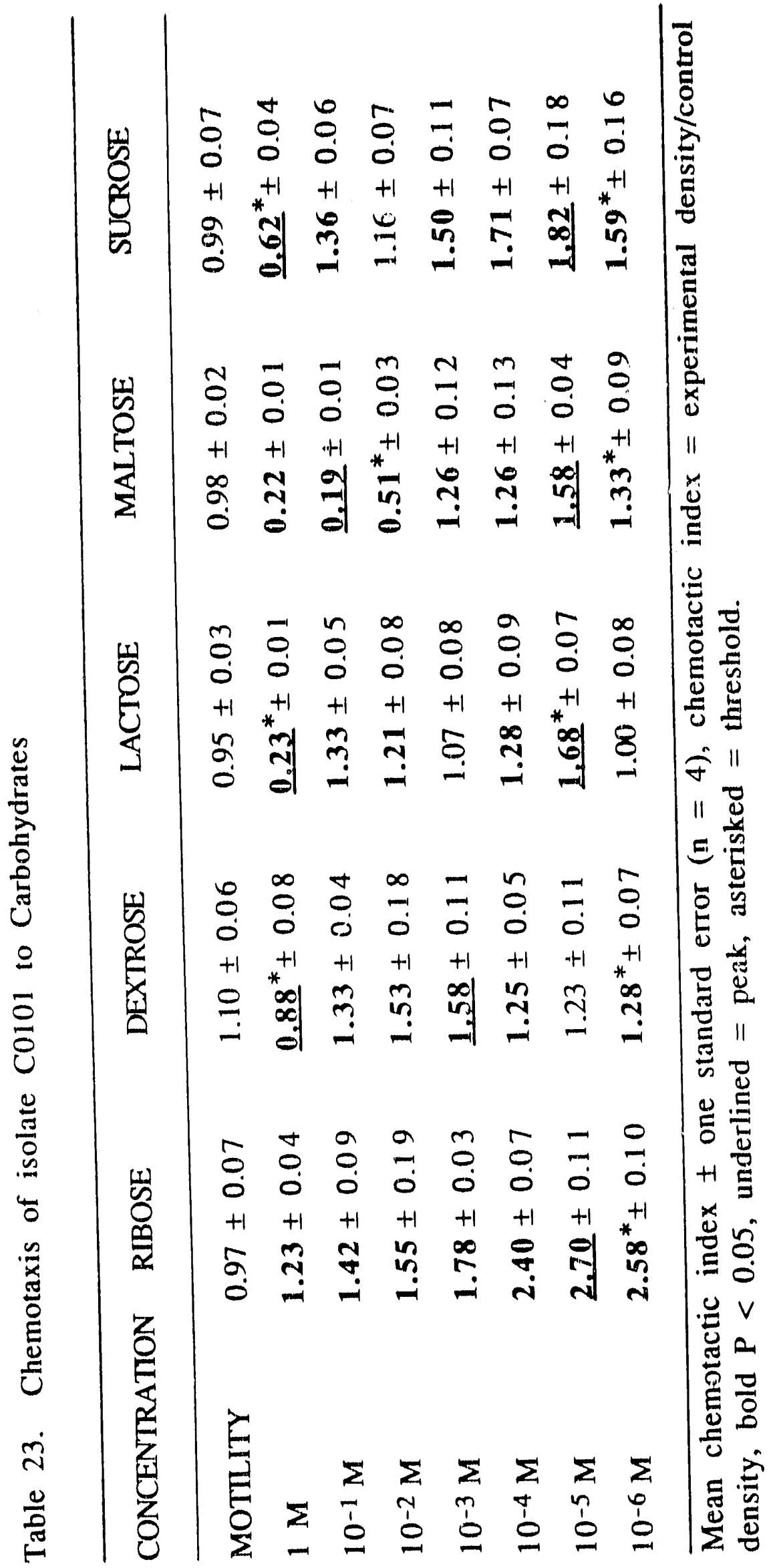




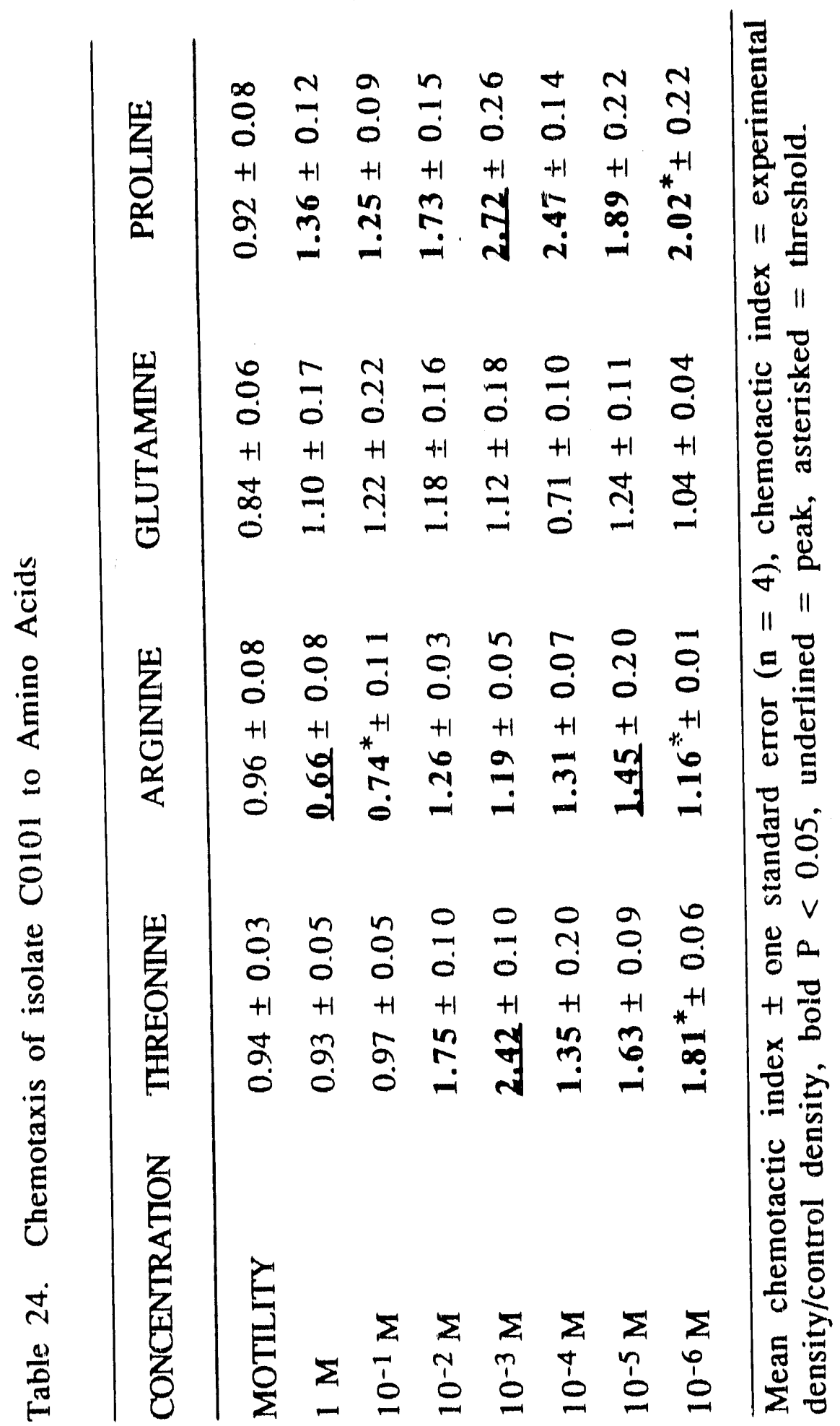


Table 25. Chemotactic Behavior of isolate C0101 to TCE

CONCENTRATION

CHEMOTACTIC INDEX

\begin{tabular}{ll} 
MOTILITY & $1.04 \pm 0.10$ \\
$1 \mathrm{M}$ & $\mathbf{1 . 7 1} \pm 0.23$ \\
$10^{-1} \mathrm{M}$ & $\mathbf{2 . 8 5} \pm 0.09$ \\
$10^{-2} \mathrm{M}$ & $\mathbf{3 . 1 1} \pm 0.10$ \\
$10^{-3} \mathrm{M}$ & $\mathbf{2 . 6 7} \pm 0.26$ \\
$10^{-4} \mathrm{M}$ & $\mathbf{3 . 0 5} \pm 0.06$ \\
$10^{-5} \mathrm{M}$ & $\mathbf{2 . 6 4} \pm 0.10$ \\
$10^{-6} \mathrm{M}$ & $\mathbf{2 . 8 3} \pm 0.20$ \\
$10^{-7} \mathrm{M}$ & $\mathbf{2 . 0 5} \pm 0.15$ \\
$10^{-8} \mathrm{M}$ & $\mathbf{1 . 3 4} \pm 0.10$ \\
$10^{-9} \mathrm{M}$ & $\mathbf{1 . 4 5} \pm 0.25$ \\
$10^{-10} \mathrm{M}$ & $\mathbf{2 . 1 4} \pm 0.07$ \\
\hline
\end{tabular}

Mean chemotactic index \pm one standard error $(n=4)$, chemotactic index $=$ experimental density/control density, bold $\mathrm{P}<0.05$, underlined $=$ peak, asterisked $=$ threshold. 
$\stackrel{\infty}{=}$

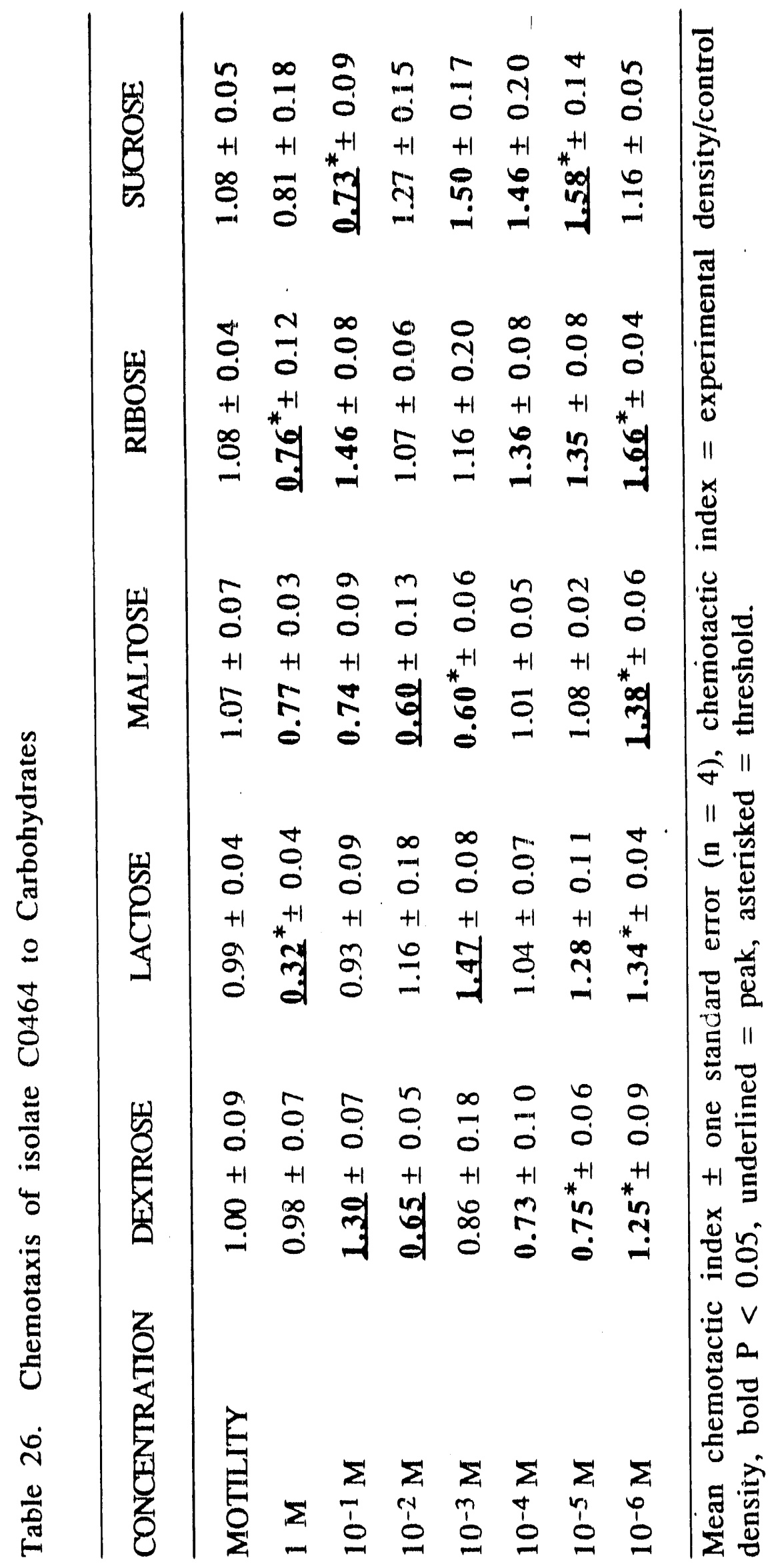




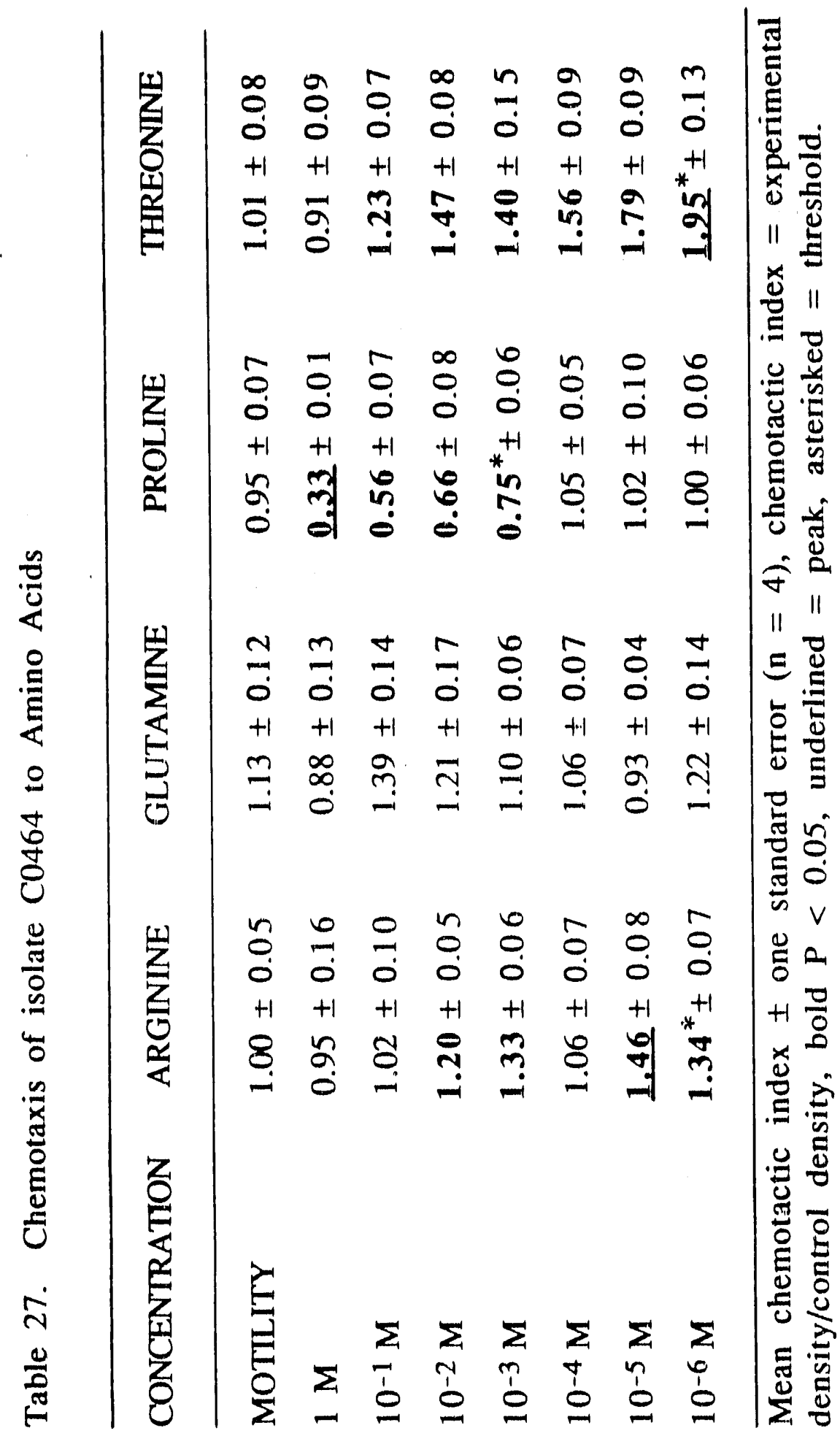


Table 28. Chemotaxis of isolate C0464 to TCE

CONCENTRATION

MOTILITY

$1 \mathrm{M}$

$10^{-1} \mathrm{M}$

$10^{-2} \mathrm{M}$

$10^{-3} \mathrm{M}$

$10^{-4} \mathrm{M}$

$10^{-5} \mathrm{M}$

$10^{-6} \mathrm{M}$

$10^{-7} \mathrm{M}$

$10^{-8} \mathrm{M}$

$10^{-9} \mathrm{M}$

$10^{-10} \mathrm{M}$
CHEMOTACTIC INDEX

$0.85 \pm 0.10$

$3.07 \pm 0.25$

$\underline{3.40} \pm 0.20$

$2.99 \pm 0.18$

$1.21 \pm 0.15$

$0.82 \pm 0.03$

$1.06 \pm 0.08$

$1.12 \pm 0.09$

$1.63 \pm 0.12$

$1.33 \pm 0.08$

$1.61^{*} \pm 0.08$

$1.19 \pm 0.10$

Mean chemotactic index \pm one standard error $(n=4)$, chemotactic index $=$ experimental density/control density, bold $\mathrm{P}<0.05$, underlined $=$ peak, asterisked $=$ thieshold . 
$\bar{\beth}$

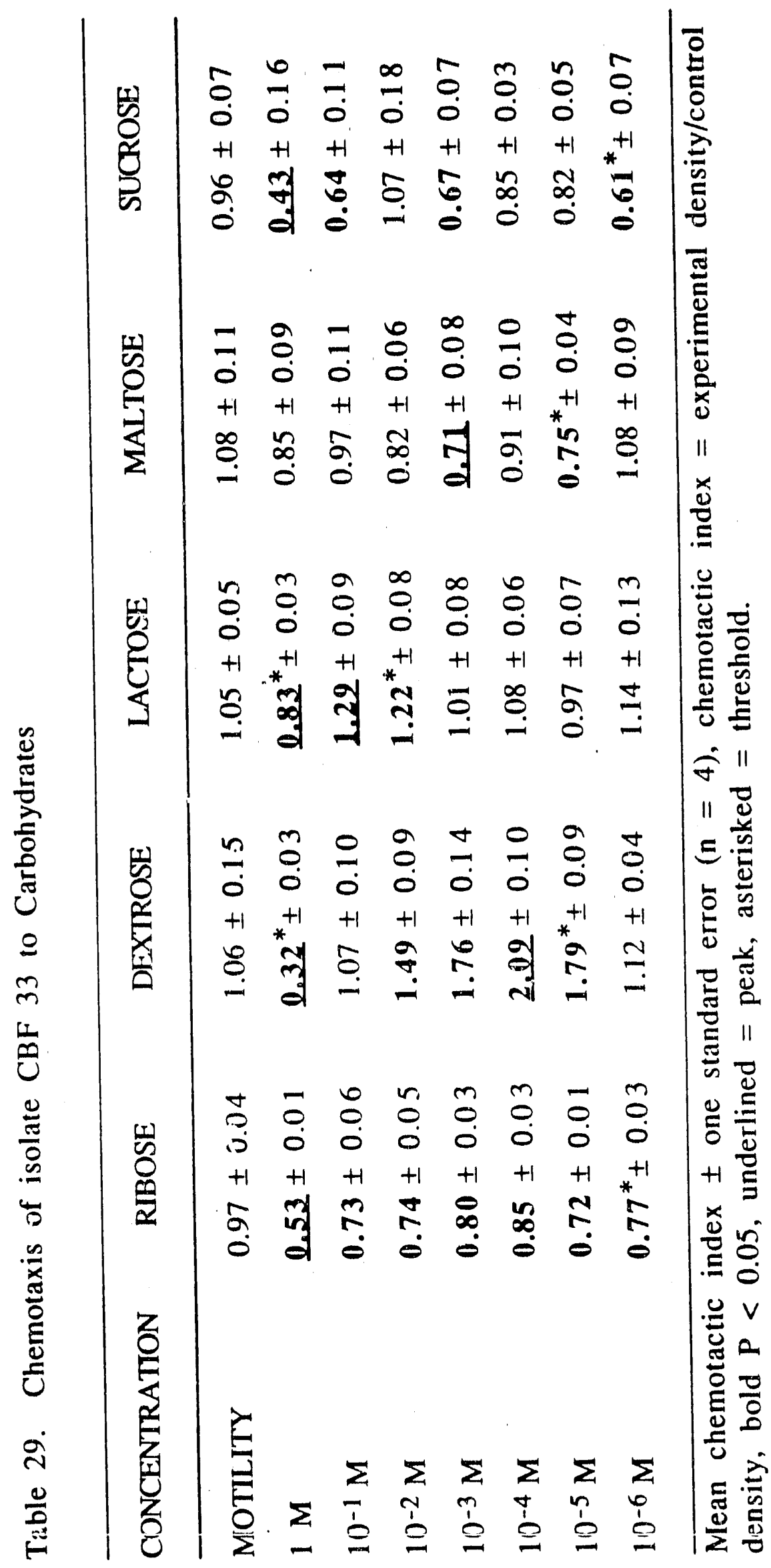




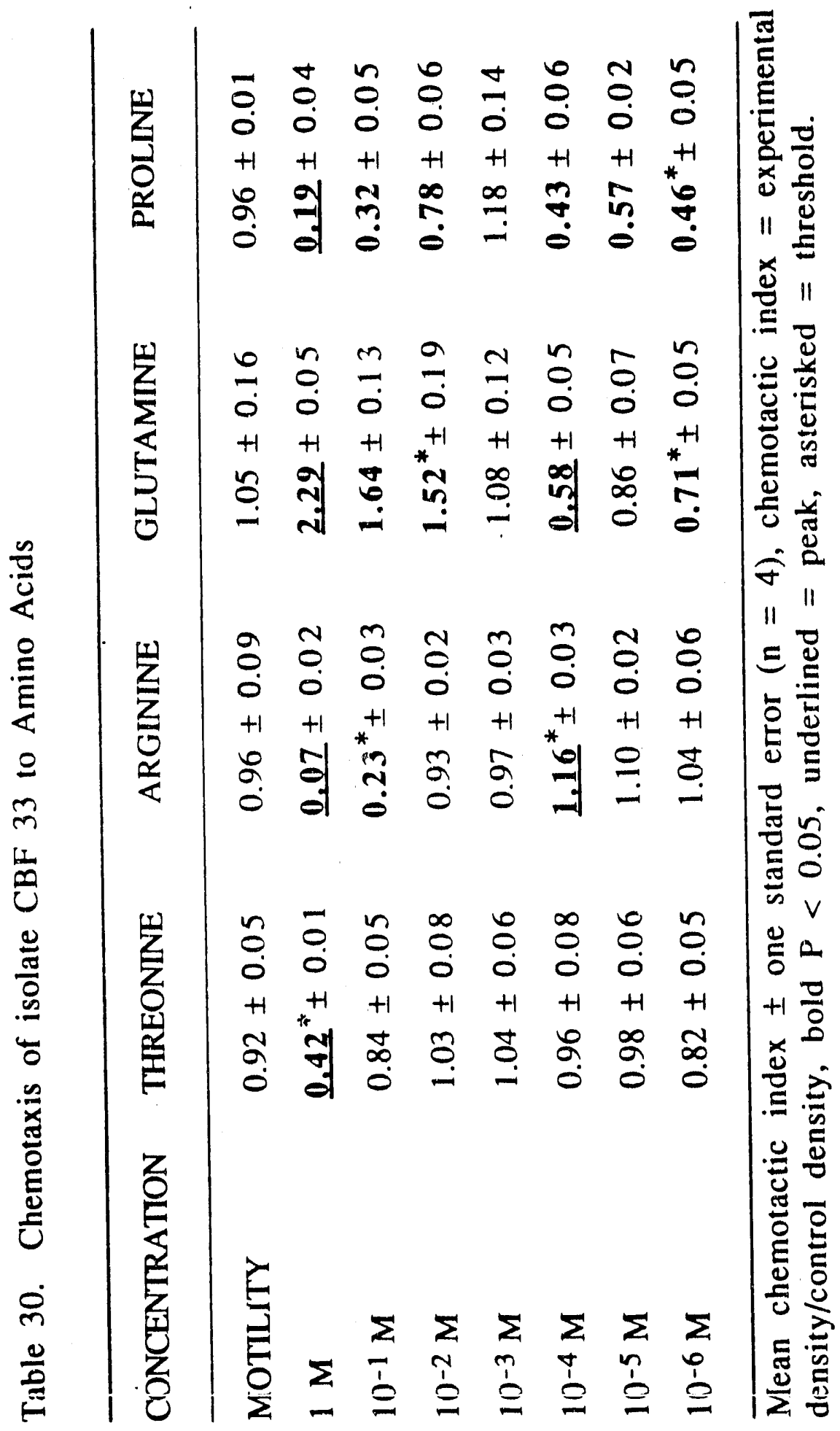


Table 31. Chemotactic Behavior of isolate CBF 33 to TCE

\begin{tabular}{lc}
\hline CONCENTRATION & CHEMOTACTIC INDEX \\
\hline MOTILITY & $0.97 \pm 0.03$ \\
$1 \mathrm{M}$ & $\mathbf{0 . 5 3}^{*} \pm 0.05$ \\
$10^{-1} \mathrm{M}$ & $0.88 \pm 0.07$ \\
$10^{-2} \mathrm{M}$ & $\mathbf{1 . 3 2} \pm 0.05$ \\
$10^{-3} \mathrm{M}$ & $1.15 \pm 0.10$ \\
$10^{-4} \mathrm{M}$ & $\mathbf{1 . 2 2} \pm 0.09$ \\
$10^{-5} \mathrm{M}$ & $\mathbf{1 . 4 5} \pm 0.08$ \\
$10^{-6} \mathrm{M}$ & $\mathbf{1 . 2 9} \pm 0.03$ \\
$10^{-7} \mathrm{M}$ & $\mathbf{1 . 2 3} \pm 0.01$ \\
$10^{-8} \mathrm{M}$ & $1.01 \pm 0.07$ \\
$10^{-9} \mathrm{M}$ & $0.97 \pm 0.05$ \\
$10^{-10} \mathrm{M}$ & $1.00 \pm 0.01$ \\
\hline
\end{tabular}

Mean chemotactic index \pm one standard error $(n=4)$, chemotactic index $=$ experimental density/control density, bold $\mathrm{P}<0.05$, underlined $=$ peak, asterisked $=$ threshold. 
Table 32. Chemotactic Behavior of isolate C0081 to TCE

$\begin{array}{ll}\text { MOTILITY } & 0.87 \pm 0.12 \\ 1 \mathrm{M} & \mathbf{2 . 0 5} \pm 0.36 \\ 10^{-1} \mathrm{M} & \mathbf{1 . 6 9} \pm 0.21 \\ 10^{-2} \mathrm{M} & \mathbf{1 . 9 3} \pm 0.54 \\ 10^{-3} \mathrm{M} & \mathbf{2 . 1 1} \pm 0.06 \\ 10^{-4} \mathrm{M} & 1.24 \pm 0.27 \\ 10^{-5} \mathrm{M} & \mathbf{2 . 0 7} \pm 0.14 \\ 10^{-6} \mathrm{M} & \mathbf{1 . 2 9} \pm 0.17 \\ 10^{-7} \mathrm{M} & 0.96 \pm 0.15 \\ 10^{-8} \mathrm{M} & \mathbf{1 . 2 9} \pm 0.12 \\ 10^{-9} \mathrm{M} & \mathbf{1 . 3 6} \pm 0.12 \\ 10^{-10} \mathrm{M} & \mathbf{1 . 4 0 *} \pm 0.09\end{array}$

Mean chemotactic index \pm one standard error $(n=4)$, chemotactic index $=$ experimental density/control density, bold $\mathrm{P}<0.05$, underlined $=$ peak, asterisked $=$ threshold. 
Table 33. Chemotactic Behavior of isolate CO128 to TCE

CONCENTRATION

MOTILITY

$1 \mathrm{M}$

$10^{-1} \mathrm{M}$

$10^{-2} \mathrm{M}$

$10^{-3} \mathrm{M}$

$10^{-4} \mathrm{M}$

$10^{-5} \mathrm{M}$

$10^{-6} \mathrm{M}$

$10^{-7} \mathrm{M}$

$10^{-8} \mathrm{M}$

$10^{-9} \mathrm{M}$

10-10 M
CHEMOTACTIC INDEX

$0.96 \pm 0.09$

$1.70^{*} \pm 0.08$

$1.14 \pm 0.08$

$1.13 \pm 0.09$

$1.16 \pm 0.03$

$1.10 \pm 0.04$

$1.10 \pm 0.08$

$0.93 \pm 0.03$

$1.08 \pm 0.02$

$0.95 \pm 0.05$

$0.77 \pm 0.02$

$0.74^{*} \pm 0.05$

Mean chemotactic index \pm one standard error $(n=4)$, chemotactic index $=$ experimental density/control density, bold $P<0.05$, underlined $=$ peak, asterisked $=$ threshold. 
$\underset{1}{N}$

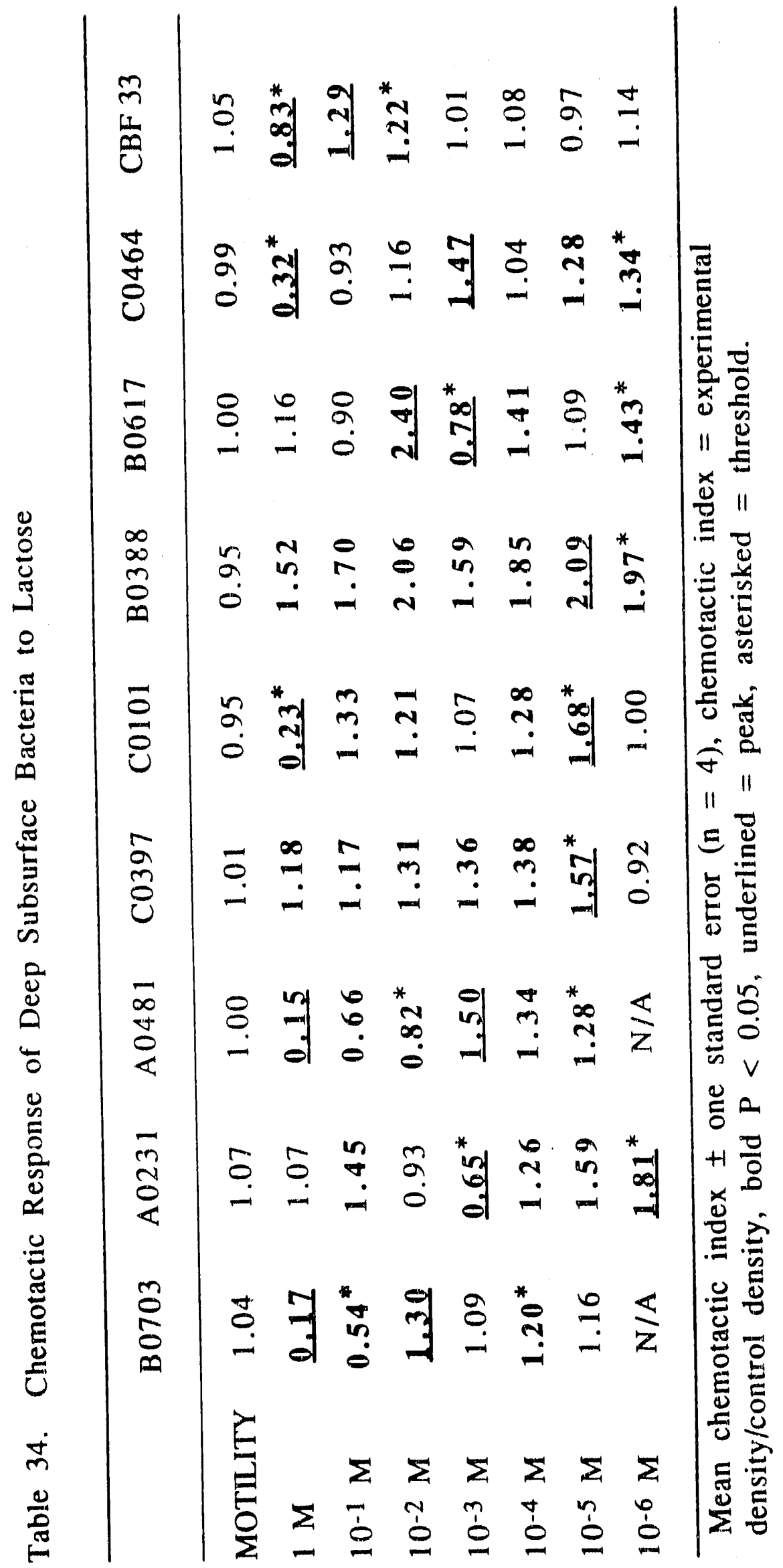


$N$

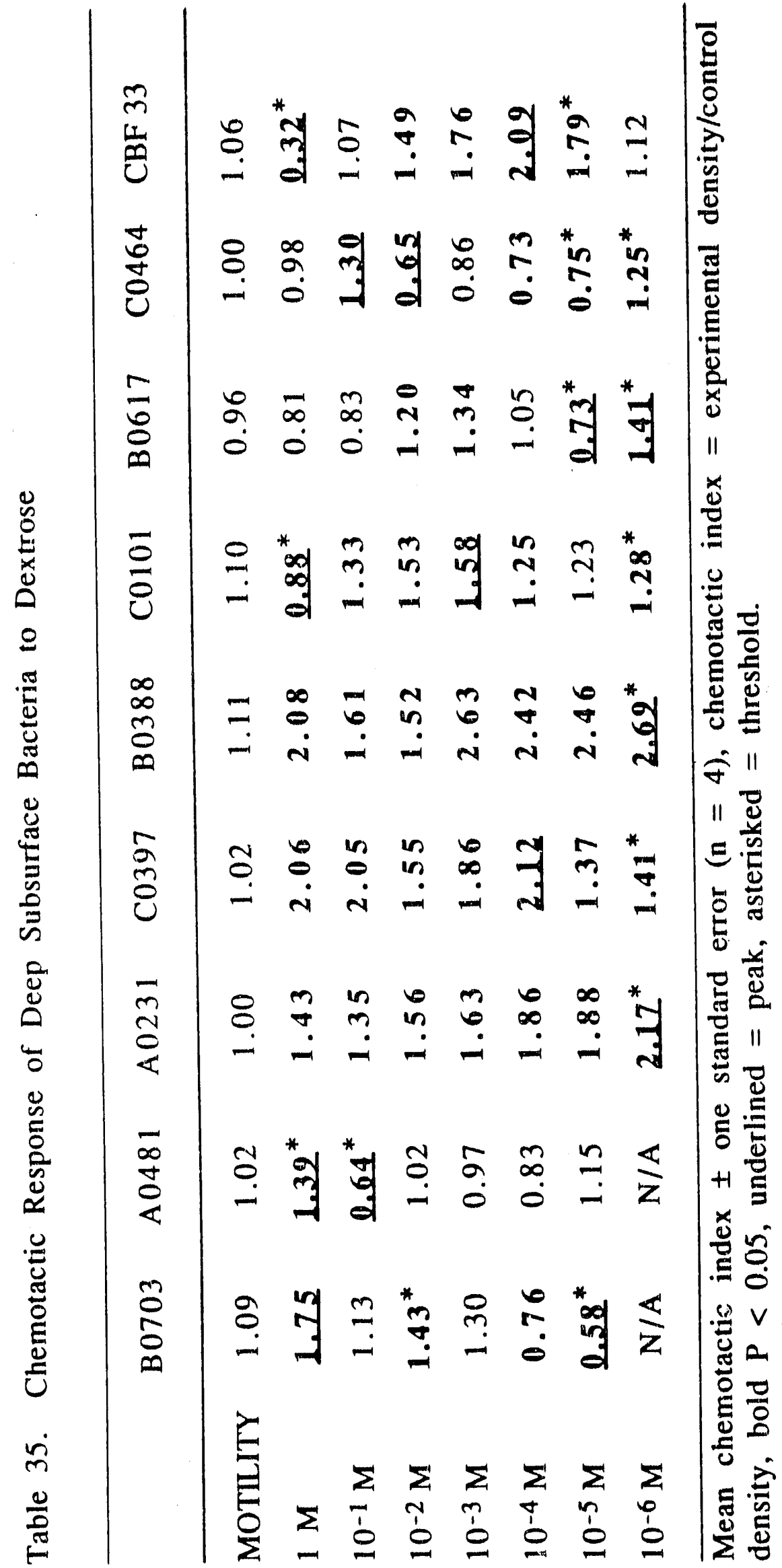




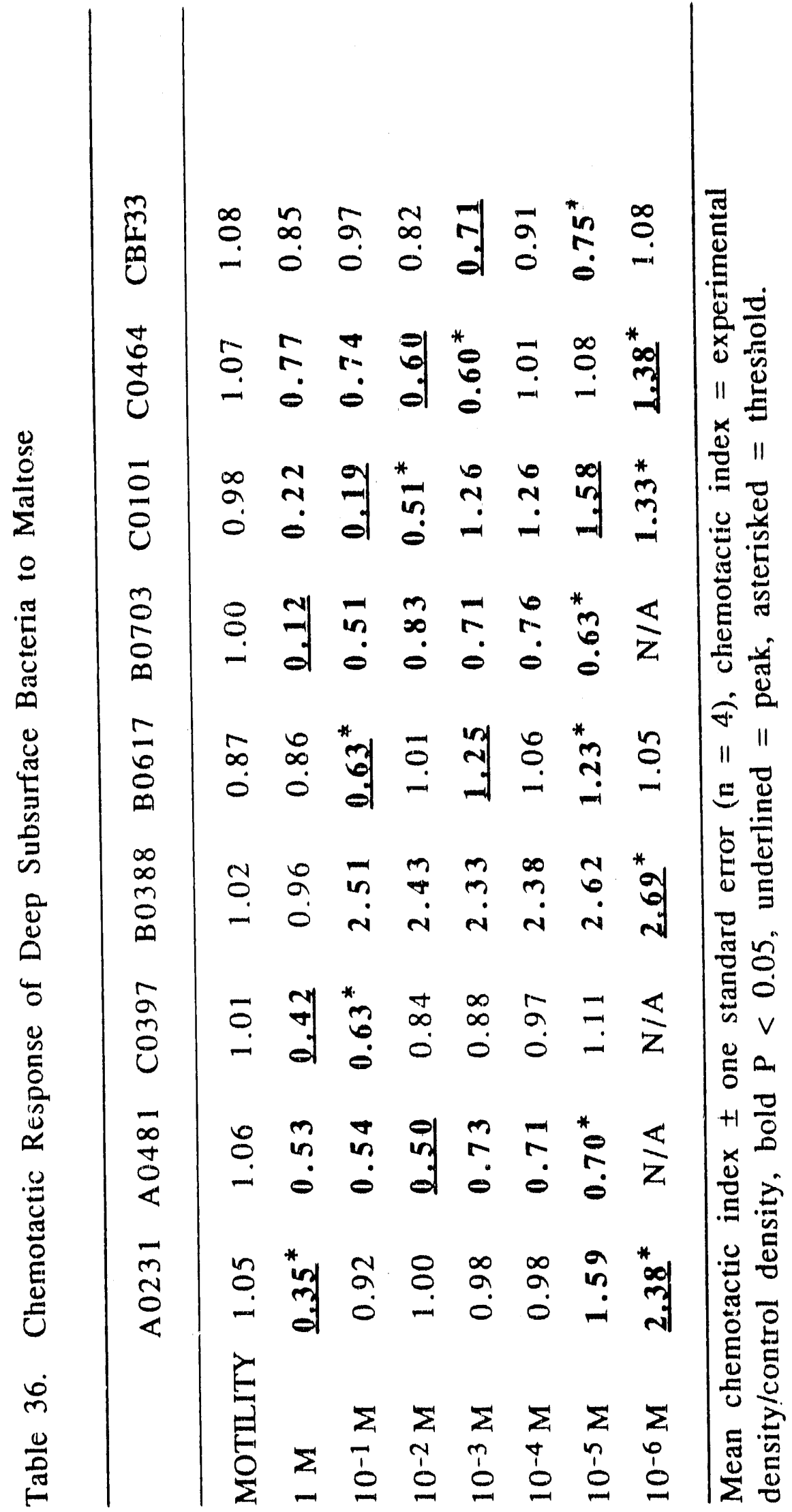


ฐ

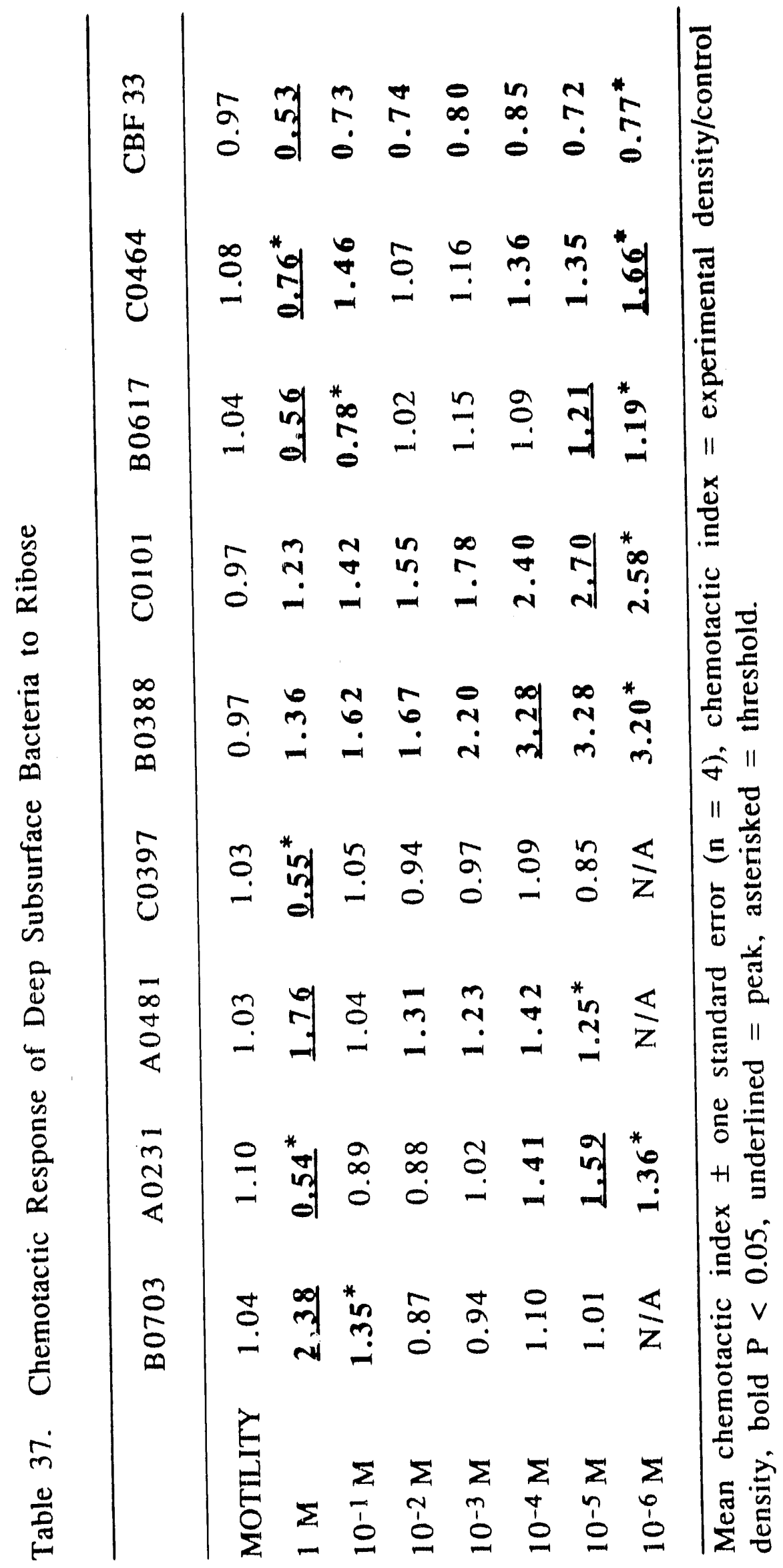


0
$m$

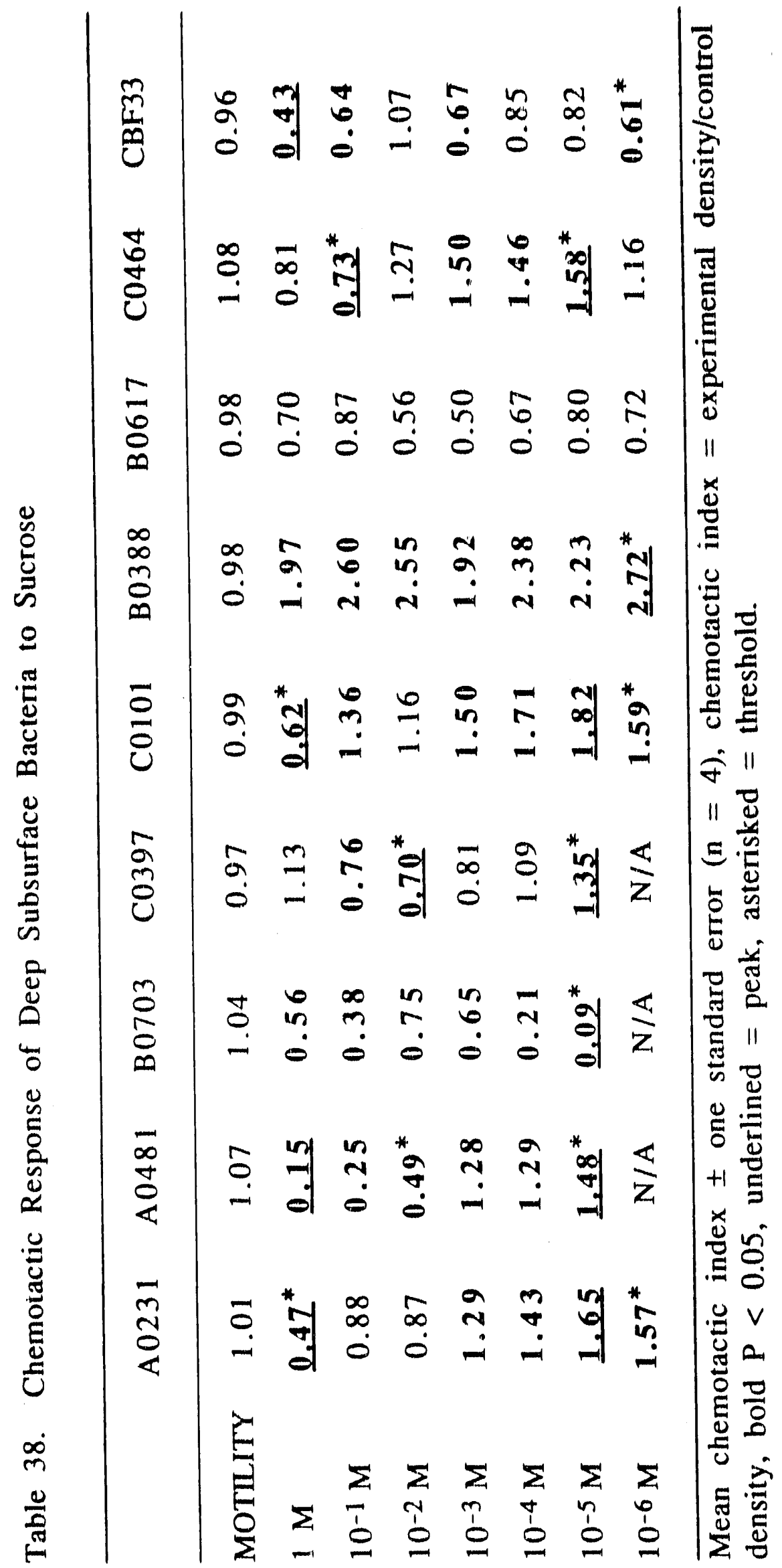


$\stackrel{N}{m}$

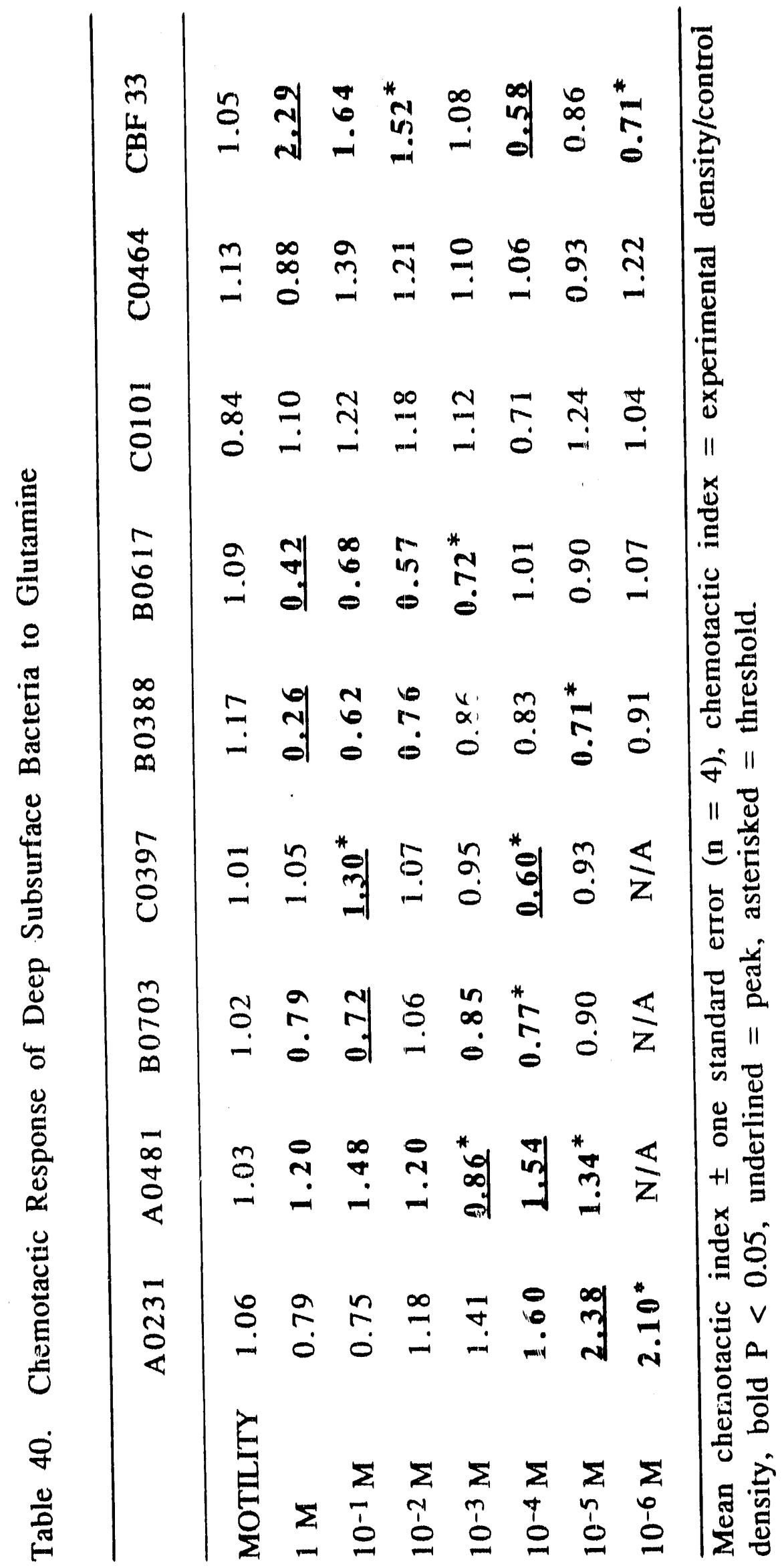


$\stackrel{m}{m}$

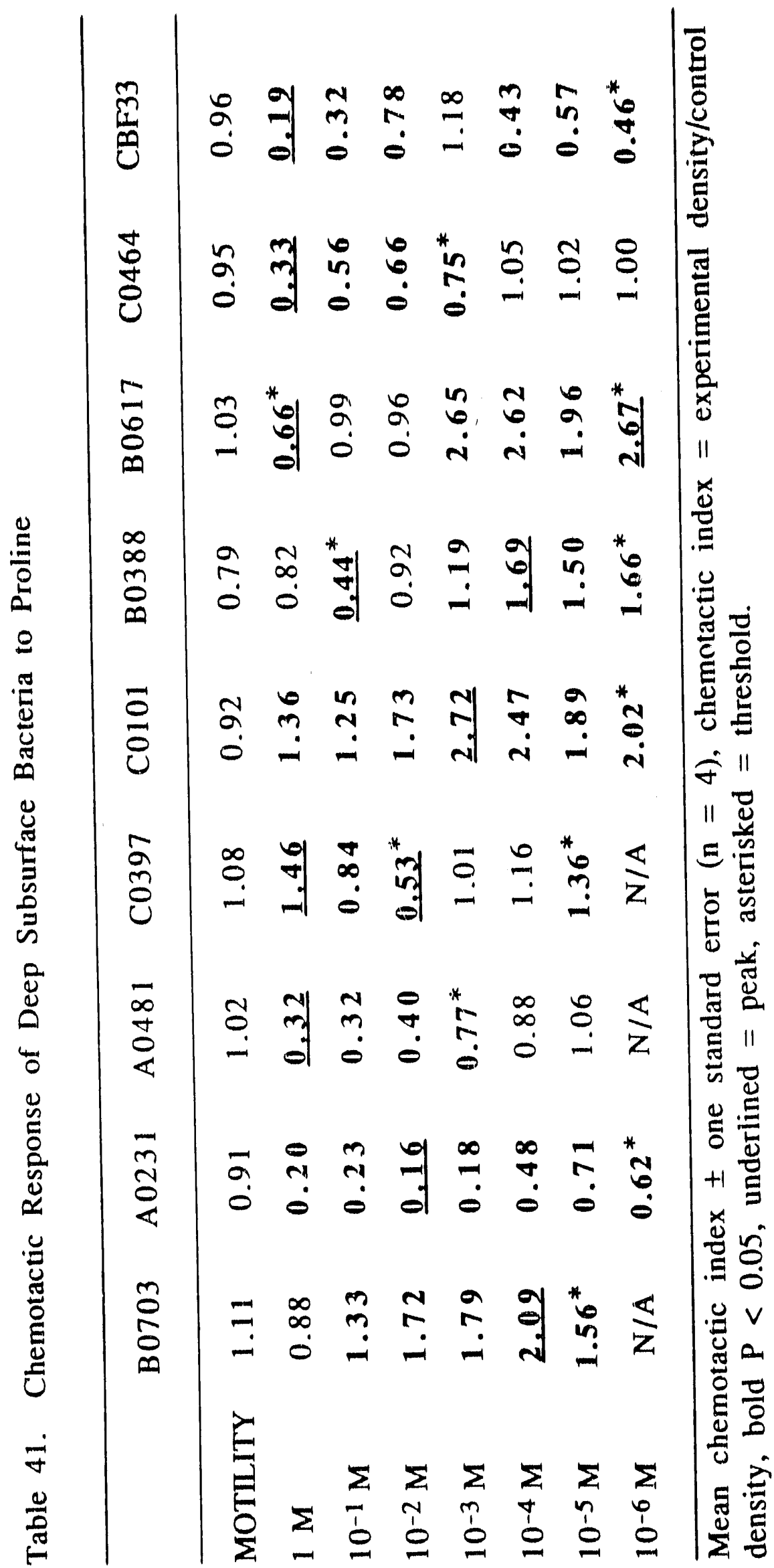


m

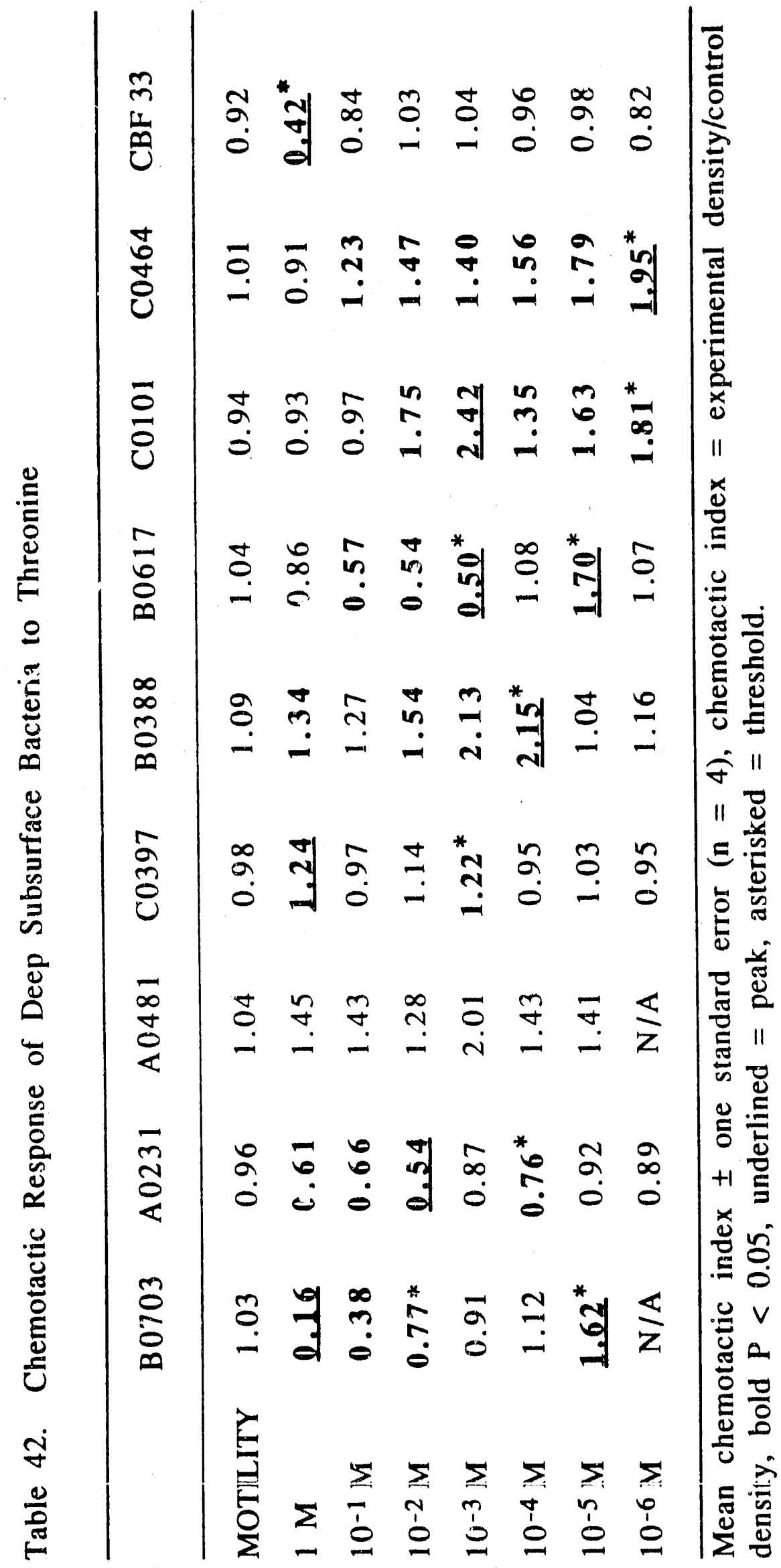


0
$n$

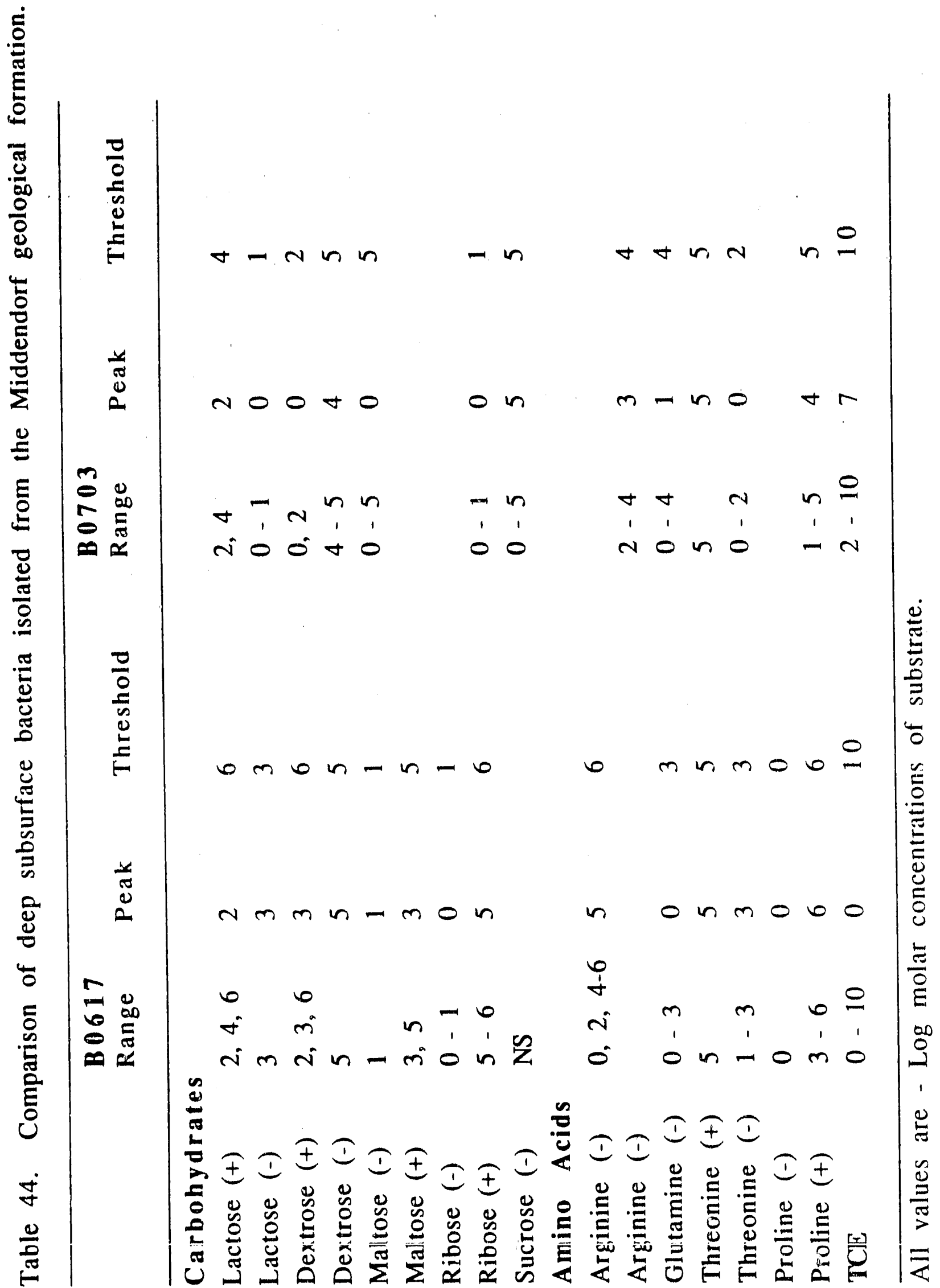




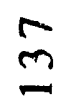

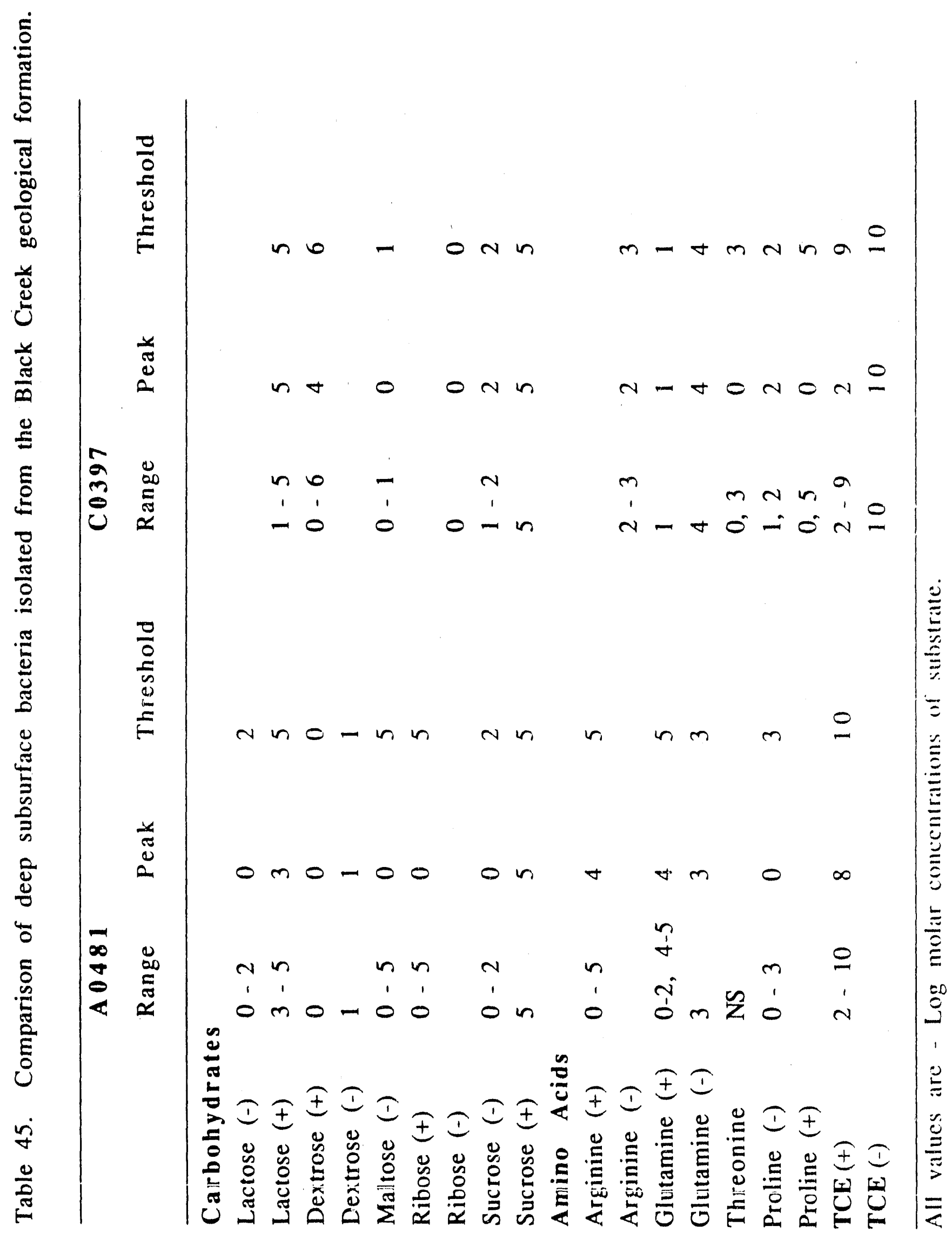


$\stackrel{\infty}{=}$

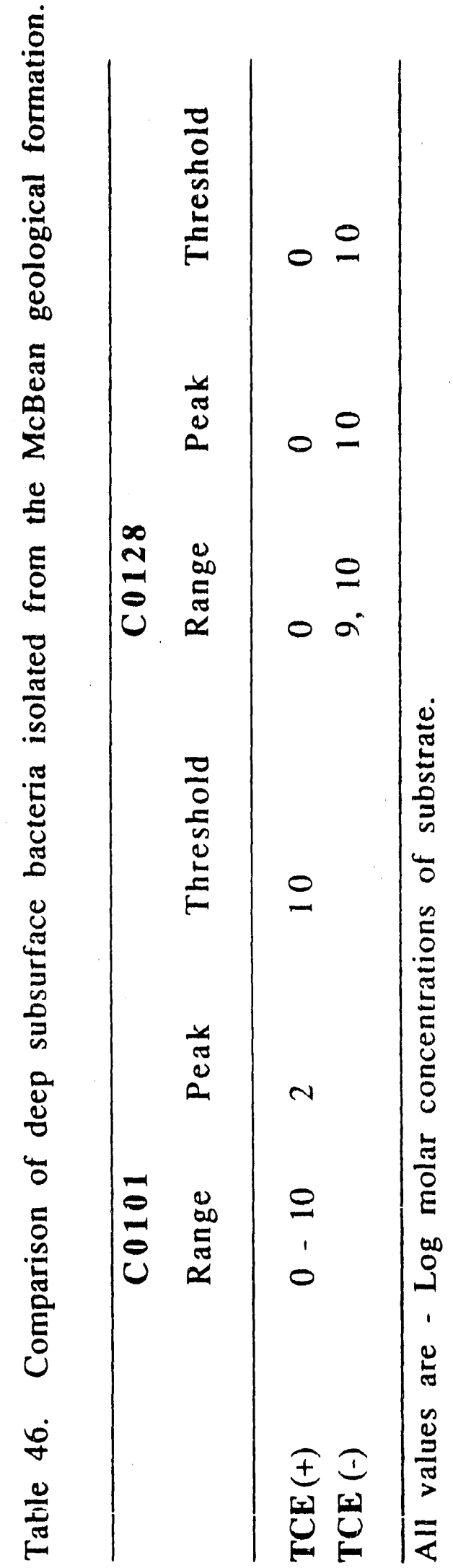


Table 47. Peak and threshold responses of isolate A0481 to carbohydrates, amino acids and trichloroethylene.

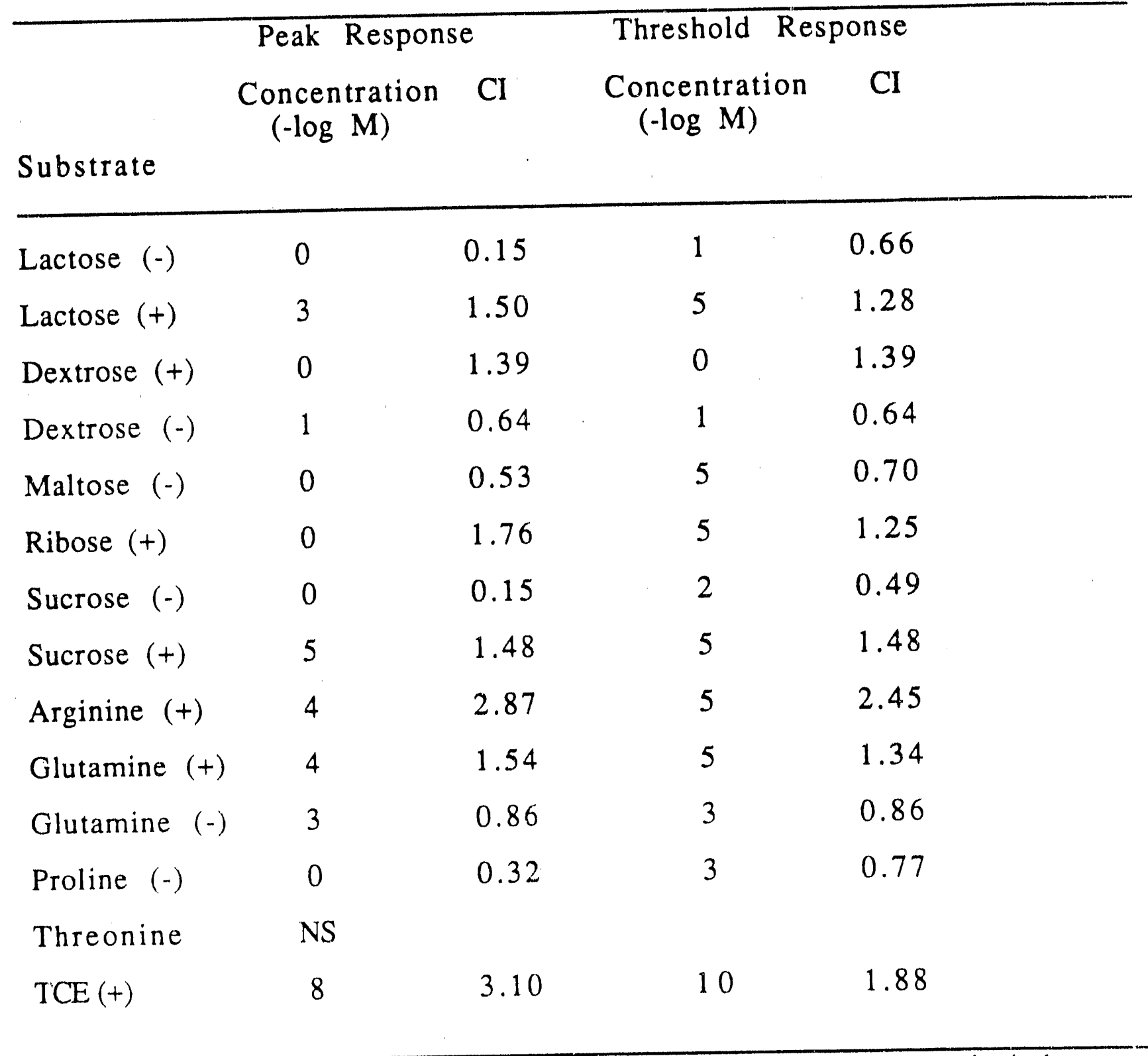

Mean chemotactic index \pm one standard error $(n=4)$, chemotactic index = experimental density/control density. 
Table 48. Peak and threshold responses of isolate A0231 to carbohydrates, amino acids and trichloroethylene.

\begin{tabular}{|c|c|c|c|c|}
\hline \multirow{2}{*}{ Substrate } & \multicolumn{2}{|c|}{ Peak Response } & \multicolumn{2}{|c|}{ Threshold Response } \\
\hline & $\begin{array}{l}\text { Concentration } \\
(-\log M)\end{array}$ & $\mathrm{CI}$ & $\begin{array}{l}\text { Concentration } \\
(-\log M)\end{array}$ & $\mathrm{CI}$ \\
\hline Lactose $(+)$ & 6 & 1.81 & 6 & 1.81 \\
\hline Lactose $(-)$ & 3 & 0.65 & 3 & 0.65 \\
\hline Dextrose $(+)$ & 6 & 2.17 & 6 & 2.17 \\
\hline Maltose (-) & 1 & 0.35 & 1 & 0.35 \\
\hline Maltose (+) & 6 & 2.38 & 6 & 2.38 \\
\hline Ribose (-) & 1 & 0.54 & 1 & 0.54 \\
\hline Ribose (+) & 5 & 1.59 & 6 & 1.36 \\
\hline Sucrose (-) & 1 & 0.47 & 1 & 0.47 \\
\hline Sucrose $(t)$ & 5 & 1.65 & 6 & 1.57 \\
\hline Arginine (-) & 1 & 0.69 & 2 & 0.74 \\
\hline Arginine $(+)$ & 4 & 1.14 & 4 & 1.14 \\
\hline Glutamine $(+)$ & 5 & 2.38 & 6 & 2.10 \\
\hline Proline (-) & 2 & 0.16 & 6 & 0.62 \\
\hline Threonine (-) & 2 & 0.54 & 4 & 0.76 \\
\hline $\operatorname{TCE}(+)$ & 6 & 2.95 & 10 & 2.21 \\
\hline
\end{tabular}

Mean chemotactic index \pm one standard error $(n=4)$, chemotactic index $=$ experimental density/control density. 
Table 49. Peak and threshold responses of isolate B0388 to carbohydrates, amino acids and trichloroethylene.

\begin{tabular}{|c|c|c|c|c|}
\hline \multirow{2}{*}{ Substrate } & \multicolumn{2}{|l|}{ Peak Response } & \multicolumn{2}{|c|}{ Threshold Response } \\
\hline & $\begin{array}{c}\text { Concentration } \\
(-\log M)\end{array}$ & $\mathrm{CI}$ & $\begin{array}{l}\text { Concentration } \\
(-\log M)\end{array}$ & $\mathrm{CI}$ \\
\hline Lactose $(+)$ & 5 & 2.09 & 6 & 1.97 \\
\hline Dextrose $(+)$ & 6 & 2.69 & 6 & 2.69 \\
\hline Maltose (t) & 6 & 2.69 & 6 & 2.69 \\
\hline Ribose (+) & 4 & 3.28 & 6 & 3.20 \\
\hline Sucrose $(+)$ & 6 & 2.72 & 6 & 2.72 \\
\hline Arginine $(+)$ & 6 & 1.74 & 6 & 1.74 \\
\hline Arginine (-) & 0 & 0.69 & 0 & 0.69 \\
\hline Glutamine (-) & 0 & 0.26 & 5 & 0.71 \\
\hline Proline $(+)$ & 0 & 1.69 & 6 & 1.66 \\
\hline Proline (-) & 1 & 0.44 & 1 & 0.44 \\
\hline Threonine $(+)$ & 4 & 2.15 & 4 & 2.15 \\
\hline $\operatorname{TCE}(+)$ & 1 & 2.70 & 10 & 2.17 \\
\hline
\end{tabular}


Table 50. Peak and threshold responses of isolate B0703 to carbohydrates, amino acids and trichloroethylene.

\begin{tabular}{ccc}
\hline Peak Response & Threshold Response \\
$\begin{array}{c}\text { Concentration } \\
(-\log M)\end{array}$ & $\begin{array}{c}\text { Concentration } \\
(-\log M)\end{array}$ & CI
\end{tabular}

Substrate

\begin{tabular}{|c|c|c|c|c|}
\hline Lactose (-) & 0 & 0.17 & 1 & 0.54 \\
\hline Lactose (+) & 2 & 1.30 & 4 & 1.20 \\
\hline Dextrose $(+)$ & 0 & 1.75 & 2 & 1.43 \\
\hline Dexirose $(-)$ & 5 & 0.58 & 5 & 0.58 \\
\hline Maltose (-) & 0 & 0.12 & 5 & 0.63 \\
\hline Ribose (+) & 0 & 2.38 & 1 & 1.35 \\
\hline Sucrose (-) & 5 & 0.09 & 5 & 0.09 \\
\hline Arginine $(+)$ & 3 & 1.43 & 4 & 1.23 \\
\hline Glutamine (-) & 1 & 0.72 & 4 & 0.77 \\
\hline Proline $(+)$ & 4 & 2.09 & 5 & 1.56 \\
\hline Threonine (-) & 0 & 0.16 & 2 & 0.77 \\
\hline Threonine $(+)$ & 5 & 1.62 & 5 & 1.62 \\
\hline $\operatorname{TCE}(+)$ & 7 & 3.47 & 10 & 1.83 \\
\hline
\end{tabular}


Table 51. Peak and threshold responses of isolate B0617 to carbohydrates, amino acids and trichloroethylene.

\begin{tabular}{|c|c|c|c|c|}
\hline & Peak Respons & & Threshold Re & onse \\
\hline & $\begin{array}{l}\text { Concentration } \\
(-\log M)\end{array}$ & $\mathrm{CI}$ & $\begin{array}{l}\text { Concentration } \\
(-\log M)\end{array}$ & $\mathrm{CI}$ \\
\hline Substrate & & & & \\
\hline Lactose $(+)$ & 2 & 2.40 & 6 & 1.43 \\
\hline Lactose (-) & 3 & 0.78 & 0 & 0.78 \\
\hline Dextrose $(+)$ & 6 & 1.41 & 6 & 1.41 \\
\hline Dextrose (-) & 5 & 0.73 & 5 & 0.73 \\
\hline Maltose $(+)$ & 3 & 1.25 & 5 & 1.23 \\
\hline Maltose (-) & 1 & 0.63 & 1 & 0.63 \\
\hline Ribose (+) & 5 & 1.21 & 6 & 1.19 \\
\hline Ribose (-) & 0 & 0.56 & 1 & 0.56 \\
\hline Sucrose & & NS & & \\
\hline Arginine (-) & 5 & .003 & 6 & 0.01 \\
\hline Glutamine (-) & 0 & 0.42 & 3 & 0.72 \\
\hline Proline (+) & 6 & 2.67 & 6 & 2.67 \\
\hline Proline (-) & 0 & 0.66 & 0 & 0.66 \\
\hline Threonine (-) & 3 & 0.50 & 3 & 0.50 \\
\hline Threonine (t) & 5 & 1.70 & 5 & 1.70 \\
\hline $\mathrm{TCE}(+)$ & 0 & 4.69 & 10 & 2.10 \\
\hline
\end{tabular}

Mean chemotactic index \pm one standard error $(n=4)$, chemotactic index = experimental density/control density 
Table 52. Peak and threshold responses of isolate C0397 to carbohydrates, amino acids and trichloroethylene.

\begin{tabular}{ccc}
\hline Peak Response & Threshold Response \\
Concentration & $\mathrm{Cl}$ & $\begin{array}{c}\text { Concentration } \\
(-\log \mathrm{M})\end{array}$
\end{tabular}

Substrate

$\begin{array}{lcccc}\text { Lactose (+) } & 5 & 1.57 & 5 & 1.57 \\ \text { Dextrose (+) } & 4 & 2.12 & 6 & 1.41 \\ \text { Maltose (-) } & 0 & 0.42 & 1 & 0.63 \\ \text { Ribose (-) } & 0 & 0.55 & 0 & 0.55 \\ \text { Sucrose (+) } & 5 & 1.35 & 5 & 1.35 \\ \text { Sucrose (-) } & 2 & 0.70 & 2 & 0.70 \\ \text { Arginine (-) } & 2 & 2.60 & 3 & 0.84 \\ \text { Glutamine (+) } & 1 & 1.30 & 1 & 1.30 \\ \text { Glutamine (-) } & 4 & 0.60 & 2 & 0.60 \\ \text { Proline (+) } & 0 & 1.46 & 5 & 1.36 \\ \text { Proline (-) } & 2 & 0.53 & 0 & 0.53 \\ \text { Threonine (+) } & 0 & 1.24 & 3 & 1.22 \\ \text { TCE (+) } & & & & \\ \text { TCE (-) } & 2 & 2.26 & 9 & 1.61 \\ & 10 & 0.79 & 0 & 0.79\end{array}$

Mean chemotactic index \pm one standard error $(n=4)$, chemotactic index $=$ experimental density/control density. 
Table 53. Peak and threshold responses of isolate C0101 to carbohydrates, amino acids and trichloroethylene.

\begin{tabular}{|c|c|c|c|c|}
\hline \multirow{2}{*}{ Substrate } & \multicolumn{2}{|c|}{ Peak Response } & \multicolumn{2}{|c|}{ Threshold Response } \\
\hline & $\begin{array}{l}\text { Concentration } \\
(-\log M)\end{array}$ & $\mathrm{CI}$ & $\begin{array}{l}\text { Concentration } \\
(-\log M)\end{array}$ & $\mathrm{CI}$ \\
\hline Lactose $(-)$ & 0 & 0.23 & 0 & 0.23 \\
\hline Lactose $(+)$ & 5 & 1.68 & 5 & 1.68 \\
\hline Dextrose $(t)$ & 3 & 1.58 & 3 & 1.58 \\
\hline Dextrose (-) & 0 & 0.88 & 0 & 0.88 \\
\hline Maltose (-) & 0 & 0.19 & 2 & 0.51 \\
\hline Maltose (+) & 5 & 1.58 & 6 & 1.33 \\
\hline Ribose $(+)$ & 5 & 2.70 & 6 & 2.58 \\
\hline Sucrose $(+)$ & 5 & 1.82 & 6 & 1.59 \\
\hline Sucrose (-) & 0 & 0.62 & 0 & 0.62 \\
\hline Arginine (+) & 5 & 1.45 & 6 & 1.16 \\
\hline Arginine (-) & 0 & 0.66 & 1 & 0.74 \\
\hline Glutamine & & NS & & \\
\hline Proline $(+)$ & 3 & 2.72 & 6 & 2.02 \\
\hline Threonine $(+)$ & 3 & 2.42 & 6 & 1.81 \\
\hline TCE $(+)$ & 2 & 3.11 & 10 & 2.14 \\
\hline
\end{tabular}


Table 54. Peak and threshold responses of isolate C0464 to carbohydrates, amino acids and trichloroethylene.

\begin{tabular}{|c|c|c|c|c|}
\hline & Peak Respon & & Threshold Res & onse \\
\hline & $\begin{array}{l}\text { Concentration } \\
(-\log M)\end{array}$ & $\mathrm{Cl}$ & $\begin{array}{l}\text { Concentration } \\
(-\log M)\end{array}$ & $\mathrm{CI}$ \\
\hline Substrate & & & & \\
\hline Lactose (-) & 0 & 0.32 & 0 & 0.32 \\
\hline Lactose $(t)$ & 3 & 1.47 & 6 & 1.34 \\
\hline Dextrose $(+)$ & 1 & 1.30 & 6 & 1.25 \\
\hline Dextrose $(-)$ & 2 & 0.65 & 5 & 0.75 \\
\hline Maltose (-) & 2 & 0.60 & 2 & 0.60 \\
\hline Maltose (t) & 5 & 1.38 & 6 & 1.38 \\
\hline Ribose (+) & 6 & 1.66 & 6 & 1.66 \\
\hline Ribose (-) & 0 & 0.76 & 0 & 0.76 \\
\hline Sucrose (-) & 1 & 0.73 & 1 & 0.73 \\
\hline Sucrose (+) & 5 & 1.58 & 5 & 1.58 \\
\hline Arginine $(+)$ & 5 & 1.46 & 6 & 1.34 \\
\hline Glutamine & NS & & & \\
\hline Proline (-) & 0 & 0.33 & 3 & 0.75 \\
\hline Threonine (+) & 6 & 1.95 & 6 & 1.95 \\
\hline TCE(-) & 1 & 3.40 & 9 & 1.61 \\
\hline
\end{tabular}

Mean chemotactic index \pm one standard error $(n=4)$, chemotactic index $=$ experimental density/control density. 
Table 55. Peak and threshold responses of isolate CBF33 to carbohydrates, amino acids and trichloroethylene.

\begin{tabular}{|c|c|c|c|c|}
\hline \multirow{2}{*}{ Substrate } & \multicolumn{2}{|c|}{ Peak Response } & \multicolumn{2}{|c|}{ Threshold Response } \\
\hline & $\begin{array}{l}\text { Concentration } \\
(-\log M)\end{array}$ & $\mathrm{CI}$ & $\begin{array}{l}\text { Concentration } \\
(-\log M)\end{array}$ & $\mathrm{CI}$ \\
\hline Lactose $(+)$ & 1 & 1.29 & 2 & 1.22 \\
\hline Lactose (-) & 0 & 0.83 & 0 & 0.83 \\
\hline Dextrose (-) & 0 & 0.32 & 0 & 0.32 \\
\hline Dextrose $(t)$ & 4 & 2.09 & 5 & 1.79 \\
\hline Maltose (-) & 3 & 0.71 & 5 & 0.75 \\
\hline Ribose (-) & 0 & 0.53 & 6 & 0.77 \\
\hline Sucrose $(-)$ & 0 & 0.43 & 6 & 0.61 \\
\hline Arginine (-) & 0 & 0.07 & 1 & 0.23 \\
\hline Arginine $(+)$ & 4 & 1.16 & 4 & 1.16 \\
\hline Glutamine $(+)$ & 0 & 2.29 & 2 & 1.52 \\
\hline Glutamine (-) & 4 & 0.58 & 6 & 0.71 \\
\hline Proline (-) & 0 & 0.19 & 6 & 0.46 \\
\hline Threonine (-) & 0 & 0.42 & 0 & 0.42 \\
\hline TCE (-) & 0 & 0.53 & 0 & 0.53 \\
\hline $\operatorname{TCE}(+)$ & 5 & 1.45 & 7 & 1.23 \\
\hline
\end{tabular}

Mean chemotactic index \pm one standard error $(n=4)$, chemotactic index $=$ experimental density/control density. 
Table 56. Peak and threshold responses of isolates C0081 and C0128 to trichloroethylene.

\begin{tabular}{llcccc}
\hline & \multicolumn{2}{c}{ Peak Response } & \multicolumn{2}{c}{ Threshold Response } \\
Concentration & CI & $\begin{array}{c}\text { Concentration } \\
(-\log M)\end{array}$ & CI & \\
Substrate & & & & & \\
\hline C0081 & TCE $(+)$ & 3 & 2.11 & 10 & 1.40 \\
C0128 & TCE $(+)$ & 0 & 1.70 & 1 & 1.70 \\
& TCE $(-)$ & 10 & 0.74 & 10 & 0.74
\end{tabular}

Mean chemotactic index \pm one standard error $(n=4)$, chemotactic index $=$ experimental density/control density. 
Table 57. Rates of movement of deep terrestrial subsurface bacteria in sediments.

ISOLATE $\begin{gathered}\text { Diffusion rate in } \\ \text { sediments } \\ (\mathrm{cm} / \mathrm{day})\end{gathered} \quad \begin{gathered}\text { Diffusion rates in } \\ \text { sediments exposed to TCE } \\ (\mathrm{cm} / \mathrm{day})\end{gathered}$

\begin{tabular}{lll}
$\mathrm{A} 0481$ & 60 & 90 \\
$\mathrm{~A} 0231$ & 2 & 2 \\
$\mathrm{~B} 0388$ & 90 & 180 \\
$\mathrm{~B} 0703$ & 90 & 120 \\
$\mathrm{~B} 0617$ & 90 & 120 \\
$\mathrm{C} 0397$ & 20 & 30 \\
$\mathrm{C} 0101$ & 20 & 30 \\
$\mathrm{C} 0464$ & 20 & 20 \\
$\mathrm{CBF} 33$ & 20 & 30 \\
$\mathrm{C} 0081$ & 30 & 36 \\
\hline
\end{tabular}




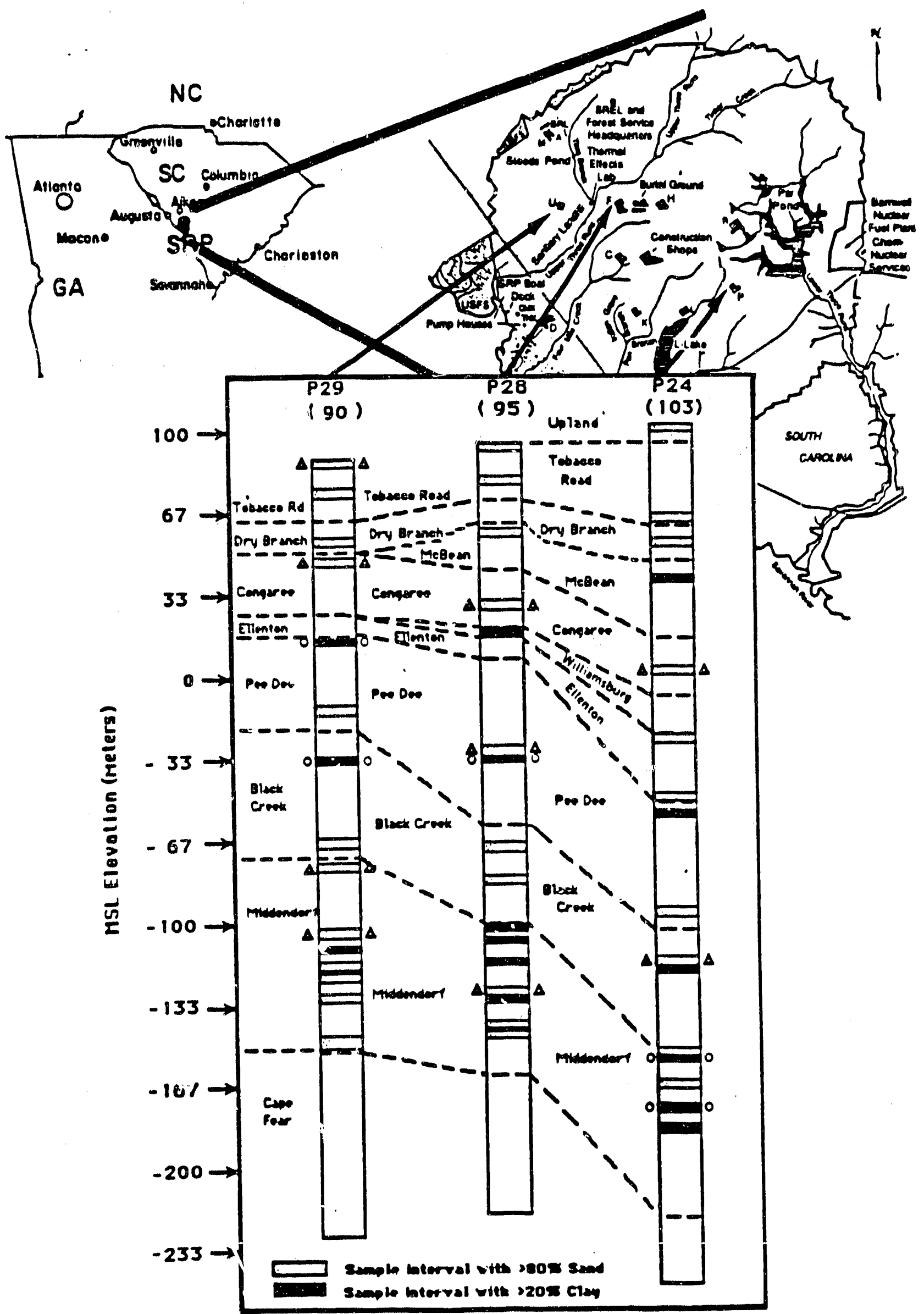

Figure 1. Map of the Savannah River Plant Aiken, S. C. 


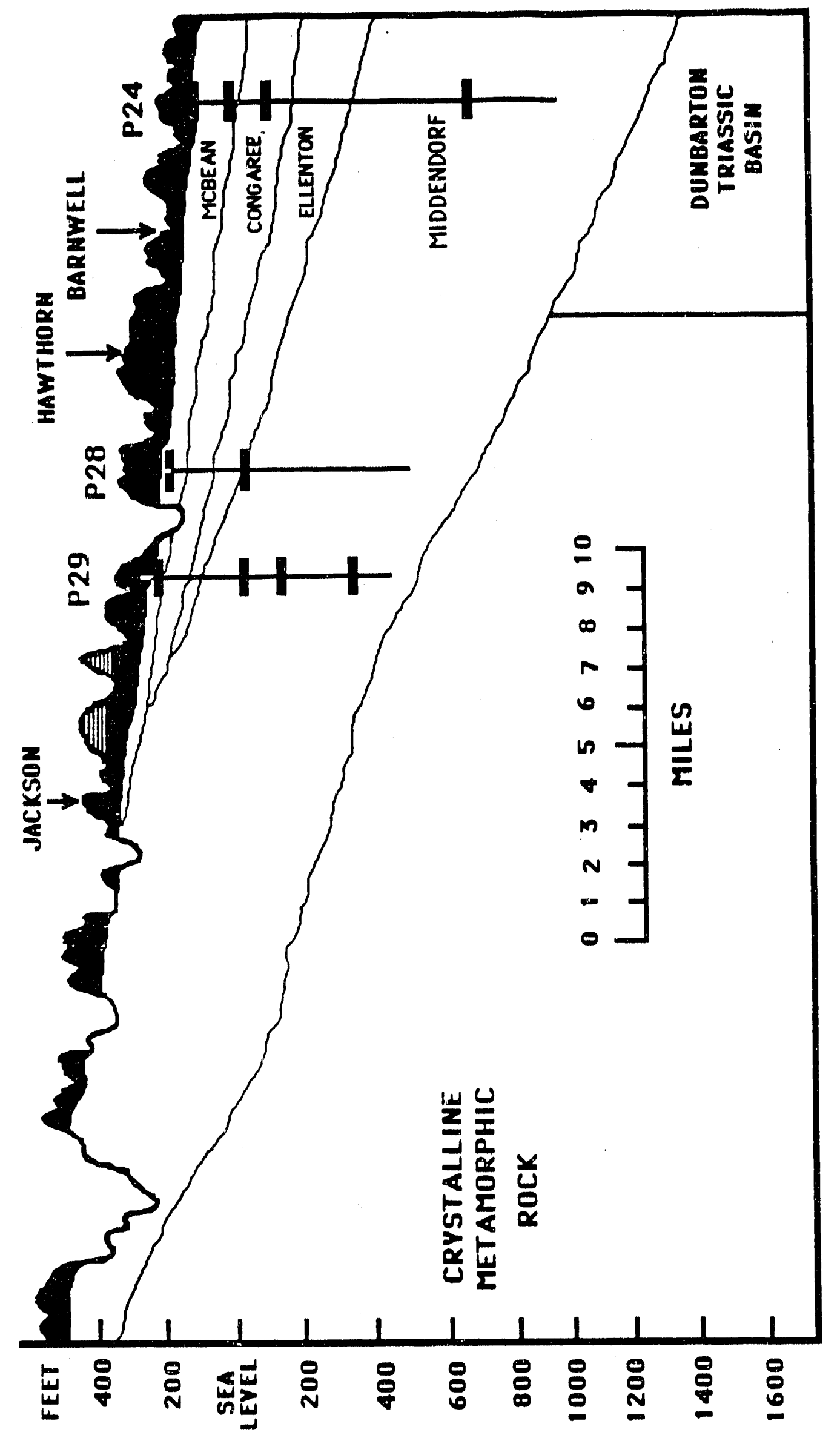

151 
Chemotaxis Chamber
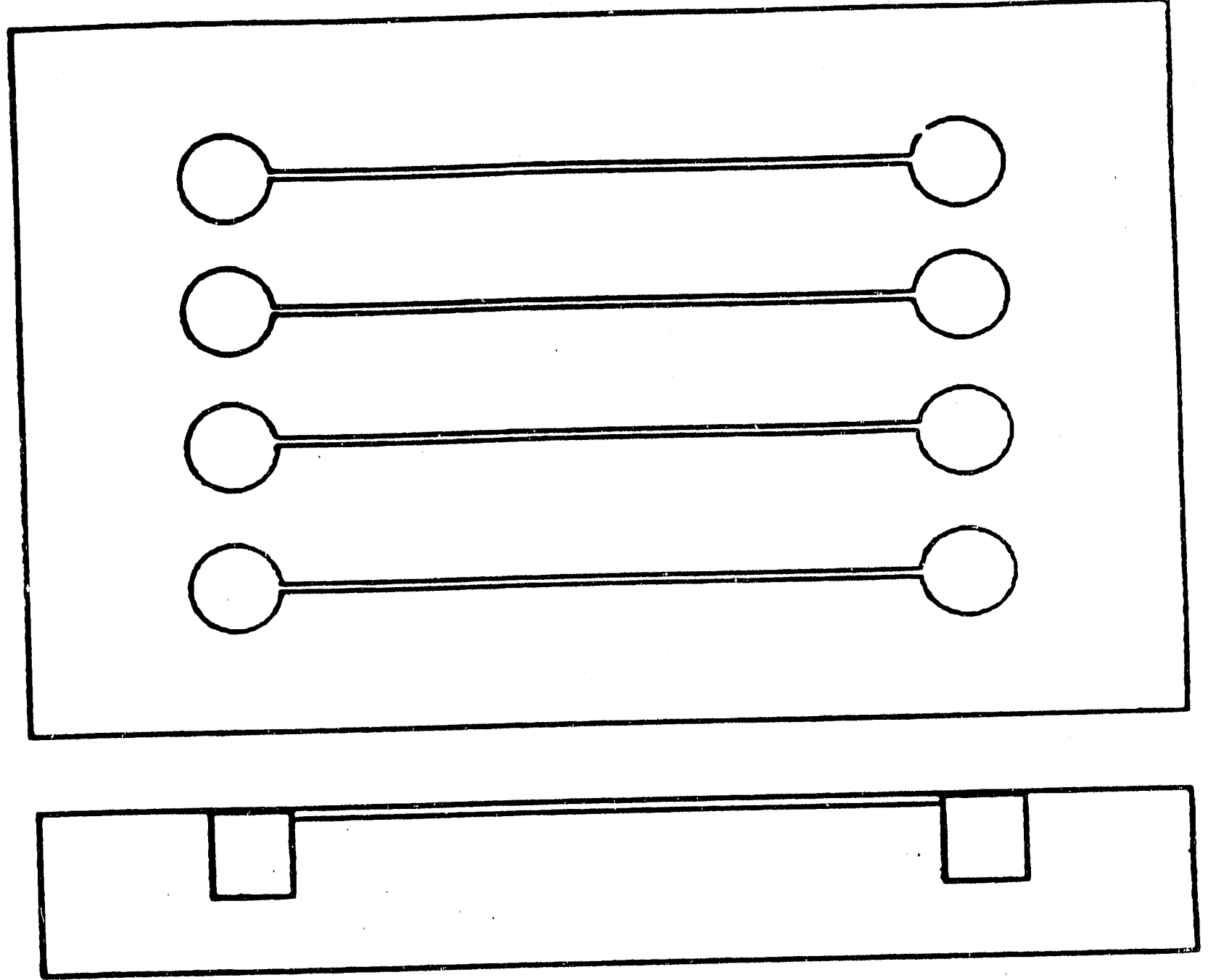

Palleroni. 1976

Figure 3. Chemotactic chamber (Palleroni, 1976): 


\section{Model}

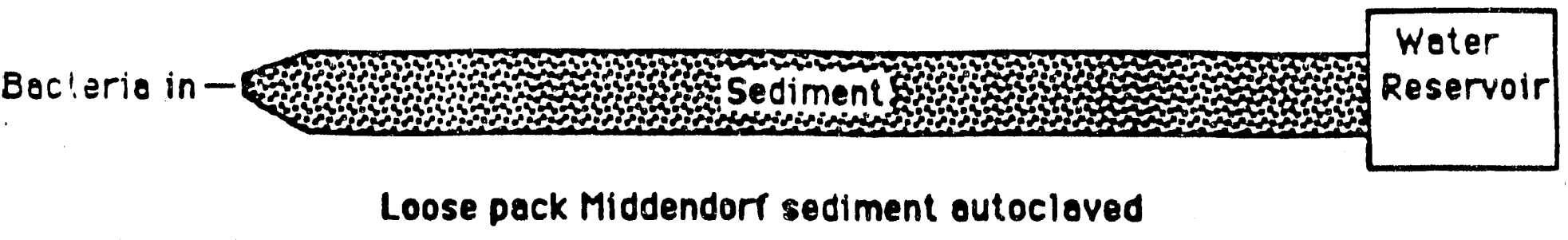

Figure 4. Chambers for bacterial mobility in sediments. 
$\stackrel{5}{5}$

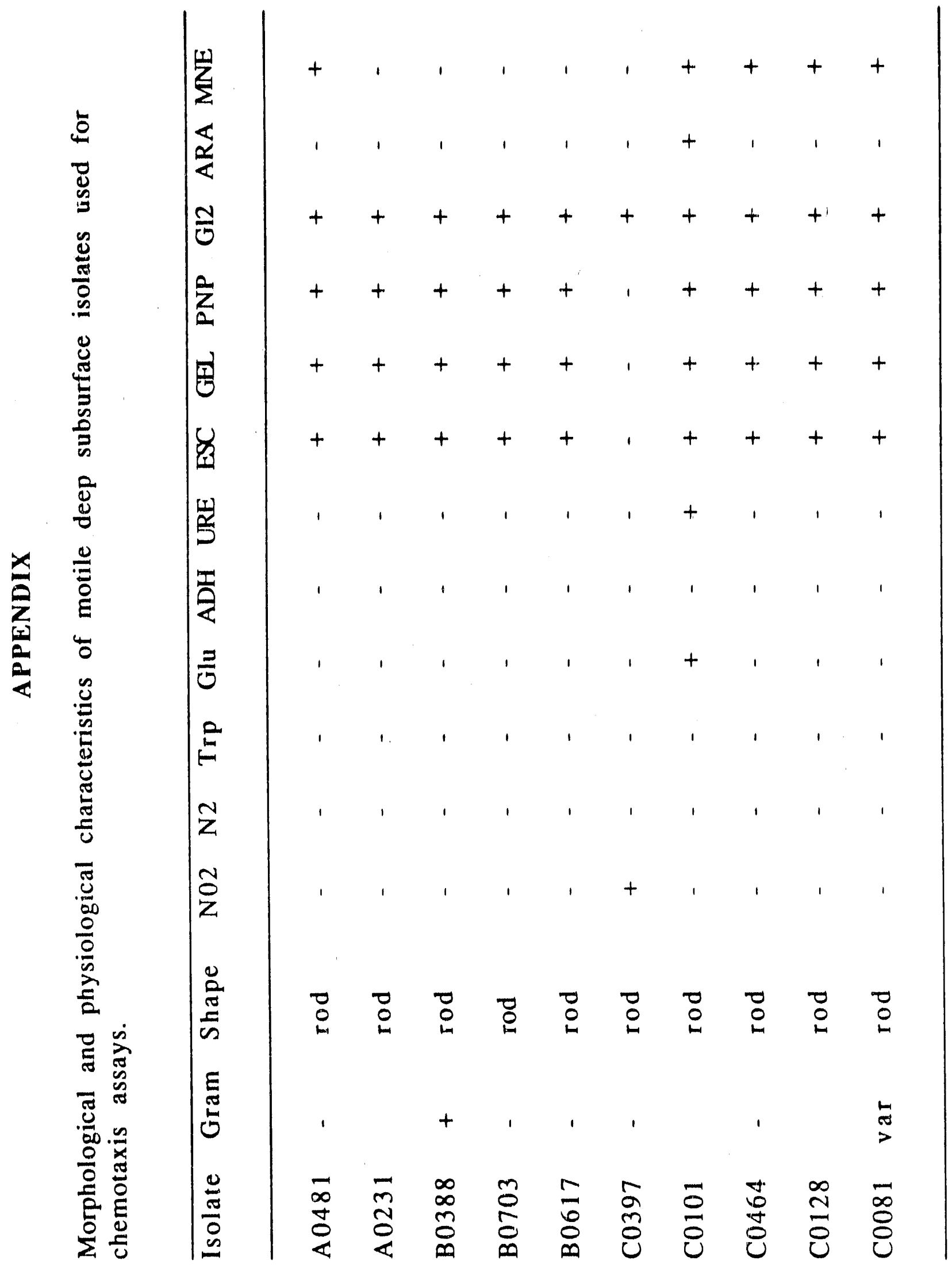


$\underline{n}$

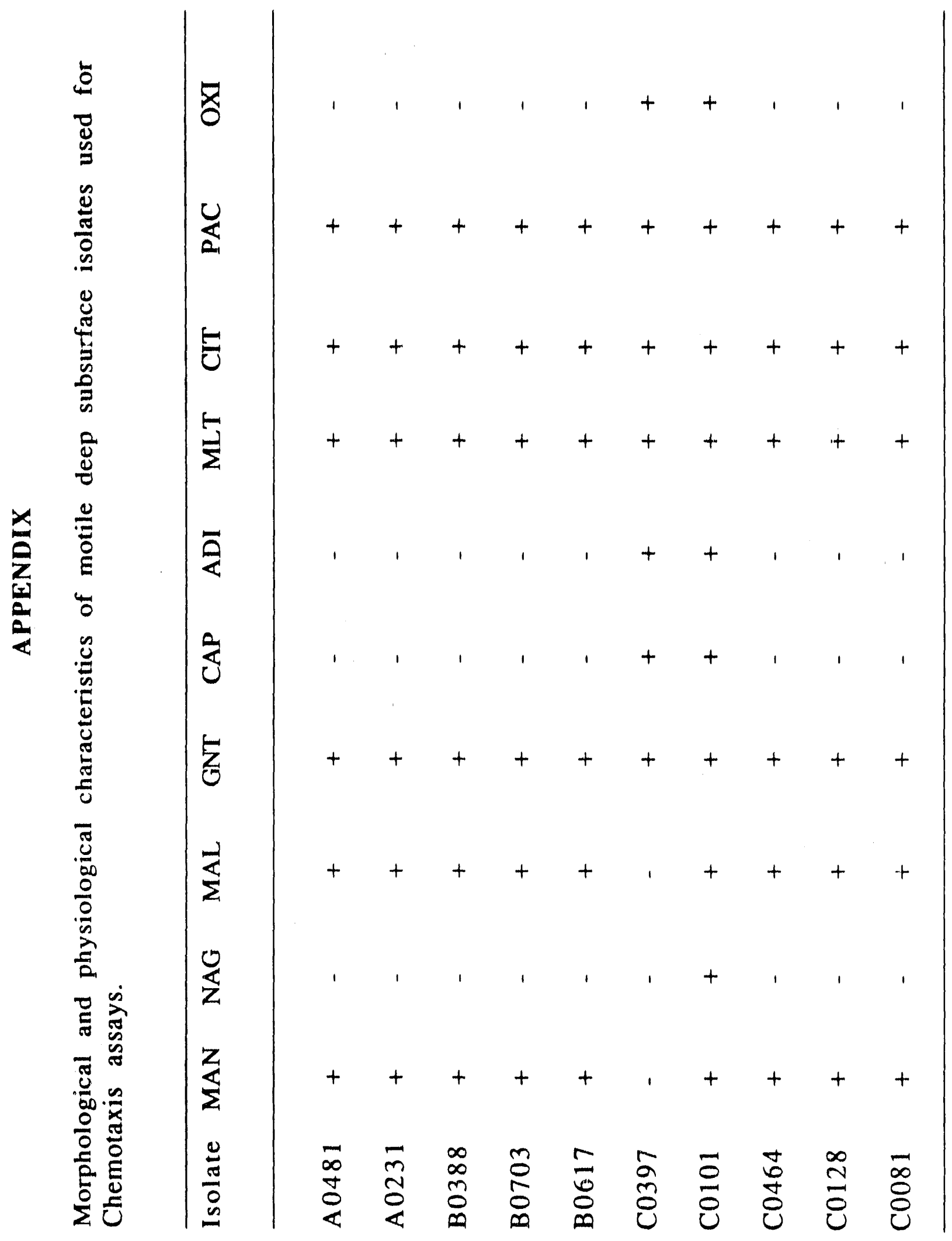


ISOLATE A0481

\begin{tabular}{llcc}
\hline SOURCE OF VARIANCE & DF & F & P \\
\hline LACTOSE & 6,21 & 56.05 & $<0.0005$ \\
DEXTROSE & 6,21 & 6.43 & $<0.001$ \\
MALTOSE & 6,21 & 20.70 & $<0.0005$ \\
RIBOSE & 6,21 & 17.48 & $<0.0005$ \\
SUCROSE & 6,21 & 51.27 & $<0.0005$ \\
THREONINE & 6,21 & 0.02 & $<0.25$ \\
GLUTAMINE & 6,21 & 12.24 & $<0.0005$ \\
PROLINE & 6,21 & 83.82 & $<0.0005$ \\
ARGININE (1) & 7,24 & 30.74 & $<0.0005$ \\
ARGININE (2) & 7,24 & 30.84 & $<0.0005$ \\
ARGININE (avg) & 7,24 & 74.67 & $<0.0005$ \\
TCE & 9,30 & 70.08 & $<0.0005$ \\
\hline
\end{tabular}


ISOLATE A0231

\begin{tabular}{llcc}
\hline SOURCE OF VARIANCE & DF & F & P \\
\hline LACTOSE & 7,24 & 31.05 & $<0.0005$ \\
DEXTROSE & 7,24 & 11.03 & $<0.0005$ \\
MALTOSE & 7,24 & 48.42 & $<0.0005$ \\
RIBOSE & 7,24 & 33.79 & $<0.0005$ \\
SUCROSE & 7,24 & 66.34 & $<0.0005$ \\
GLUTAMINE & 7,24 & 16.46 & $<0.0005$ \\
THREONINE & 7,24 & 5.59 & $<0.001$ \\
PROLINE & 7,24 & 34.89 & $<0.0005$ \\
ARGININE & 7,24 & 2.58 & $<0.05$ \\
TCE & 9,30 & 32.82 & $<0.0005$ \\
\hline
\end{tabular}


ISOLATE B0388

\begin{tabular}{llcc}
\hline SOURCE OF VARIANCE & DF & F & P \\
\hline LACTOSE & 7,24 & 13.42 & $<0.0005$ \\
DIXTROSE & 7,24 & 37.76 & $<0.0005$ \\
MALTOSE & 7,24 & 20.06 & $<0.0005$ \\
RIBOSE & 7,24 & 31.59 & $<0.0005$ \\
SUCROSE & 7,24 & 28.25 & $<0.0005$ \\
GLUTAMINE & 7,24 & 11.50 & $<0.0005$ \\
THREONINE & 7,24 & 21.32 & $<0.0005$ \\
PROLINE & 7,24 & 26.65 & $<0.0005$ \\
ARGININE & 7,24 & 13.41 & $<0.0005$ \\
TCE & 11,36 & 4.39 & $<0.0005$ \\
\hline
\end{tabular}


ISOLATE B0703

\begin{tabular}{llcc}
\hline SOURCE OF VARIANCE & DF & F & P \\
\hline LACTOSE & 6,21 & 94.34 & $<0.0005$ \\
DEXTROSE & 6,21 & 6.29 & $<0.001$ \\
MALTOSE & 6,21 & 19.47 & $<0.0005$ \\
RIBOSE & 6,21 & 112.42 & $<0.0005$ \\
SUCROSE & 6,21 & 81.40 & $<0.0005$ \\
GLUTAMINE & 6,21 & 6.89 & $<0.0005$ \\
THREONINE & 6,21 & 40.92 & $<0.0005$ \\
PROLINE & 6,21 & 4.21 & $<0.01$ \\
ARGININE & 6,21 & 6.20 & $<0.001$ \\
TCE(1) & 9,30 & 63.57 & $<0.0005$ \\
TCE(2) & 9,30 & 77.36 & $<0.0005$ \\
TCE (avg) & 9,30 & 140.81 & $<0.0005$ \\
\hline
\end{tabular}


ISOLATE B0617

\begin{tabular}{llcc}
\hline SOURCE OF VARIANCE & DF & F & P \\
\hline LACTOSE & 7,24 & 42.68 & $<0.0005$ \\
DEXTROSE & 7,24 & 12.38 & $<0.0005$ \\
MALTOSE & 7,24 & 4.60 & $<0.0005$ \\
RIBOSE & 7,24 & 11.62 & $<0.0005$ \\
SUCROSE & 7,24 & 2.25 & $<0.10$ \\
GLUTAMINE & 7,24 & 10.47 & $<0.0005$ \\
THREONINE & 7,24 & 23.43 & $<0.0005$ \\
PROLINE & 7,24 & 45.48 & $<0.0005$ \\
ARGININE & 7,24 & 16.55 & $<0.0005$ \\
TCE & 11,36 & 15.90 & $<0.0005$ \\
\hline
\end{tabular}


ISOLATE C0397

\begin{tabular}{|c|c|c|c|}
\hline SOURCE OF VARIANCE & DF & $\mathbf{F}$ & $\mathbf{P}$ \\
\hline $\operatorname{LACTOSE}_{(1)}$ & 7,24 & 11.74 & $<0.0005$ \\
\hline $\operatorname{LACTOSE}_{(\overline{2})}$ & 7,24 & 22.34 & $<0.0005$ \\
\hline $\operatorname{LACTOSE}_{(3)}$ & 7,24 & 78.11 & $<0.0005$ \\
\hline LACTOSE $_{(\text {avg })}$ & 7,24 & 63.21 & $<0.0005$ \\
\hline DEXTROSE & 7,24 & 18.22 & $<0.0005$ \\
\hline MALTOSE & 7,24 & 15.29 & $<0.0005$ \\
\hline RIBOSE & 7,24 & 4.74 & $<0.0005$ \\
\hline SUCROSE & 7,24 & 3.44 & $<0.0005$ \\
\hline GLUTAMINE & 7,24 & 6.08 & $<0.0005$ \\
\hline THREONINE & 7,24 & 21.32 & $<0.0005$ \\
\hline PROLINE & 7,24 & 26.65 & $<0.0005$ \\
\hline ARGININE & 7,24 & 8.55 & $<0.0005$ \\
\hline TCE & 9,30 & 16.38 & $<0.0005$ \\
\hline
\end{tabular}


ISOLATE C0101

\begin{tabular}{llcc}
\hline SOURCE OF VARIANCE & DF & F & P \\
\hline LACTOSE & 7,24 & 39.62 & $<0.0005$ \\
DEXIROSE & 7,24 & 5.19 & $<0.0025$ \\
MALTOSE & 7,24 & 51.82 & $<0.0005$ \\
RIBOSE & 7,24 & 44.68 & $<0.0005$ \\
SUCROSE & 7,24 & 13.97 & $<0.0005$ \\
GLUTAMINE & 7,24 & 1.78 & $<0.25$ \\
THREONINE & 7,24 & 28.70 & $<0.0005$ \\
PROLINE & 7,24 & 12.32 & $<0.0005$ \\
ARGININE & 7,24 & 8.38 & $<0.0005$ \\
TCE & 11,36 & 22.59 & $<0.0005$ \\
\hline
\end{tabular}


ISOLATE C0464

\begin{tabular}{llcc}
\hline SOURCE OF VARIANCE & DF & F & P \\
\hline LACTOSE & 7,24 & 13.82 & $<0.0005$ \\
DEXTROSE & 7,24 & 5.99 & $<0.0005$ \\
MALTOSE & 7,24 & 15.53 & $<0.0005$ \\
RIBOSE & 7,24 & 7.66 & $<0.0005$ \\
SUCROSE & 7,24 & 4.69 & $<0.0005$ \\
GLUTAMINE & 7,24 & 2.00 & $<0.10$ \\
THREONINE & 7,24 & 12.62 & $<0.0005$ \\
PROLINE & 7,24 & 14.47 & $<0.0005$ \\
ARGININE & 7,24 & 4.79 & $<0.0005$ \\
TCE & 11,36 & 36.48 & $<0.0005$ \\
\hline
\end{tabular}


ISOLATE CBF 33

\begin{tabular}{llll}
\hline SOURCE OF VARIANCE & DF & F & P \\
\hline LACTOSE & 7,24 & 3.40 & $<0.025$ \\
DEXTROSE & 7,24 & 31.29 & $<0.0005$ \\
MALTOSE & 7,24 & 2.45 & $<0.05$ \\
RIBOSE & 7,24 & 11.47 & $<0.0005$ \\
SUCROSE & 7,24 & 3.97 & $<0.01$ \\
GLUTAMINE & 7,24 & 25.04 & $<0.0005$ \\
THREONINE & 7,24 & 11.61 & $<0.0005$ \\
PROLINE & 7,24 & 26.80 & $<0.0005$ \\
ARGININE & 7,24 & 94.78 & $<0.0005$ \\
TCE & 11,36 & 16.67 & $<0.0005$ \\
\hline
\end{tabular}


ISOLATE C0128

\begin{tabular}{cccc}
\hline SOURCE OF VARIANCE & DF & F & P \\
\hline TCE & 11,36 & 15.92 & $<0.0005$ \\
\hline
\end{tabular}

ISOLATE C0081

\begin{tabular}{cccc}
\hline SOURCE OF VARIANCE & DF & F & P \\
\hline TCE & 11,36 & 3.43 & $<0.005$ \\
\hline
\end{tabular}



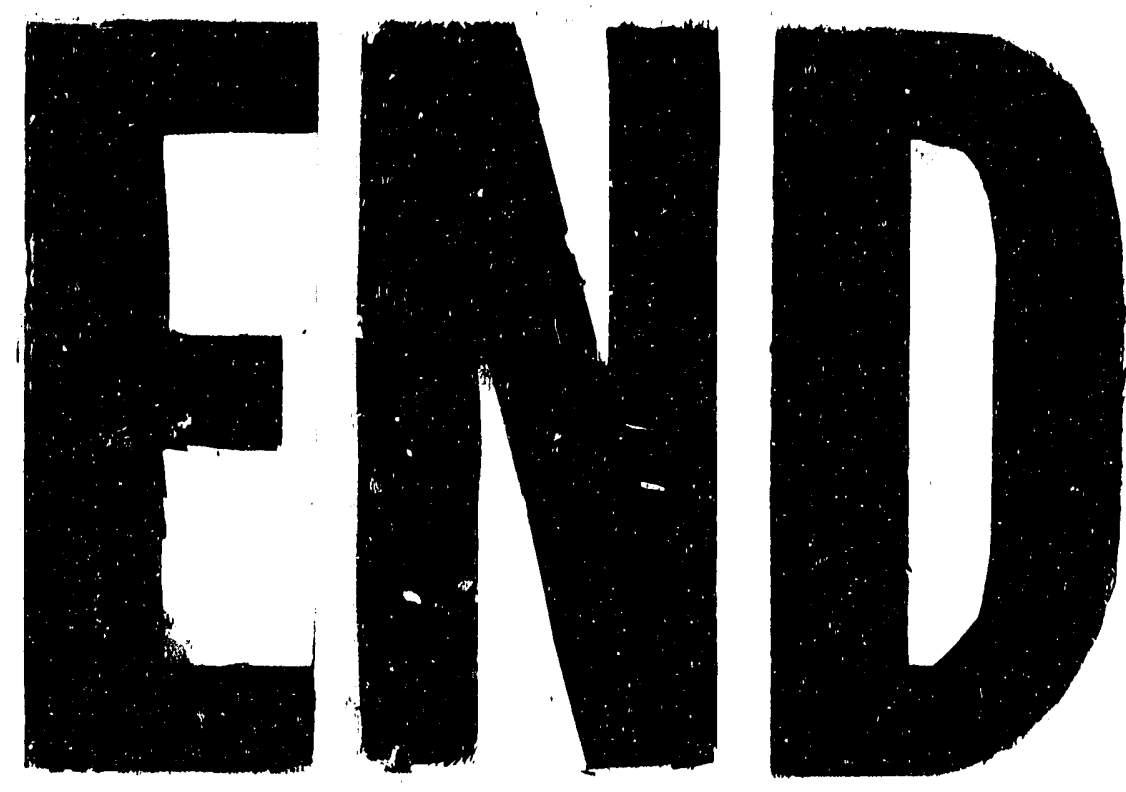

4
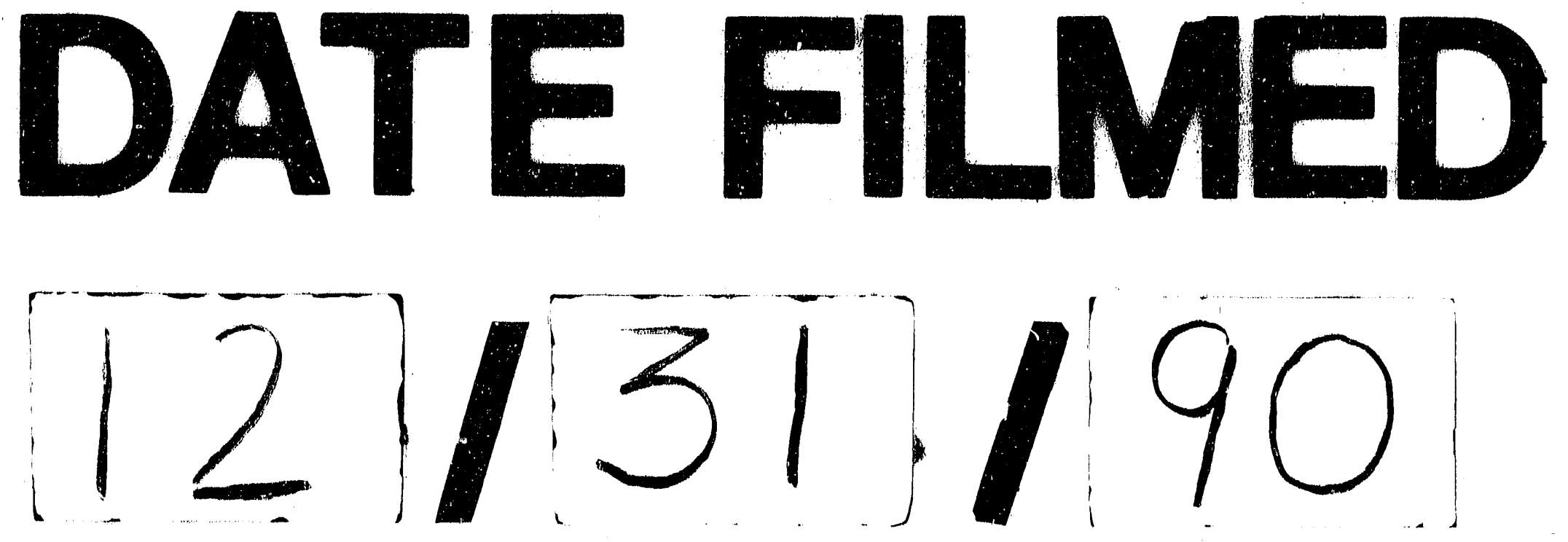


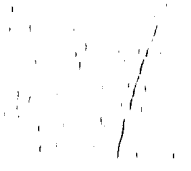

